\title{
Ecological Effects of Forest Canopy Disturbance on the Understory Plant, American Ginseng (Panax quinquefolius L.)
}

Jennifer L. Chandler

Follow this and additional works at: https://researchrepository.wvu.edu/etd

\section{Recommended Citation}

Chandler, Jennifer L., "Ecological Effects of Forest Canopy Disturbance on the Understory Plant, American Ginseng (Panax quinquefolius L.)" (2016). Graduate Theses, Dissertations, and Problem Reports. 5336. https://researchrepository.wvu.edu/etd/5336

This Dissertation is protected by copyright and/or related rights. It has been brought to you by the The Research Repository @ WVU with permission from the rights-holder(s). You are free to use this Dissertation in any way that is permitted by the copyright and related rights legislation that applies to your use. For other uses you must obtain permission from the rights-holder(s) directly, unless additional rights are indicated by a Creative Commons license in the record and/ or on the work itself. This Dissertation has been accepted for inclusion in WVU Graduate Theses, Dissertations, and Problem Reports collection by an authorized administrator of The Research Repository @ WVU. For more information, please contact researchrepository@mail.wvu.edu. 
Ecological Effects of Forest Canopy Disturbance on the Understory Plant, American

Ginseng (Panax quinquefolius L.)

Jennifer L. Chandler

Dissertation submitted to the

Eberly College of Arts and Sciences

at West Virginia University

in partial fulfillment of the requirements for the degree of

Doctor of Philosophy

in

Biology

James B. McGraw, Ph.D., Chair

Mary Beth Adams, Ph.D.

Frank Gilliam, Ph.D.

William Peterjohn, Ph.D.

Richard Thomas, Ph.D.

Department of Biology

Morgantown, West Virginia

2016

Keywords: American ginseng; herbaceous layer; timber harvest; canopy disturbance; physiology; demography; forest canopy; eastern deciduous forest

Copyright 2016, Jennifer L. Chandler 


\begin{abstract}
Ecological effects of forest canopy disturbance on the understory plant, American ginseng
\end{abstract}

(Panax quinquefolius L.)

\title{
Jennifer L. Chandler
}

Historical accounts suggest that American ginseng was once far more abundant than it is today, and extensive changes in forest canopy structure and ginseng habitat caused by clearcut timber harvest occurred coincidently to the precipitous decline in abundance. The presence of natural American ginseng populations after widespread clearcuts suggests that ginseng can survive under sparse canopies, and the presence of ginseng in the second growth forests common today suggest that ginseng can survive under dense canopies. However, performance may not be optimal at either end of the disturbance spectrum, and the net effect of direct and indirect anthropogenic canopy disturbances on ginseng has been unknown. The present suite of studies addresses the question "how does American ginseng respond to changes in forest dynamics that result from changes in canopy disturbance regimes caused by humans?" I first determined how different types of disturbances affected canopy openness on the scale of a small herbaceous plant. In Chapter 2, I found that canopy openness after timber harvest was greatest at the most intensely harvested site, and that subsequent understory canopy closure differed from that occurring in higher strata. Relative canopy closure was greatest in areas with high densities of shade-intolerant weedy and invasive species. The purpose of Chapter 3 was to determine if canopy disturbances via patch cut timber harvest were physiological stressors to American ginseng, or whether increases in light following timber harvest benefited carbon assimilation and growth. I found that ginseng is a 'slow opportunist;' photosynthesis and growth increased following canopy disturbance, but stimulation lagged behind changes in canopy structure. Although ginseng benefited from a patch cut timber harvest, it was unclear whether varying intensities of timber harvest differentially affected the survival, growth, and reproduction of ginseng. In Chapter 4, I found that survival generally decreased following timber harvest, and was lowest at the most intensely harvested site. However, growth and seed production increased in individuals that survived. In order to provide an integrated assessment of survival, growth, and fertility following canopy disturbance, I quantified the demographic response of five populations of American ginseng to natural disturbances whose regimes are being altered by climate change. In Chapter 5, I found that population growth rate increased after natural canopy disturbances, and did so even at the current frequency of disturbance within American ginseng populations. Additionally, canopy disturbances produced sustained increases in population size via influxes of seeds to the seed bank. These studies provide clear evidence that American ginseng is surprisingly resilient in the face of rapid environmental shifts. Further, American ginseng, and perhaps similar herbs, benefit from moderate intensity, anthropogenic canopy disturbances whose frequencies and spatial extents are predicted to increase. 


\section{Acknowledgements}

First, I would like to express my most sincere gratitude to my advisor, Dr. James McGraw. The amount of dedication Jim puts toward his students and his research is unparalleled, and I feel incredibly fortunate to have been trained by such a dedicated, thoughtful scientist. From the first summer research trip to Alaska to the last ESA conference in Baltimore, Jim enthusiastically provided me with exciting opportunities to hone my research and communication skills, and it is through Jim that I have become a competent, enthusiastic researcher. I would also like to thank my committee members, Dr. Mary Beth Adams, Dr. Frank Gilliam, Dr. William Peterjohn, and Dr. Richard Thomas, for their guidance and support throughout this process. Your comments and suggestions have been invaluable and are very much appreciated.

I am also thankful for my amazing labmates. Amy Hruska, thank you for being a great friend and for always trekking into the field with me. I can honestly say that fieldwork with you was one of the best, most efficient, and most fun parts of graduate school. Jessi Brie Turner, you have been a great friend and a wonderful travel buddy. I will never forget the 14-hour days we spent sitting at the dining room table studying for preliminary exams and the many trips we have taken over the past five years. Thank you, also, to the undergraduate interns who helped with my research throughout the years. Alix Wagner, Zac Zacavish, Kyle Gregory, Mike Elza, Anne Jarrell, and Mark Arbuiso, you have all been so helpful and so fun. Thank you to Chris Walter, Mark Burnham, and Leigh Ann Papademetrio for your helpful manuscript comments and for your friendship.

I would like to thank the many people who made the logistics of my research possible. Thank you Dr. Mary Beth Adams, Dr. Thomas Schuler, and Dr. Pam Edwards for guidance and access to the Fernow Experimental Forest. Thank you Stephen McAnarney for spending your day off taking me to the forest in search of ginseng and outlining where timber harvests were going to taking place. Thank you to Mrs. Lawson for letting me spend countless hours in her woods and for always checking to make sure I was okay once it started getting dark.

Finally, though I cannot do them proper justice, I would like to thank my family for their constant support, encouragement, and love. Only family knows you well enough to comfort you when you need comforting and to give you space when you are stressed about a deadline. Mom, Dad, Leigh, Grandpa and Grandma, Pappaw, and Colin: you have all been my rock throughout this process, and I love you all very much. There is no possible way that I can repay you for your kindness, but I want you to know that your support has meant everything to me. 


\section{Table of Contents}

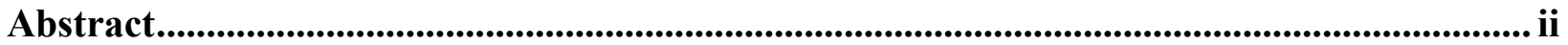

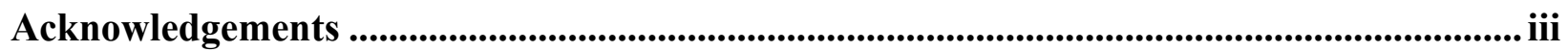

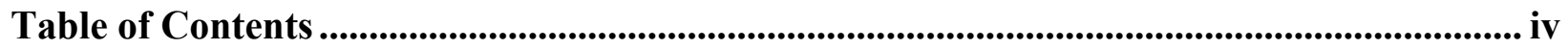

List of Figures....................................................................................................................................... vii

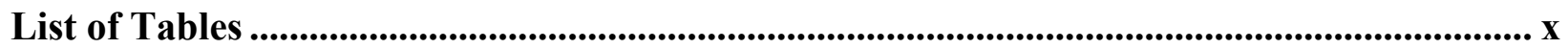

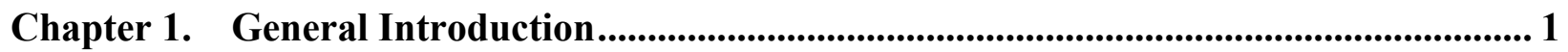

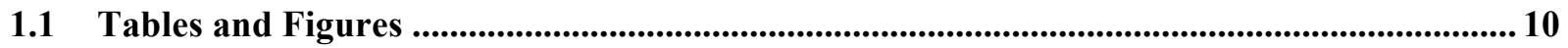

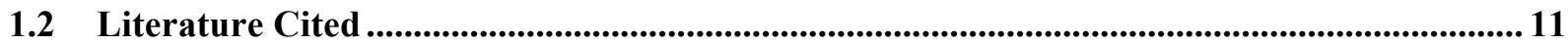

Chapter 2. A Panax-centric View of Changes in Forest Canopy Openness Following

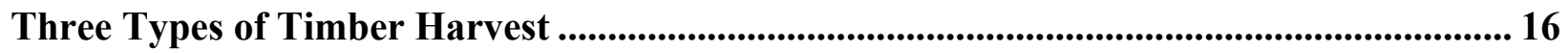

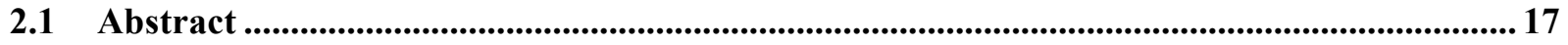

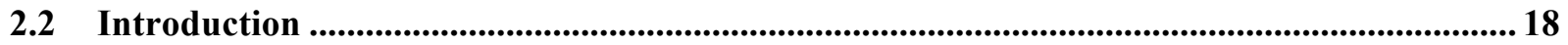

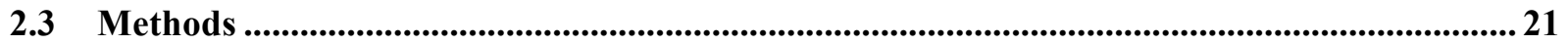

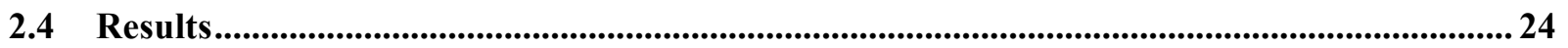

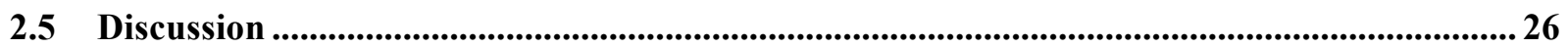

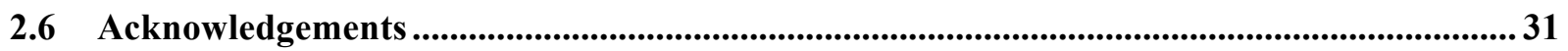

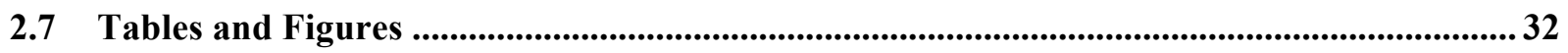

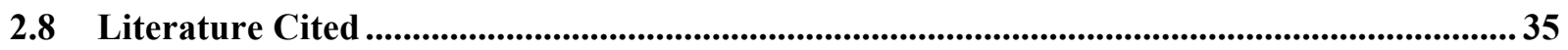

Chapter 3. A Slow Opportunist: Physiological and Growth Response of an Obligate

Understory Plant to Patch Cut Harvesting ................................................................................ 37

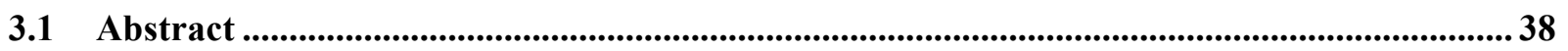

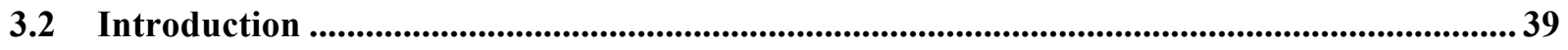




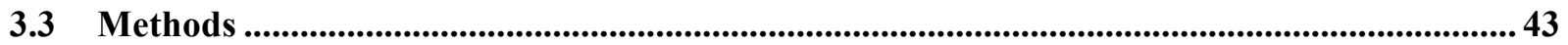

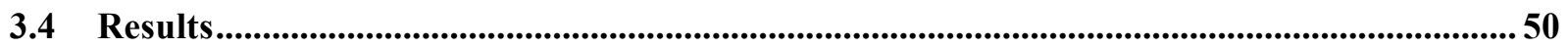

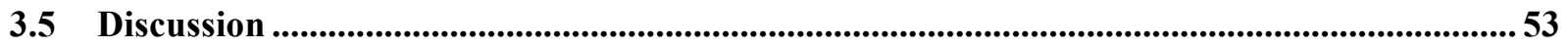

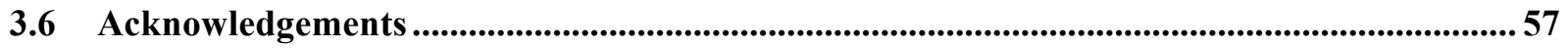

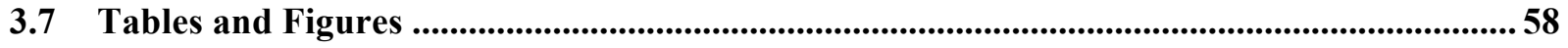

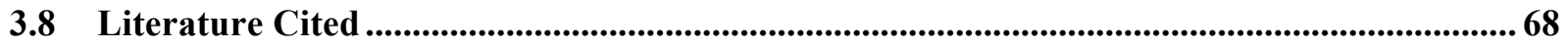

Chapter 4. Variable Effects of Timber Harvest on the Survival, Growth, and Reproduction of American Ginseng (Panax quinquefolius L.) ........................................ 72

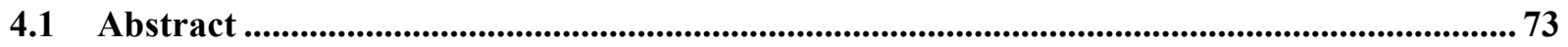

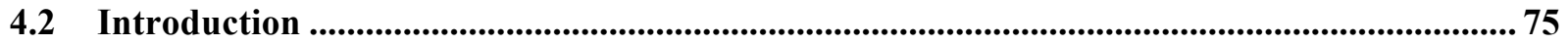

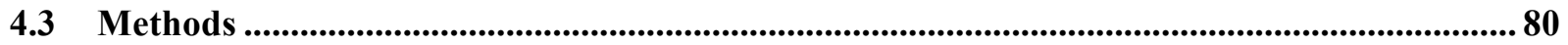

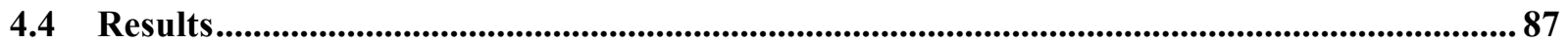

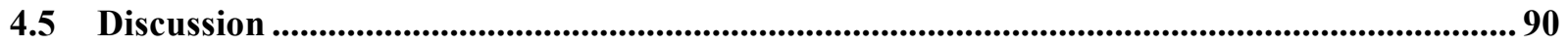

4.6 Acknowledgements ...................................................................................................................... 97

4.7 Tables and Figures …..................................................................................................................... 98

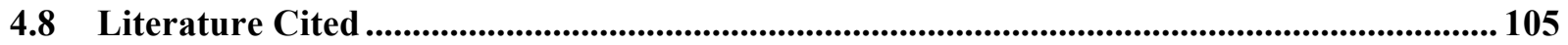

Chapter 5. Demographic Response of a Model Obligate Understorey Herb to Canopy

Disturbances in a Mixed Mesophytic Forest ............................................................. 110

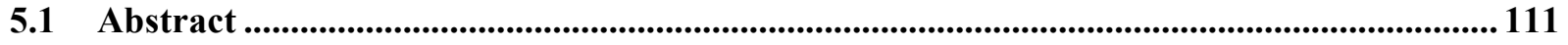

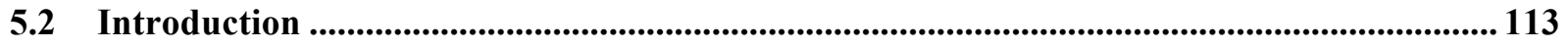

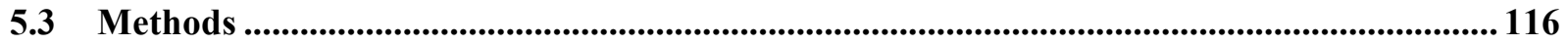

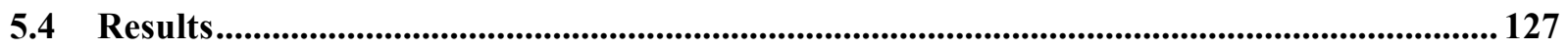

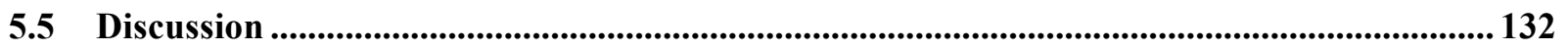

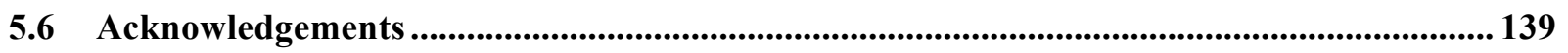

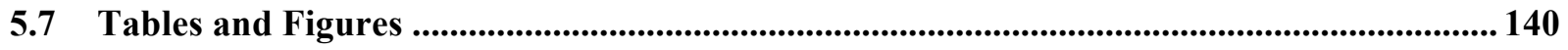




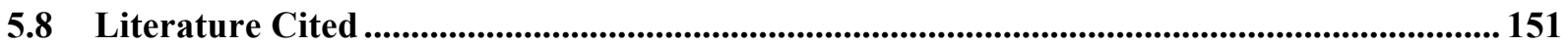

Chapter 6. General Conclusion ..................................................................................................... 158

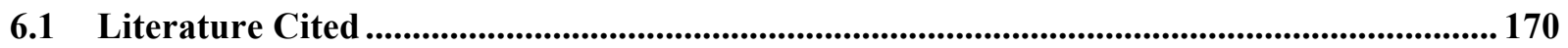




\section{List of Figures}

Figure 2.1. Mean canopy openness (+/- S.E.) at each site at three time periods relative to the timber harvest: before the timber harvest (BC/Reference), one summer following timber harvest $\left(\mathrm{AC}_{1}\right)$, and two summers following the timber harvest $\left(\mathrm{AC}_{2}\right)$......

Figure 2.2. Sample hemispherical images depicting the general patterns of canopy openness from each site $(43,41$, and 44$)$ for each time period (BC/Reference, $\mathrm{AC}_{1}$, and $\mathrm{AC}_{2}$ ).

Figure 3.1. Example of hemispherical images taken above the same plant the summer before timber harvest (a; 2013), the summer after timber harvest (b; 2014), and two summers after timber harvest (c; 2015). These and other hemispherical images were used to calculate canopy openness above each individual or small aggregation of individuals each growing season.

Figure 3.2. Linear regressions showing relative growth rate (RGR) of American ginseng as a function of variation in percent canopy openness (a) before timber harvest $\left(\mathrm{RGR}_{\mathrm{BT}}\right)$, and (b) after timber harvest $\left(\mathrm{RGR}_{\mathrm{AT}}\right)$.

Figure 3.3. Linear regression showing change in relative growth rate after the timber harvest compared to before the timber harvest as a function of the change in percent canopy openness between the growing season prior to timber harvest (2013) and the growing season directly following timber harvest (2014)

Figure 3.4. Differential effects of time period relative to timber harvest year (Before; 2013-2014, After; 2014-2015) and treatment (harvested vs. control) on the relative growth rate of American ginseng $( \pm \mathrm{SE})$.

Figure 3.5. Mean light response curve ( \pm SE) depicting $A_{\text {net }}$ at each of five levels of PPFD (0, $100,300,500$, and 700) per year for each individual whose physiological measurements were obtainable all three of the three growing seasons. Data points from greater PPFD values are excluded, as $\mathrm{A}_{\text {net }}$ within years did not vary significantly at these levels.

Figure 3.6. Linear regressions illustrating relative growth rate (RGR) of American ginseng as a function of maximum photosynthetic rate $\left(\mathrm{A}_{\max }\right)(\mathrm{a})$ the transition period prior to timber harvest $\left(\mathrm{RGR}_{\mathrm{BT}}\right)$, and (b) the transition period following timber harvest $\left(\mathrm{RGR}_{\mathrm{AT}}\right)$. 
Figure 4.1. Characteristics of each population are listed on the left, including initial population size (growing season prior to timber harvest). For each population, a jagged vertical line indicates the timing of the timber harvest. Remaining symbols indicate recorded data. LA represents leaf area, SP represents seed production, HP represents the collection of hemispherical photographs, and $\mathrm{RGR}_{\mathrm{x}}$ represents the calculation of relative growth rate. $R_{G R}$ represents the $R G R$ prior to the cut, $R_{\text {GR }}$ ac1 represents the RGR one year after the cut, and $\mathrm{RGR}_{\mathrm{ac} 2}$ represents RGR two years following the cut. F18 was excluded from pre- vs. post-cut analyses of survival and RGR due to the late date of cutting, however some variables could be included for this population, effectively increasing replication, so it is included in those analyses. Likewise, WY, F27, and F18 were excluded from some measures of reproduction due to small sample size and/or late date of cutting, however data from these populations were included for more short-term analyses.

Figure 4.2. Canopy openness as measured by hemispherical images taken above the American ginseng plants at four populations: CAB [12" $(30.5 \mathrm{~cm})$ diameter limit cut], F27 [18" $(45.7 \mathrm{~cm})$ diameter limit cut], LAW (selection cut), and F18 (patch clearcut).

Figure 4.3. The proportion of individuals surviving in two of the long-term ginseng populations (LAW and WY).

Figure 4.4. The proportion of individuals surviving the first year after timber harvest at four ginseng populations.

Figure 4.5. A) Relative growth rate (RGR) of individuals present both one year before and one year after the timber harvest at four populations (WY, LAW, CAB, and F27) B) Relative growth rate of individuals in four populations, independent of the harvesting events. C) Relative growth rate three years before cut and two years after cut at two long-term populations (LAW and WY).

Figure 4.6. The proportion of individuals that produced seeds each year relative to timber harvest at two of the long-term populations (CAB and LAW).

Figure 4.7. A) Short-term differential effects of timber harvest and population on seed production efficiency. B) Long-term differential effects of timber harvest and population on seed production efficiency $\left(\mathrm{BC}\right.$ - before cut, $\mathrm{AC}_{1}$ - one year after cut, $\mathrm{AC}_{2}-$ two years after cut, $\mathrm{AC}_{3}-$ three years after cut). 104

Figure 5.1. Life-cycle stages used for demographic modeling and analysis. The seed bank classes (stages 1-4) was based on seed ages, while the stage-classified portion of the model was based on leaf number for one leaf plants (stage 5) or leaf area for adults (stages 6-9). Arrows indicate all possible life-stage transitions. Stage transition probabilities $\left(\mathrm{a}_{\mathrm{ij}}\right)$ represent the number of individuals $(i)$ in each stage at the spring census in year $t+1$ per individual size $(j)$ at the spring census in year $t$. 
Figure 5.2. Mean population growth rate $(\phi i)$ for the transition period not affected by canopy disturbance and for the subsequent transition period affected by canopy disturbance for: the NY population that incurred forest tent caterpillar defoliation (a), the WKY populations whose canopies were damaged by a severe ice storm (b) and the EKY population whose canopy was damaged by a lightning strike (c). The horizontal dashed line represents $\lambda=1$, above which populations are growing and below which populations are decreasing.

Figure 5.3. Mean stochastic population growth rates (+/- 95\% C.I.) for: the NY population that incurred forest tent caterpillar defoliation (a), the WKY populations whose canopies were damaged by a severe ice storm (b) and the EKY population whose canopy was damaged by a lightning strike (c). 145

Figure 5.4. Mean population size projected over fifteen years using transient population dynamic simulations for the NY population that incurred forest tent caterpillar defoliation (a), the WKY populations that incurred canopy damage from an ice storm (b) and the EKY population that incurred canopy damage from a lightning strike (c). For each of the three disturbance types, 10,000 runs were performed with the disturbance matrices included in the model and 10,000 runs were performed with the disturbance matrices excluded. Vertical arrow represents the insertion of the post disturbance matrix reflecting the canopy opening.

Figure 5.5. Percent mortality for the average undisturbed matrix and for the matrix representing the disturbance period (a) and fertility for the average undisturbed matrix and for the matrix representing the disturbance period (b) for each of the three populations (NY, WKY and EKY). All aboveground stage classes (5, 6, 7, 8 and 9) are depicted in the figure that quantifies mortality (a), while only reproductive aboveground stage classes $(6,7,8$ and 9$)$ are depicted in the figure that quantifies fertility (b).......... 148

Figure 5.6. Proportion of plants in each of the five aboveground stages $(5,6,7,8$ and 9$)$ for the pre-disturbance period (Year 4) and the post-disturbance period (Year 5) for each of the three populations (NY, WKY and EKY). 149

Figure 5.7. Theoretical model illustrating the population-level response of $P$. quinquefolius to varying levels of canopy openness. Specific forest types and specific types of disturbances are offered as examples of corresponding level of canopy openness. 150 


\section{List of Tables}

Table 2.1. Type of timber harvest implemented, land ownership, dominant canopy species and physical characteristics for each site studied.

Table 3.1. Results of paired t-tests comparing a. relative growth rate, $\mathbf{b}$. maximum rate of photosynthesis, c. daytime dark respiration rate $\left(R_{d}\right)$, d. photosynthetic water use efficiency, e. intrinsic water use efficiency, and f. stomatal conductance of individuals one growing season before and after timber harvest $(2013,2014)$, one growing season after and two growing seasons after timber harvest $(2014,2015)$, and one growing season before and two growing seasons after timber harvest (2013, 2015).

Table 3.2. Mean daytime dark respiration and stomatal conductance ( \pm standard errors) for individuals in each of three growing seasons: $\mathrm{BC}-2013, \mathrm{AC}_{1}-2014, \mathrm{AC}_{2}-2015$.

Table 5.1. (a-c) Results of Life Table Response Experiments (LTRE) comparing matrices for the two transition periods surrounding a FTC defoliation event at the NY population (a), matrices for the two transition periods surrounding an ice storm at the WKY populations (b) and matrices for the two transition periods surrounding a death of canopy trees due to lightning strike at the EKY population (c). Transitions that contributed significantly to $\Delta \lambda$ are depicted in bold.

Table 5.2. (a-c). Sum of the change in lambda for each vital rate one transition year before and after insect defoliation at the NY population (a), ice storm at the WKY populations (b) and tree death due to lightning strike at the EKY population (c). Each represents a sum of transitions from a single stage to any of four other stages $\left(a_{i 5}, a_{i 6}, a_{i 7}, a_{i 8}\right.$, $\mathrm{a}_{\mathrm{i} 9}$ ). Sum of transitions that most contributed to $\Delta \lambda$ are depicted in bold. 142 
Chapter 1. General Introduction 
Forest canopy disturbances play integral roles in temperate forest ecosystems by initiating forest succession and by maintaining spatially and temporally heterogeneous forest environments (Sousa 1984a, Dale et al. 2000). Historically, many temperate forests were shaped by natural disturbances that were typically small in both spatial extent and in severity (Sousa 1984a). However, in recent centuries, both indirect and direct anthropogenic disturbances have been the primary drivers of forest landscape transformation, and have altered disturbance regimes across the landscape (Dale et al. 2000, IPCC 2007a). The types of anthropogenic disturbances that affect forest systems vary greatly, and include both discrete disturbances that prompt acute, short-lived responses from forest plants and chronic disturbances that occur on longer timescales and elicit long-lasting, "legacy" responses (Gilliam 2007).

The understory light environments of closed-canopy deciduous forests consist of low levels of diffuse light interspersed with patches of direct light called sunflecks (Chazdon and Pearcy 1991). Light is the primary resource limiting understory plant establishment and productivity in undisturbed, closed-canopy forests (Chazdon and Pearcy 1991, Beckage et al. 2000, Whigham 2004a, Neufeld and Young 2014).

However, light availability in the understory increases in intensity, duration, and in many cases, spatial and temporal heterogeneity following canopy disturbances (Chazdon and Fetcher 1984, Sousa 1984a, Canham 1988a, 1988b, Lawton 1990, Beaudet et al. 2004, Roberts 2004). Additionally, canopy disturbances typically result in increases in the air and soil temperature at the forest floor, greater temperature fluctuations at the forest floor, and higher levels of evapotranspiration, while relative humidity at the forest floor and soil surface moisture decrease following canopy disturbance (Liechty et al. 1992, 
Roberts 2004, Muscolo et al. 2014, Roberts and Gilliam 2014). The extent of environmental alterations in the understory caused by canopy disturbance depends on the intensity of each disturbance. Disturbance intensity, also referenced to as severity, exists along a scale that accounts for the amount of forest canopy removed, the amount of understory vegetation removed, and the amount of forest soils removed or disturbed (Oliver and Larson 1996, Roberts 2004).

To date, most forest disturbance research has focused on trees, the dominant stratum in terms of biomass and light interception (Roberts 2004, Gilliam 2007). Research quantifying the response of the herbaceous layer to disturbance has been relatively scarce, even though this stratum is a vital component in forest ecosystems (Gilliam 2007). The herbaceous layer contains the majority of biodiversity in many temperate forests, is tightly linked to species distribution and community composition in the forest canopy, and contains numerous economically and ecologically valuable nontimber forest products (Gilliam 2007, Gilliam and Roberts 2014).

Human activity is indirectly altering natural disturbance regimes that affect temperate forest systems. Fossil fuel combustion has contributed to the rise in global temperature, causing significant climate shifts (IPCC 2007a, 2007b). Climate shifts alter the frequency and intensity of natural disturbance regimes, the most common of which are insect defoliation, windthrow, ice storms, and lightning (Sousa 1984a, Dale et al. 2001, Dukes et al. 2009, Roberts and Gilliam 2014). Such disturbances typically involve the periodic defoliation, limb loss, and mortality of single trees and small groups of trees (Sousa 1984a, Roberts 2004), however, climate shifts are predicted to increase the intensity and frequency of these disturbances (Ryan et al. 2008). Whereas increasing 
temperatures alone will undoubtedly affect forest ecosystems, increases in the frequency and intensity of otherwise "natural" disturbance events, coupled with other indirect effects of climate change could elicit stronger demographic responses than temperature alone (Souther et al. 2012).

Timber harvest is often a cyclical, direct anthropogenic disturbance that affects all forest strata, including the herbaceous layer. Although research examining herbaceous response to varying intensities of timber harvest has been performed (Reader and Bricker 1992, Halpern and Spies 1995, Hammond et al. 1998, Gilliam 2002, Kern et al. 2006, 2014), no general consensus has been reached concerning patterns and levels of response across a wide range of environmental conditions (Roberts and Gilliam 2014). Timber harvest and advances in harvesting technology have vastly increased the frequency, spatial extent, and severity of forest disturbances (Wyatt and Silman 2014). Large-scale commercial timber harvest has been common in eastern North America since widespread clearcuts removed all but $0.09 \%$ of old growth forests in the late 1800 's and early 1900 's (Wyatt and Silman 2014). Old growth forests are characterized by gap-phase dynamics and consist of an uneven canopy structure that shows minimal evidence of anthropogenic disturbance (Martin 1992, Busing 1998, Bellemare et al. 2002). Because of the consistent global demand for wood products, timber harvest is one predominant form of direct anthropogenic forest disturbance that is predicted to continue and increase in some areas of the United States as second growth forests reach merchantable size (Fajvan et al. 1998, Wear and Greis 2002).

Changes in understory habitat caused by anthropogenic canopy disturbances, whether direct or indirect, can have profound effects on the physiological, growth, and 
demographic successes of understory species. American ginseng (Panax quinquefolius L.) is one such understory species whose long-term persistence and success is potentially altered by canopy disturbances, especially if such disturbances are more frequent or more intense due to direct and indirect anthropogenic change.

American ginseng is a long-lived, obligate understory herb that exhibits slow growth and reproduction, qualities that are shared among many understory herbs (McGraw et al. 2013). American ginseng's range is broad, extending throughout the eastern portion of the United States and in southern portions of Canada, although natural populations are uncommon, and most natural populations typically consist of fewer than 200 individuals (Anderson et al. 1993, McGraw et al. 2003). Habitat suitability for American ginseng varies widely, and populations have been observed over a range of aspects, elevations, and slopes, though populations are most often located in mixedmesophytic forests (McGraw et al. 2013). Wagner and McGraw (2013) investigated the response of American ginseng to the duration and intensity of sunflecks reaching the forest floor and determined that American ginseng is adapted to the light environments of old growth forests. Old growth forests are characterized by well-developed canopy layers and by temporally and spatially varying gap formations and closures (Knohl et al. 2003, Spies et al. 2006, Manabe et al. 2009, Wagner and McGraw 2013). Nevertheless, the net effect of forest canopy disturbance on the physiology, growth, and demography of American ginseng is unknown.

American ginseng is the premier, wild-harvested medicinal plant throughout the eastern United States (Robbins 2000). The yearly harvest of ginseng provides millions of dollars of supplemental income to people in Appalachia from the steady demand for its 
root on the Asian market (Bailey 1999). Historical accounts suggest that ginseng was once far more abundant that it is today; evidenced by the precipitous decline in annual export from the mid 1800's to the late 1900's (Carlson 1986, Robbins 1998).

Overharvesting of American ginseng for its root is often described as the primary cause for decreased abundance (Carlson 1986, Nantel et al. 1996, Robbins 1998, 2000, McGraw et al. 2010). However, extensive timber harvests altered forest canopy structure and American ginseng habitat concurrent to the substantial decreases in American ginseng abundance. The presence of natural ginseng populations following widespread clearcuts in the late 1800's and early 1900's suggest ginseng can survive under sparse canopies, and the presence of natural ginseng populations under the closed-canopy, second growth forests of today suggest ginseng can survive under dense shade. Although ginseng is capable of surviving at two opposite extremes of canopy openness, ginseng performance may not be optimal at either end of the disturbance spectrum. The following series of studies takes advantage of natural populations of American ginseng to examine the multidimensional response of ginseng physiology, growth, and demography to varying intensities of both direct and indirect anthropogenic canopy disturbances in order to determine if American ginseng benefits from such disturbances, or alternatively, if discrete changes in ginseng habitat lead to individual- and population-level declines.

The purpose of Chapter 2 was to use hemispherical photography to determine if differences in canopy openness depended on the type of harvest implemented and to determine how differences varied during the dynamic period immediately before and after cutting, all from the perspective of an herbaceous understory plant. I predicted that effective closure would be greatest on sites where more tree biomass was removed due to 
greater release of weedy and invasive species and increased overtopping by these species. Few studies have focused on changes in canopy structure at the scale of an understory herb, but rather focus on changes that affect trees and saplings in higher strata. Forest canopy structure changes abruptly after the formation of canopy gaps, leading to a more open canopy and increased transmittal of light to the forest floor (Canham 1988a, 1988b). Changes in canopy structure following timber harvest can greatly affect the productivity of herbaceous species that are light limited in the absence of disturbance. I used a Panaxcentric sampling design at three sites whose timber was harvested at varying intensities to determine how canopy structure varied above a naturally distributed understory herb in response to different types of timber harvest.

The purpose of Chapter 3 was to determine if canopy disturbances via timber harvest are physiological stressors to American ginseng, or whether increases in light following timber harvest provide physiological benefits, particularly in those physiological traits that directly relate to carbon accumulation. In undisturbed forests, maximum photosynthetic rates of American ginseng increase with increases in the duration of sunflecks and increases in the percent photosynthetic photon flux density (PPFD) in sunflecks (Wagner and McGraw 2013). The same study found that transpiration was unaffected by both sunfleck properties (Wagner and McGraw 2013). However, some species experience high leaf temperature, wilting, and photoinhibition during long-lasting sunflecks and sunflecks with high PPFD (Le Gouallec et al. 1990, Chazdon and Pearcy 1991). To determine how the shade-obligate species, American ginseng, responds to light levels and durations that far exceeded those present in sunflecks, I compared the effects of canopy openness on photosynthesis, respiration, 
water use efficiency, and stomatal conductance before and after a patch cut timber harvest.

The purpose of Chapter 4 was to determine if varying intensities of timber harvest common throughout the eastern deciduous forest negatively and differentially affected the survival, growth, and reproduction of American ginseng. Timber harvest strategies lie along a gradient of forest disturbance intensity, with strategies such as single-tree selection being the least intense and clearcut harvest being the most intense (Gilliam and Roberts 1995, Roberts and Gilliam 2014). Gap formations and timber harvests of different intensities affect the forest canopy and the forest understory differently through changes in canopy structure, light availability, resource heterogeneity, and soil surface properties (Sousa 1984a, Canham 1988a, 1988b, Beaudet et al. 2004, Roberts 2004). Though increase in resources following small canopy disturbances can be beneficial to understory species (Chazdon and Pearcy 1991, Fournier et al. 2004, Whigham 2004a), it is unknown whether larger increases in canopy openness caused by timber harvest would be detrimental to the persistence and growth of a shade-obligate herb. Five study sites that contained natural populations of American ginseng and that were prescribed different intensities of timber harvest were located throughout central Appalachia. Survival, growth, and reproductive data were collected for each population before and after timber harvest, and these data were analyzed to better understand the multidimensional response of a rare, model obligate understory herb to varying types of timber harvest.

Climate change is indirectly affecting forest systems by altering the frequency, intensity, duration, and extent of natural disturbance regimes (Baker 1995, Turner et al. 1998, Dale et al. 2001, IPCC 2007a). The dual purpose of Chapter 5 was to determine: 1) 
if a species found primarily in low light understory environments benefits demographically from additional inputs of light from "natural" canopy disturbances, or alternatively, due to long-term selection under low light conditions, such disturbances bring about a population decline; and 2) if the demographic response was consistent across different canopy disturbance types, regardless of severity, duration, and effects beyond light enhancement. I used population growth rates, which are integrated measures of plant survival, growth, and fertility, to determine how vital rates of an understory species vary in response to three types of disturbance events that bracket a substantial range of natural disturbance severity.

These four research chapters address the central question, "how does American ginseng respond to canopy disturbances caused by both direct human actions and by the indirect effects of humans actions on climate?" An understanding of the multi-level response of American ginseng to disturbances whose frequency, intensity, and spatial extent are increasing due to human activity may guide future forest management strategies in the conservation of ginseng and similar species within the exceedingly diverse herbaceous understory. 


\subsection{Tables and Figures}




\section{$1.2 \quad$ Literature Cited}

Anderson RC, Fralish JS, Armstrong JE, Benjamin PK (1993) The ecology and biology of Panax quinquefolium L. (Araliaceae) in Illinois. Am Midl Nat 129:357-372.

Bailey B (1999) Social and economic impacts of wild harvested products. West Virginia University

Baker W (1995) Long-term response of disturbance landscapes to human intervention and global change. Landsc Ecol 10:143-159.

Beaudet M, Messier C, Leduc A (2004) Understorey light profiles in temperate deciduous forests: Recovery process following selection cutting. J Ecol 92:328-338.

Beckage B, Clark JS, Clinton BD, Haines BL (2000) A long-term study of tree seedling recruitment in southern Appalachian forests: The effects of canopy gaps and shrub understories. Can J For Res 30:1617-1631.

Bellemar, J., Motzkin, G., and Foster, D.R. 2002. Legacies of the agricultural past in the forested present: An assessment of historical land-use effects on rich mesic forests. J Biogeogr. 29: 1401-1420.

Busing, R. 1998. Composition, structure and diversity of cove forest stands in the Great Smoky Mountains: a patch dynamics perspective. J Veg Sci. 9: 881-890.

Canham CD (1988a) An index for understory light levels in and around canopy gaps. Ecology 69:1634-1638.

Canham CD (1988b) Growth and canopy architecture of shade-tolerant trees: Response to canopy gaps. Ecology 69:786-795.

Carlson A (1986) Ginseng-America's botanical drug connection to the Orient. Econ Bot 40:233-249.

Chazdon R, Fetcher N (1984) Photosynthetic light environments in a lowland tropical rainforest in Costa Rica. J Ecol 72:553-564.

Chazdon RL, Pearcy RW (1991) The importance of sunflecks for forest understory plants. Bioscience 41:760-766. doi: 10.2307/1311725

Dale VH, Joyce L a., McNulty S, Neilson RP (2000) The interplay between climate change, forests, and disturbances. Sci Total Environ 262:201-204. doi:

$10.1016 / \mathrm{S} 0048-9697(00) 00522-2$

Dale VH, Joyce LA, McNulty S, et al (2001) Climate change and forest disturbances. Bioscience 51:723-734. doi: 10.1641/0006-3568(2001)051[0723:CCAFD]2.0.CO;2

Dukes JS, Pontius J, Orwig D, et al (2009) Responses of insect pests, pathogens, and invasive plant species to climate change in the forests of northeastern North America: What can we predict? Can J For Res 39:231-248. doi: 10.1139/X08-171

Fajvan MA, Grushecky ST, Hassler CC (1998) The effects of harvesting practices on 
West Virginia's wood supply. J For 96:33-39.

Fournier AR, Gosselin A, Proctor JTA, et al (2004) Relationship between understory light and growth of forest-grown American ginseng (Panax quinquefolius L.). J Am Soc Hortic Sci 129:425-432.

Gilliam FS (2007) The ecological significance of the herbaceous layer in temperate forest ecosystems. Bioscience 57:845-858.

Gilliam FS (2002) Effects of harvesting on herbaceous layer diversity of a central Appalachian hardwood forest. For Ecol Manage 155:33-43.

Gilliam FS, Roberts MR (2014) Interactions between the herbaceous layer and the overstory canopy of eastern forests: A mechanism for linkage. In: Gilliam FS (ed) The Herbaceous Layer in Forests of Eastern North America, 2nd edn. Oxford University Press, Oxford, pp 233-254.

Gilliam FS, Roberts MR (1995) Impacts of forest management on plant diversity. Ecol Appl 5:911-912.

Halpern CB, Spies TA (1995) Plant species diversity in natural and managed forests of the Pacific Northwest. Ecol Appl 5:913-934. doi: 10.2307/2269343

Hammond DN, Smith DW, Zedaker SM, et al (1998) Floral diversity following harvest on southern Appalachian mixed oak sites. In: Proceedings of the Ninth Southern Biennial Silvicultural Research Conference. Clemson, SC, pp 461-465.

IPCC (2007a) Climate Change 2007: Impacts, Adaptation and Vulnerability. In: Parry M, Canziani O, Palutikof J, et al. (eds) Contribution of Working Group II to the Fourth Assessment Report of the Intergovernmental Panel on Climate Change. Cambridge University Press, Cambridge and New York,

IPCC (2007b) Climate Change 2007: The physical science basis. In: Solomon S, Qin D, Manning M, et al. (eds) Contribution of Working Group I to the Fourth Assessment Report of the Intergovernmental Panel on Climate Change. Cambridge University Press, Cambridge and New York,

Kern CC, Montgomery RA, Reich PB, Strong TF (2014) Harvest-created canopy gaps increase species and functional trait diversity of the forest ground- layer community. For Sci 60:335-344.

Kern CC, Palik BJ, Strong TF (2006) Ground-layer plant community responses to evenage and uneven-age silvicultural treatments in Wisconsin northern hardwood forests. For Ecol Manage 230:162-170. doi: 10.1016/j.foreco.2006.03.034

Knohl A, Schulze E-D, Kolle O, Buchmann N (2003) Large carbon uptake by an unmanaged 250-year-old deciduous forest in Central Germany. Agric For Meteorol 118:151-167. doi: 10.1016/S0168-1923(03)00115-1

Lawton R (1990) Canopy gaps and light penetration into a wind-exposed tropical lower montane rain forest. Can J For Res 20:659-667. 
Le Gouallec JL, Cornic G, Blanc P (1990) Relations between sunfleck sequences and photoinhibition of photosynthesis in a tropical rain forest understory herb. Am J Bot 77:999-1006. doi: 10.2307/2444571

Liechty H, Holmes M, Reed D, Mroz G (1992) Changes in microclimate after stand conversion in two northern hardwood stands. For Ecol Manage 50:253-264.

Manabe T, Shimatani K, Kawarasaki S, et al (2009) The patch mosaic of an old-growth warm-temperate forest: Patch-level descriptions of 40-year gap-forming processes and community structures. Ecol Res 24:575-586. doi: 10.1007/s11284-008-0528-7

Martin, W. 1992. Characteristics of old-growth mixed mesophytic forests. Nat Area J. 12: $127-135$.

McGraw JB, Lubbers AE, Van der Voort M, et al (2013) Ecology and conservation of ginseng (Panax quinquefolius) in a changing world. Ann N Y Acad Sci 62-91. doi: $10.1111 /$ nyas. 12032

McGraw JB, Sanders SM, Van der Voort M (2003) Distribution and abundance of Hydrastis canadensis L.(Ranunculaceae) and Panax quinquefolius L.(Araliaceae) in the central Appalachian region. J Torrey Bot Soc 130:62-69.

McGraw JB, Souther S, Lubbers AE (2010) Rates of harvest and compliance with regulations in natural populations of American ginseng (Panax quinquefolius L.). Nat Areas J 30:202-210. doi: 10.3375/043.030.0207

Muscolo A, Bagnato S, Sidari M, Mercurio R (2014) A review of the roles of forest canopy gaps. J For Res 25:725-736. doi: 10.1007/s11676-014-0521-7

Nantel P, Gagnon D, Nault A (1996) Population viability analysis of American ginseng and wild leek harvested in stochastic environments. Conserv Biol 10:608-621. doi: 10.1046/j.1523-1739.1996.10020608.x

Neufeld HS, Young DR (2014) Ecophysiology of the herbaceous layer in temperate deciduous forests. In: Gilliam FS (ed) The Herbaceous Layer in Forests of Eastern North America, 2nd edn. Oxford University Press, New York, pp 35-91.

Oliver CD, Larson BC (1996) Forest stand dynamics. Updated ed. John Wiley \& Sons, New York.

Reader RJ, Bricker BD (1992) Response of five deciduous forest herbs to partial canopy removal and patch size. Am Midl Nat 127:149-157.

Robbins CS (2000) Comparative analysis of management regimes and medicinal plant trade monitoring mechanisms for American ginseng and goldenseal. Conserv Biol 14:1422-1434.

Robbins CS (1998) American ginseng: The root of North America's medicinal herb trade. TRAFFIC, Washington, D.C.

Roberts MR (2004) Response of the herbaceous layer to natural disturbance in North American forests. Can J Bot 82:1273-1283. doi: 10.1139/b04-091 
Roberts MR, Gilliam FS (2014) Response of the Herbaceous Layer to Disturbance in Eastern Forests. In: Gilliam FS (ed) The Herbaceous Layer in Forests of Eastern North America, 2nd edn. Oxford University Press, Oxford, pp 321-339.

Ryan MG, Archer SR, Birdsey R, et al (2008) Land Resources: Forest and Arid Lands. Washington, D.C.

Sousa WP (1984) The role of disturbance in natural communities. Annu Rev Ecol Syst 15:353-391.

Souther S, Lechowicz MJ, McGraw JB (2012) Experimental test for adaptive differentiation of ginseng populations reveals complex response to temperature. Ann Bot 110:829-837. doi: 10.1093/aob/mcS155

Spies TA, Hemstrom MA, Youngblood A, Hummel S (2006) Conserving old-growth forest diversity in disturbance-prone landscapes. Conserv Biol 20:351-362. doi: 10.1111/j.1523-1739.2006.00389.x

Turner MG, Baker WL, Peterson CJ, Peet RK (1998) Factors influencing succession: Lessons from large, infrequent natural disturbances. Ecosystems 1:511-523. doi: $10.1007 / \mathrm{s} 100219900047$

Wagner A, McGraw JB (2013) Sunfleck effects on physiology, growth, and local demography of American ginseng (Panax quinquefolius L.). For Ecol Manage 291:220-227. doi: 10.1016/j.foreco.2012.11.038

Wear DN, Greis JG (2002) Southern forest resource assessment: Summary of findings. J For 100:6-14.

Whigham D (2004) Ecology of woodland herbs in temperate deciduous forests. Annu Rev Ecol Evol Syst 35:583-621.

Wyatt JL, Silman M. (2014) Long-term effects of clearcutting in the southern Appalachians. In: Gilliam FS (ed) The Herbaceous Layer in Forests of Eastern North America, 2nd edn. Oxford University Press, New York, pp 412-437. 
Chapter 2. A Panax-centric View of Changes in Forest Canopy Openness Following Three Types of Timber Harvest

Formatted for, and submitted to, Canadian Journal of Forest Research - Notes 


\section{$2.1 \quad$ Abstract}

Increases in canopy openness following timber harvest affect forest strata differently, but most studies quantify canopy structure above mid-story saplings rather than herbs, even though the latter contains the majority of biodiversity in many deciduous forests. The purpose of this research was to determine if patterns of canopy openness differed among harvest types during the dynamic period surrounding timber harvest, from the perspective of an understory herb. We analyzed canopy openness above American ginseng populations one summer before and two summers after three common types of timber harvest. Understory canopy openness increased directly following harvest at all sites, but was higher and most variable after the patch-cut harvest. Gap closure occurred faster from the perspective of an herbaceous species compared to taller shrubs and trees, and this difference was due to rapid growth of weeds and invasive species that overtopped and shaded the short-stature plants. Moderately severe canopy disturbances can produce an intermediate pulse of light in the understory that may be longer lasting than those produced by intense disturbances due to relaxed competition from shadeintolerant species. 


\subsection{Introduction}

Understory light environments of undisturbed deciduous forests consist primarily of diffuse light with spatially- and temporally-varying patches of direct sunlight (Chazdon and Pearcy 1991). The strength and duration of light in the understory is dictated by canopy structure, including canopy height, flexibility, and leaf arrangement (Chazdon and Pearcy 1991, Smith and Berry 2013). Disturbance history influences light availability, and changes in canopy structure following both natural and anthropogenic disturbances increase the intensity, duration, and in some cases spatial and temporal heterogeneity of direct sunlight reaching the forest floor (Chazdon and Fetcher 1984, Sousa 1984a, Canham and Marks 1985, Canham 1988a, 1988b, Canham et al. 1990, Lawton 1990, Beaudet et al. 2004).

Natural canopy disturbances in temperate deciduous forests are typically smallscale, and consist primarily of scattered defoliation, limb loss, and death of single trees or small groups of neighboring trees by windthrow, ice storms, and insect defoliation (Sousa 1984a, Roberts and Gilliam 2014). One study reported that the mean size of a treefall gap formed by natural disturbances in southern Appalachia was $31 \mathrm{~m}^{2}$ (Sousa 1984a). However, anthropogenic canopy disturbances such as timber harvest often lead to larger, more spatially extensive canopy openings whose patterns often differ from those created by natural disturbances.

Research into the changes in forest structure and canopy dynamics following timber harvest is plentiful, but the majority of studies focus on trees. The herbaceous understory (the stratum containing vascular plants less than $1 \mathrm{~m}$ in height) constitutes up to $90 \%$ of the biodiversity in many temperate deciduous forests, yet relatively few studies 
have focused on environmental changes following disturbance from the perspective of an understory herb (Roberts 2004, Gilliam 2007).

One study, which focused on the rate of canopy closure following natural canopy disturbance, measured canopy openness $50 \mathrm{~cm}$ above the forest floor for three consecutive years, and found that canopy closure occurred exponentially (Valverde and Silvertown 1997). However, hemispherical photographs used in Valverde and Silvertown (1997) focused on the canopy at its maximum height, and were devoid of any obstructions caused by shrubs and other short vegetation. The study by Valverde and Silvertown (1997) was fundamental in understanding canopy closure patterns, but the perspective did not mimic that of a short-stature, understory herb. A separate study used hemispherical photography to analyze light availability at heights of $0.2,1,2$, and $5 \mathrm{~m}$ above the forest floor after a small-scale selection cut timber harvest (Beaudet et al. 2004), but did not explore the effects of alternative types of timber harvest. Beaudet et al. (2004) found that percent photosynthetic photon flux density (PPFD) increased substantially immediately after selection cutting. The PPFD was consistently lower 0.2 $\mathrm{m}$ above the forest floor than at any higher sampling position throughout the experiment, indicating that the light environment at the forest floor differed significantly from light above the understory (Beaudet et al. 2004). However, Beaudet et al. (2004) did not directly quantify canopy openness from the perspective of an understory plant. Canopy openness predicts the seasonal total of percent diffuse and direct beam radiation (McCarthy and Robison 2003), and is an important metric in understanding environmental changes in the understory after timber harvest. 
In contrast to many other studies, the purpose of the present study was to determine if differences in canopy openness depended on the type of harvest implemented and to determine how differences varied during the dynamic period immediately before and after cutting, all from the perspective of an herbaceous understory plant. We predicted that canopy closure following the initial harvest would be most rapid on sites where more tree biomass was removed due to greater release of weedy and invasive species and increased overtopping by these species. This study took advantage of three common types of timber harvests that occurred within natural populations of Panax quinquefolius L. (American ginseng) in the eastern deciduous forest. American ginseng is a widespread, long-lived perennial herb similar to many forest herbs in terms of habitat requirements, size, and phenological strategy (McGraw et al. 2013). 


\subsection{Methods}

We located three study sites within second growth eastern deciduous forests. Each site contained natural populations of American ginseng, and each site was subjected to a different type of timber harvest (Table 2.1). Due to the economic and conservation value of American ginseng, we withheld specific site names and locations, substituting numerical identifiers (Table 2.1). Land ownership varied among sites, and included one state forest located in West Virginia, U.S.A., and two forested compartments within a federally managed forest in West Virginia, U.S.A. (Table 2.1). The forests on each of these three sites are described as mixed mesophytic, with Acer saccharum (sugar maple) being a dominant canopy species (Table 2.1).

We analyzed partial harvest strategies commonly used throughout central Appalachia (Schuler 2004). On site 41, trees were harvested in Fall 2011 using a $30.5 \mathrm{~cm}$ diameter-limit harvest. Trees on site 43 were harvested in Fall 2012 using a $45.7 \mathrm{~cm}$ diameter-limit threshold. Finally, on site 44 trees were harvested in Fall 2013 using a patch-cut harvest with circular openings of ca. 0.162 ha (Table 2.1). We quantified canopy openness one summer before and two summers after timber harvest at the 45.7 cm DLH and the patch cut harvest sites (43 and 44, respectively). However, canopy openness at the $30.5 \mathrm{~cm}$ DLH (site 41) was only quantified two summers following timber harvest because harvest plans were not known in advance. Three unharvested reference sites were located within $100 \mathrm{~m}$ of site 41 to provide the estimate of pre-harvest canopy structure. Physical characteristics of the sites varied in terms of aspect, slope, and elevation (Table 2.1). 
The sites used in the current study were the subject of prior research which quantified the multidimensional response of Panax quinquefolius to canopy disturbance caused by timber harvest (Chandler and McGraw 2015, J. L. Chandler submitted). Therefore, the sampling design used in this study was 'Panax-centric,' and based on the natural distribution of wild American ginseng on each site. American ginseng plants were located on each site, and labeled with subterranean tags to ensure that hemispherical images were taken at the same location each year. Hemispherical images were taken directly above each sub-population of tightly aggregated ginseng plants at each site each year throughout the study. Excluding the reference images, 20 images were captured each year at the population that was harvested using a $30.5 \mathrm{~cm}$ DLH (site 41). Eleven separate images were taken each year at the site that was harvested using a $45.7 \mathrm{~cm} \mathrm{DLH}$ (site 43) and at the site harvested using a patch cut (site 44).

Hemispherical images were taken skyward from a position $20 \mathrm{~cm}$ above the forest floor (the average height of a typical ginseng plant) in an effort to capture the changes in canopy structure. Therefore, the canopy referenced in this study consisted of all understory, mid-story, and canopy vegetation extending greater than $20 \mathrm{~cm}$ from the forest floor. Eighteen-megapixel digital images were taken on overcast days in mid-June of each year using a Canon EOS Rebel T2i equipped with a 180-degree fisheye lens (Sigma $4.5 \mathrm{~mm}$ F2.8 EXDC) with the top of each photograph oriented northward. Hemispherical images were analyzed and the percentage of open sky visible beneath the forest canopy was calculated using Gap Light Analyzer software (Frazer et al. 1999). Canopy openness (\%) is determined by separating pixels into "sky" and "non-sky" categories and then calculating the distribution of sky based on these pixel categories 
(Frazer et al. 1999). We chose to analyze canopy openness in this study, because canopy openness is a good predictor of the combined percentage of diffuse and direct beam total season radiation (global radiation) in temperate forest systems (McCarthy and Robison 2003).

We compared canopy openness using repeated measures for the $45.7 \mathrm{~cm}$ DLH (site 43) and for the patch cut harvest (site 44). A subsequent two-way ANOVA was performed to determine if the canopy openness varied among all sites before the cut (BC), one summer after the cut $\left(\mathrm{AC}_{1}\right)$, and two summers after the cut $\left(\mathrm{AC}_{2}\right)$. We hypothesized that a more severe harvest would open the canopy above the understory more, but that the gap would close more quickly due to growth of weedy and invasive species. 


\subsection{Results}

The repeated measures analyses indicated that canopy openness varied each growing season at both the $45.7 \mathrm{~cm} \mathrm{DLH} \mathrm{(site} \mathrm{43;} F=69.04, \mathrm{p}<0.0001$ ) and at the patch cut harvest (site 44; $\mathrm{F}=25.32, \mathrm{p}<0.0001$ ). Further, the two-way ANOVA showed that canopy openness differed among the three harvested sites before, one summer after, and two summers after timber harvest (Figs. $2.1 \& 2.2$ ). Mean canopy openness increased the summer after timber harvest $\left(\mathrm{AC}_{1}\right)$ at each of the three sites. The patch cut site (site 44), had the highest mean canopy openness the summer directly after timber harvest (36\%), and retained high canopy openness two summers following harvest (28\%; Fig. 2.1). Although the greatest canopy openness occurred at the patch cut site (site 44), the largest relative increase in canopy openness $(133 \%)$ occurred the summer after timber harvest $\left(\mathrm{AC}_{1}\right)$ at the $45.7 \mathrm{~cm}$ diameter-limit harvest site (site 43). However, the strong relative increase was due primarily to the very low canopy openness at this site before timber harvest. Canopy openness was most variable two summers after timber harvest $\left(\mathrm{AC}_{2}\right)$ at the $30.5 \mathrm{~cm}$ DLH site (site 41) and the patch cut harvested site (site 44) (Fig. $2.1)$.

As expected, absolute canopy openness was lower two summers after timber harvest $\left(\mathrm{AC}_{2}\right)$ relative to the summer after timber harvest $\left(\mathrm{AC}_{1}\right)$ at all sites $($ Figs. $2.1 \&$ 2.2), indicating that canopy closure was occuring. However, the relative closure that occurred between these two periods differed among the three sites. The lowest amount of relative canopy closure occurred at the site that was harvested using a $45.7 \mathrm{~cm}$ diameterlimit harvest (site $43 ; 19 \%$ ), followed by the patch cut site (site $44 ; 22 \%$ ). The highest 
amount of relative canopy closure occurred at the site that was harvested using a $30.5 \mathrm{~cm}$ diameter-limit harvest (site 41; 34\%). 


\subsection{Discussion}

Due to the Panax-centric sampling design, the results of this study do not quantify the understory canopy environment throughout an entire site. Rather, the values reflect changes in canopy structure as they pertain to a patchily distributed, wild understory herb. Further, this study did not quantify canopy openness after the most severe form of timber harvest, clearcutting.

Insofar as our sites represent the various cutting practices they experienced, canopy closure was rapid following each timber harvest, but varied among the harvest strategies. We predicted that closure above the herbaceous layer would be highest on sites where post-harvest canopy openness was greatest. Our results partially support this hypothesis, as relative canopy closure one year after compared to two years after harvest was lowest at the $45.7 \mathrm{~cm}$ DLH site (site 43). Although we expected that relative closure would be greatest at the patch cut site (site 44) due to overtopping by weedy and invasive species, this was not the case. Instead, relative closure was greatest at the $30.5 \mathrm{~cm}$ diameter-limit harvest (site 41) where significant forest floor and soil disturbance was observed following timber extraction (Chandler and McGraw 2015). The understory and mid-story at the $30.5 \mathrm{~cm}$ DLH site (site 41) closed rapidly due to fast growing species such as Urtica dioica (stinging nettle) and Rubus sp., and due to influxes of invasive species such as Persicaria perfoliata (mile-a-minute) and Ailanthus altissima (tree of heaven). Although weedy and invasive species were present at the other sites after timber harvest, they were less abundant. Studies indicate that the abundance of weedy and invasive species increases after timber harvest, and in some cases abundance increases as a function of increasing timber harvest intensity (Belote et al. 2012, Kern et 
al. 2014). Further, some studies suggest that increases in weedy and invasive species may depend heavily on forest floor and soil disturbances caused by skid roads and timber extraction, and less on the residual canopy after harvest (Buckley et al. 2003, Kern et al. 2006). Although not directly quantified in this study, it is possible that the forest floor disturbance that was observed after the $30.5 \mathrm{~cm}$ DLH (site 41) contributed to the large amount of weedy and invasive plants on the site after timber harvest.

Canopy openness was more variable at the $30.5 \mathrm{~cm}$ DLH site (site 41) and the patch cut harvested site (site 44). Greater variability after the $30.5 \mathrm{~cm}$ DLH harvest (site 41) two summers after harvest may have been caused by differential release of understory and mid-story growth among sample locations on the site. The timber extraction at this site resulted in the scattered destruction and compaction of the soil profile (Chandler and McGraw 2015). Native and invasive graminoids dominated much of the area whose soils were severely disturbed. Forb, shrub, and sapling growth was released and rapidly extended into the canopy in areas where the soil was less damaged. Variability during both years post-timber harvest at the patch cut site (site 44) resulted from spatial variation in residual canopy and new growth between sampling points that were near the edge of the cut patches and sampling points that were located closer to the center of the patch cut. A separate study found that canopy openness was more variable in harvested stands compared to unharvested control stands (Beaudet and Messier 2002), and our study corroborates that finding.

Our results support previous work which determined that light levels near the forest floor decreased rapidly following timber harvest (Beaudet et al. 2004). When measuring at a height $5 \mathrm{~m}$ above the forest floor, Beaudet and Messier (2002) found that 
canopy openness was 2.3 times higher two years after selection harvest than at an uncut control. Our results differ from these, and indicate that mean openness in the herbaceous layer two years after harvest was only 1.5 times greater than pre-harvested openness. The discrepancy between these findings was due to sampling perspective $(0.2 \mathrm{~m}$ and $5 \mathrm{~m}$ aboveground), with only the $0.2 \mathrm{~m}$ perspective capturing both the changes in height and lateral growth of mid-story and canopy trees as well as release and overtopping of herbs and shrubs in the understory following gap formation.

Field observations suggest that the harvest performed at the $30.5 \mathrm{~cm}$ DLH site (site 41) led to more damage to the forest floor and more breakage of residual tree limbs and boles than occurred at other sites. We suspect that the high density of skid roads at site 41 contributed to a canopy that was more open the summer after a timber harvest than would typically result from a $30.5 \mathrm{~cm}$ diameter-limit harvest. The federally managed research sites (43 and 44) provide a more accurate estimation of the canopy disturbance that follows timber harvest when such harvest is carefully planned and implemented, but may underestimate the disturbance that occurs following harvest on some private lands in which the primary goal is the extraction of valuable timber rather than silvicultural research.

Understory productivity benefits from the increased light availability caused by canopy gap formation (Roberts and Gilliam 2014). Even small canopy gaps increase the seasonal cumulative photosynthetically active radiation in a forest, and as canopy gap size increases, light penetrates even farther into the understory (Canham et al. 1990). However, the duration of photosynthetic and growth stimulations in shade adapted herbs is limited due to growth of taller plants and rapid gap closure (J. L. Chandler submitted). 
An understory herb whose growth is determinate and depends on carbon storage from previous growing seasons will benefit from additional light caused by canopy disturbance (J. L. Chandler submitted). However, due to delayed acclimation, stimulations will lag behind canopy changes (J. L. Chandler submitted), a phenomenon also observed in preexisting leaves of shade-tolerant sugar maple saplings under natural canopy gaps (Naidu and DeLucia 1997). Nevertheless, the adaptation of understory herbs like American ginseng to low light environments enable these herbs to persist through what Beaudet and Messier (2002) term the "decline cascade," which is the increased mortality caused by maladaptation to lower light levels that occur as the canopy closes.

Changes in canopy dynamics after timber harvest are determined by characteristics of the disturbance as well as the composition of the regenerating species in each strata, including the herbaceous understory (Valverde and Silvertown 1997, Beaudet and Messier 2002). From the perspective of a shade-tolerant understory plant, a high severity canopy disturbance produces intense, brief canopy openings and rapid closures (Small and McCarthy 2002), with closure depending on harvest intensity and the presence of highly responsive weedy and invasive species. Some understory plants will benefit from light increases following severe disturbances, but stimulation will be shortlived, as understory light rapidly decreases with the development of early successional canopies (Oliver and Larson 1990, Small and McCarthy 2002). Moderate canopy disturbances, by contrast, may produce for the herbaceous layer an intermediate pulse of light energy that is longer lasting especially where competition from shade-intolerant weedy species is relaxed. As a result, frequent moderate disturbances could be more 
beneficial to understory plants due to increases in the duration and the net degree of stimulation (Canham 1989, J. L. Chandler submitted). 


\subsection{Acknowledgements}

We would like to thank the USDA Forest Service and the West Virginia Division of Forests for access to the study sites. We would also like to thank Amy Hruska, Alix Wagner, Michael Elza, Kyle Gregory, Anne Jarrell, and Quinn Doyle for their assistance and hard work in the field. This project was funded in part by NSF grants DEB-0613611 and DEB-1118702 to J.B.M. 


\subsection{Tables and Figures}

Table 2.1. Type of timber harvest implemented, land ownership, dominant canopy species and physical characteristics for each site studied.

\begin{tabular}{|c|c|c|c|c|c|c|}
\hline Population & $\begin{array}{c}\text { Harvest } \\
\text { Type }\end{array}$ & $\begin{array}{l}\text { Ownership } \\
\text { Type }\end{array}$ & $\begin{array}{c}\text { Dominant canopy } \\
\text { species }\end{array}$ & $\begin{array}{c}\text { Mean } \\
\text { Aspect }\end{array}$ & $\begin{array}{l}\text { Mean } \\
\text { Slope }\end{array}$ & $\begin{array}{l}\text { Elev. } \\
\text { (m) }\end{array}$ \\
\hline $43 *$ & $\begin{array}{c}45.7 \mathrm{~cm} \\
\text { Diameter- } \\
\text { limit Harvest }\end{array}$ & USDA forest & $\begin{array}{c}\text { Acer saccharum } \\
\text { Acer rubrum } \\
\text { Quercus rubra }\end{array}$ & $168^{\circ}$ & $16^{\circ}$ & 689 \\
\hline 41 & $\begin{array}{c}30.5 \mathrm{~cm} \\
\text { Diameter- } \\
\text { limit Harvest }\end{array}$ & $\begin{array}{l}\text { West Virginia } \\
\text { State Forest }\end{array}$ & $\begin{array}{c}\text { Acer saccharum } \\
\text { Fagus grandifolia }\end{array}$ & $0^{\circ}$ & $9.5^{\circ}$ & 373 \\
\hline $44 *$ & $\begin{array}{l}0.162 \text { ha } \\
\text { Patch Cut }\end{array}$ & USDA forest & $\begin{array}{c}\text { Acer saccharum } \\
\text { Acer rubrum } \\
\text { Quercus rubra }\end{array}$ & $355^{\circ}$ & $7.7^{\mathrm{o}}$ & 841 \\
\hline
\end{tabular}

* Species data were taken from Schuler (2004), and represents the rank of woody overstory species among multiple compartments within the federally managed forest. Canopy species composition data from 43 and 44 were not collected in the current study. 


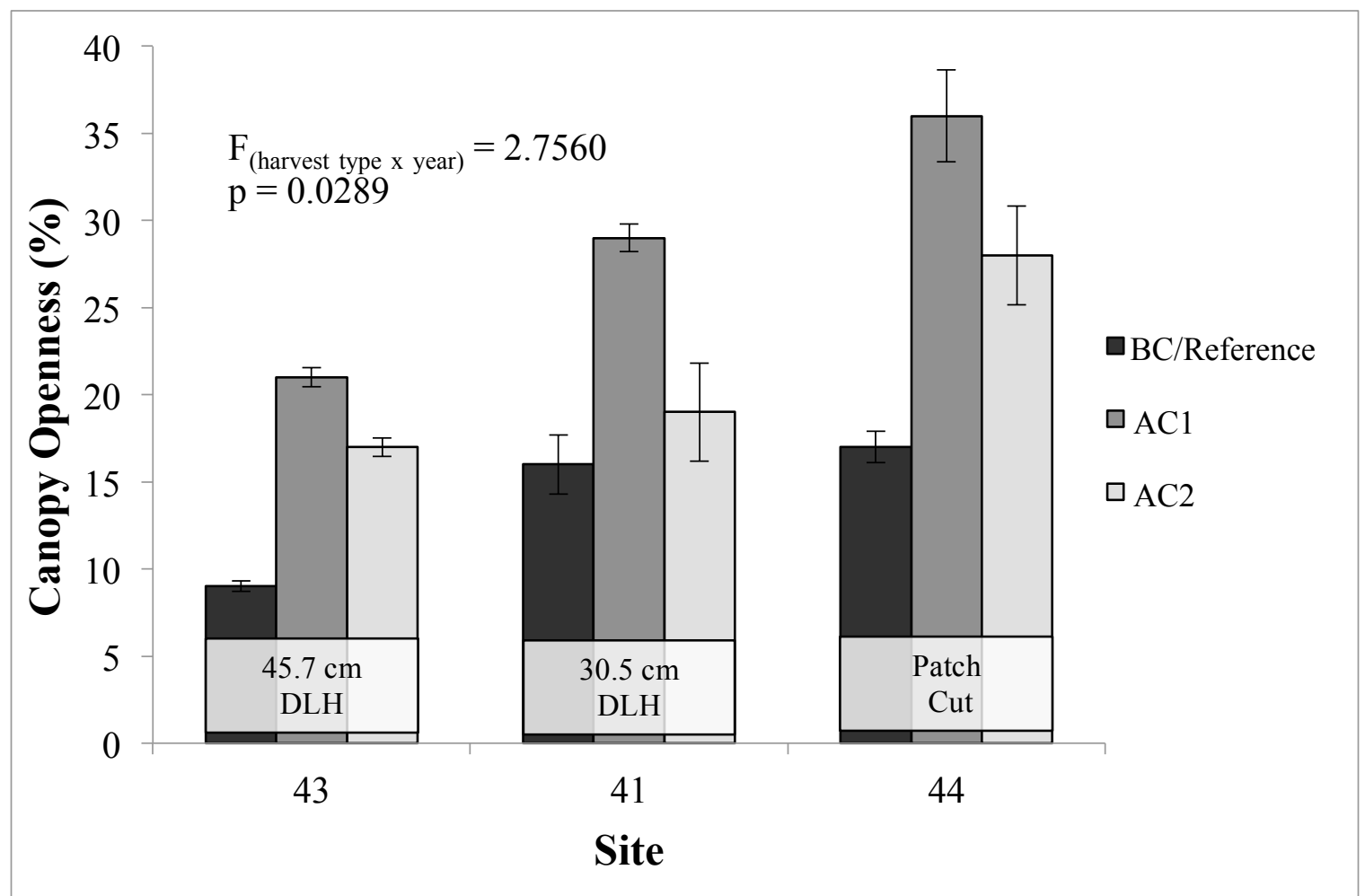

Figure 2.1. Mean canopy openness (+/- S.E.) at each site at three time periods relative to the timber harvest: before the timber harvest (BC/Reference), one summer following timber harvest $\left(\mathrm{AC}_{1}\right)$, and two summers following the timber harvest $\left(\mathrm{AC}_{2}\right)$. 


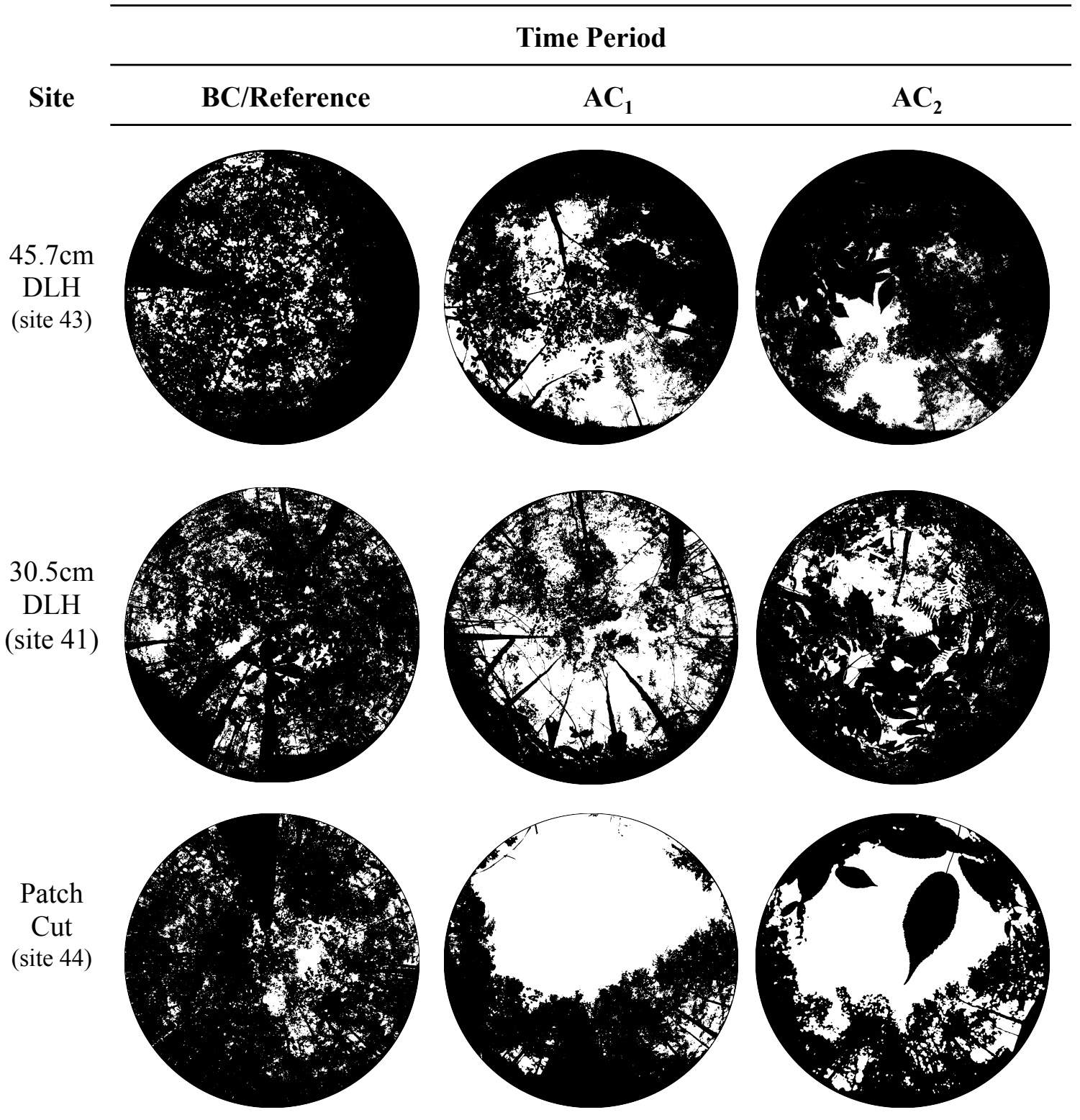

Figure 2.2. Sample hemispherical images depicting the general patterns of canopy openness from each site $(43,41$, and 44$)$ for each time period (BC/Reference, $\mathrm{AC}_{1}$, and $\mathrm{AC}_{2}$ ). 


\subsection{Literature Cited}

Beaudet, M., and Messier, C. 2002. Variation in canopy openness and light transmission following selection cutting in northern hardwood stands: An assessment based on hemispherical photographs. Agric. For. Meteorol. 110(3): 217-228.

Beaudet, M., Messier, C., and Leduc, A. 2004. Understorey light profiles in temperate deciduous forests: Recovery process following selection cutting. J. Ecol. 92(2): 328338 .

Belote, R.T., Jones, R.H., and Wieboldt, T.F. 2012. Compositional stability and diversity of vascular plant communities following logging disturbance in Appalachian forests. Ecol. Appl. 22(2): 502-16.

Buckley, D.S., Crow, T.R., Nauertz, E.A., and Schulz, K.E. 2003. Influence of skid trails and haul roads on understory plant richness and composition in managed forest landscapes in Upper Michigan, USA. For. Ecol. Manage. 175: 509-520.

Canham, C.D. 1988a. An index for understory light levels in and around canopy gaps. Ecology 69(5): 1634-1638.

Canham, C.D. 1988b. Growth and canopy architecture of shade-tolerant trees: Response to canopy gaps. Ecology 69(3): 786-795.

Canham, C.D. 1989. Different responses to gaps among shade-tolerant tree species. Ecology 70(3): 548-550. doi:10.2307/1940200.

Canham, C.D., Denslow, J.S., Platt, W.J., Runkle, J.R., Spies, T.A., and White, P.S. 1990. Light regimes beneath closed canopies and tree-fall gaps in temperate and tropical forests. Can. J. For. Res. 20: 620-631. doi:10.2307/1940194.

Canham, C.D., and Marks, P.L. 1985. The response of woody plants to disturbance: Patterns of establishment and growth. In The Ecology of Natural Disturbance and Patch Dynamics. Edited by S.T.A. Pickett and P.S. White. Academic Press, New York. pp. 197-216.

Chandler, J.L., and McGraw, J.B. 2015. Variable effects of timber harvest on the survival, growth, and reproduction of American ginseng (Panax quinquefolius L.). For. Ecol. Manage. 344: 1-9. Elsevier B.V. doi:10.1016/j.foreco.2015.02.007.

Chazdon, R., and Fetcher, N. 1984. Photosynthetic light environments in a lowland tropical rainforest in Costa Rica. J. Ecol. 72: 553-564.

Chazdon, R.L., and Pearcy, R.W. 1991. The importance of sunflecks for forest understory plants. Bioscience 41(11): 760-766. doi:10.2307/1311725.

Frazer, G., Canham, C., and Lertzman, K. 1999. Gap Light Analyzer. Simon Fraser University, Burnaby, BC, Canada.

Gilliam, F.S. 2007. The ecological significance of the herbaceous layer in temperate forest ecosystems. BioScience 57 (10): 845-858. 
Kern, C.C., Montgomery, R.A., Reich, P.B., and Strong, T.F. 2014. Harvest-created canopy gaps increase species and functional trait diversity of the forest ground-layer community. For. Sci. 60(2): 335-344.

Kern, C.C., Palik, B.J., and Strong, T.F. 2006. Ground-layer plant community responses to even-age and uneven-age silvicultural treatments in Wisconsin northern hardwood forests. For. Ecol. Manage. 230: 162-170.

doi:10.1016/j.foreco.2006.03.034.

Lawton, R. 1990. Canopy gaps and light penetration into a wind-exposed tropical lower montane rain forest. Can. J. For. Res. 20: 659-667.

McCarthy, B.C., and Robison, S.A. 2003. Canopy openness, understory light environments, and oak regeneration. In Characteristics of mixed oak forest ecosystems in southern Ohio prior to the reintroduction of fire. USDA Forest Service. pp. 57-66.

McGraw, J.B., Lubbers, A.E., Van der Voort, M., Mooney, E.H., Furedi, M.A., Souther, S., Turner, J.B., and Chandler, J. 2013. Ecology and conservation of ginseng (Panax quinquefolius) in a changing world. Ann. N. Y. Acad. Sci. (The Year in Ecology and Conservation): 62-91. doi:10.1111/nyas.12032.

Naidu, S.L., and DeLucia, E.H. 1997. Acclimation of shade-developed leaves on saplings exposed to late-season canopy gaps. Tree Physiol. 17: 367-376.

Oliver, C.D., and Larson, B.C. 1990. Forest stand dynamics. McGraw-Hill, Inc., New York.

Roberts, M.R. 2004. Response of the herbaceous layer to natural disturbance in North American forests. Can. J. Bot. 82(9): 1273-1283. doi:10.1139/b04-091.

Roberts, M.R., and Gilliam, F.S. 2014. Response of the herbaceous layer to disturbance in eastern forests. In The Herbaceous Layer in Forests of Eastern North America, 2nd edition. Edited by F.S. Gilliam. Oxford University Press, Oxford. pp. 321-340.

Schuler, T.M. 2004. Fifty years of partial harvesting in a mixed mesophytic forest: composition and productivity. Can. J. For. Res. 34(5): 985-997. doi:10.1139/x03262.

Small, C.J., and McCarthy, B.C. 2002. Effects of simulated post-harvest light availability and soil compaction on deciduous forest herbs. Can. J. For. Res. 32(10): 1753-1762.

Smith, W.K., and Berry, Z.C. 2013. Sunflecks? Tree Physiol. 33(3): 233-7. doi:10.1093/treephys/tpt005.

Sousa, W.P. 1984. The role of disturbance in natural communities. Annu. Rev. Ecol. Syst. 15: 353-391.

Valverde, T., and Silvertown, J. 1997. Canopy closure rate and forest structure. Ecology 78(5): 1555-1562. 
Chapter 3. A Slow Opportunist: Physiological and Growth Response of an Obligate Understory Plant to Patch Cut Harvesting

Formatted for, and submitted to, Oecologia 


\subsection{Abstract}

Patches of light reaching the understory increase in intensity, duration, and in some cases spatial and temporal heterogeneity following different types of timber harvest, and while many understory species utilize and benefit from the additional light, this response is not ubiquitous in shade-obligate species. I examined the effects of patch cut timber harvest on the physiology and growth of an obligate forest understory species in order to determine if disturbances via timber harvest are physiological stressors or whether such disturbances provide physiological benefits and growth increases in this understory species. Forest canopy structure, along with photosynthesis, daytime dark respiration, water use efficiency, stomatal conductance, and growth rates of American ginseng were quantified one summer before and two summers after patch cut timber harvest. Survival following timber harvest was lower than was observed at undisturbed populations: however, growth of survivors increased post-harvesting, with growth increasing as a function of canopy openness. Light response curves and comparisons of photosynthesis and respiration indicated that plants were not well-acclimated to higher light levels in the growing season after timber harvest, but were well-acclimated two growing seasons after harvest. Relative growth rate increased as a function of increases in maximum photosynthesis following timber harvest. My study suggests that ginseng is a "slow opportunist," because while it benefits from sudden light increases, acclimation lags behind canopy changes. American ginseng is surprisingly resilient in the face of a discrete environmental shift, and may benefit from forest management strategies that mimic the natural disturbance regimes common in mature forests throughout its range. 


\subsection{Introduction}

The understories of undisturbed second-growth forests are spatially and temporally heterogeneous due to aspect, topography, solar path, weather, and canopy architecture (Chazdon 1988, Chazdon and Pearcy 1991, Baker 1996, Prévost and Raymond 2012, Smith and Berry 2013). The light environments within these understories are characterized by low levels of diffuse light interspersed with patches of direct light known as sunflecks (Chazdon and Pearcy 1991, Fournier et al. 2004, Smith and Berry 2013). The light intensity in sunflecks can be up to 100 times greater than that of ambient understory light (Chazdon and Pearcy 1991). Sunflecks constitute up to $85 \%$ of total daily photosynthetic photon flux density (PPFD) in the understory and contribute significantly to photosynthesis and carbon storage (Chazdon 1988, Chazdon and Pearcy 1991, Kursar and Coley 1993). Nevertheless, light still remains one of the primary limiting resources in second growth, mixed mesophytic forests (Chazdon 1988, Canham et al. 1990, Chazdon and Pearcy 1991, Kursar and Coley 1993, Beckage et al. 2000, Whigham 2004a, Neufeld and Young 2014).

The understory light environment changes rapidly following canopy disturbance. The potentially intense, yet transient sunflecks common in undisturbed forest understories become much more intense and longer lasting. Correlated with this are increases in forest floor air and soil temperature, temperature fluctuations, and evapotranspiration, and decreases in both relative humidity and soil surface moisture (Liechty et al. 1992, Roberts and Gilliam 2014, Roberts 2004, Muscolo et al. 2014).

Commercial timber harvest has been a common, recurrent form of anthropogenic disturbance throughout North American forests ever since the extensive harvest of old- 
growth forests in the late 1800's and early 1900's (Wyatt and Silman 2014). Timber harvesting and regeneration strategies can range from individual tree gaps caused by single-tree selection to stand replacing disturbances such as clearcutting (Lorimer and Frelich 1994, Gilliam and Roberts 1995, Roberts and Gilliam 2014). As with natural canopy disturbances, following timber harvest, patches of direct light reaching the forest understory increase in duration and intensity, and potentially increase in temporal and spatial heterogeneity (Chazdon and Fetcher 1984, Sousa 1984a, Canham 1988a, 1988b, Roberts 2004). Although changes in the light environment following canopy disturbance can increase productivity in light limited understory plants, these changes favor understory species in different ways (Roberts and Gilliam 2014, Prévost and Raymond 2012). Smaller canopy gaps formed during disturbance promote the establishment and growth of shade-tolerant species, while larger canopy gaps promote shade-intolerant understory species (Roberts and Gilliam 2014, Prévost and Raymond 2012). One such shade-tolerant understory herb that may be affected by changing canopy dynamics is the ecologically, economically, and culturally valuable herb, American ginseng (Panax quinquefolius L).

American ginseng is an uncommon to rare, but widespread, medicinal herb found throughout much of eastern North America (McGraw et al. 2013). Historical accounts suggest that ginseng was once abundant throughout its range, but centuries of both habitat disturbance and of over-harvest for the sale of its root on the Asian traditional medicine market have resulted in decreases in range-wide abundance (McGraw et al. 2013, Chandler and McGraw 2015). Prior research suggests that ginseng is adapted to the dynamic light environments of old-growth forests (Wagner and McGraw 2013). Old- 
growth forests are characterized by an overstory that varies in individual age, size, and species composition, and has dynamic gap formations and closures (Knohl et al. 2003, Spies et al. 2006, Manabe et al. 2009).

Wagner and McGraw (2013) determined that maximum photosynthetic rates of American ginseng increased with greater sunfleck duration and the percentage of mean PPFD contributed by sunflecks. The relative growth rate of adult ginseng plants also increased as a function of both sunfleck characteristics (Wagner and McGraw 2013). The same study found that transpiration and seed production efficiency were not affected by either sunfleck characteristic, but that germination decreased as percent of mean PPFD provided by sunflecks increased (Wagner and McGraw 2013). While carbon assimilation, growth, and reproduction of many understory species respond positively to increases in sunfleck intensity and duration, this response is not ubiquitous (Le Gouallec et al. 1990, Chazdon and Pearcy 1991, Fournier et al. 2004, Whigham 2004a). In fact, long-lasting sunflecks and sunflecks with high levels of PPFD have led to high leaf temperature, wilting, and even photoinhibition in some species (Le Gouallec et al. 1990, Chazdon and Pearcy 1991, Oláh and Masarovičová 1997). How then do shade-adapted species respond to light levels and durations that far exceed those present in sunflecks?

The known consequences of timber harvest for American ginseng are equivocal. However, one study found that American ginseng survival decreased sharply following timber harvest, with the lowest survival occurring at the most intensely harvested site (Chandler and McGraw 2015). While the direct mechanisms controlling survival were not explicitly tested, soil profile disruption or compaction through the mechanical extraction of timber was thought to be the likely cause, not physiological stress due to 
photoinhibition. However, the latter was not examined. The same study determined that relative growth rate increased in those individuals that survived the initial timber harvest, and was greatest at the sites with the highest amount of timber extracted. Seed production decreased initially due to desiccation of the inflorescence in the prior study, but increased in the years following timber harvest while increases in seed production efficiency (seeds per unit leaf area) were population-dependent and short-lived. While Chandler and McGraw (2015) established the multi-faceted response of ginseng to varying intensities of timber harvest, the physiological underpinnings of the response were ignored.

Based on the results of Chandler and McGraw (2015), it is not clear whether canopy disturbances via timber harvest are physiological stressors, or whether increases in light following timber harvest provide physiological benefits, particularly in those physiological traits that directly relate to carbon accumulation. To resolve this uncertainty, I quantified the effects of canopy openness on photosynthesis, respiration, water use efficiency, and stomatal conductance of American ginseng before and after timber harvest. I further evaluated the growth response of American ginseng as a function of the changes in canopy openness and maximum photosynthesis that occurred after a harvest event. 


\subsection{Methods}

\section{Study Species}

Similar to many other herbs found throughout the eastern deciduous forest, American ginseng is a widespread, long-lived perennial herb that exhibits 'slow' life history patterns (McGraw et al. 2013). These qualities make ginseng a good model species for understanding how canopy disturbances affect shade-obligate understory herbs generally. Emergence from winter dormancy, elongation, and leaf expansion all occurs concurrent with overstory canopy development and closure in late April and May (Lewis and Zenger 1982, Hackney and McGraw 2001, Fournier et al. 2004). Flowering takes place in June and July, and is followed by fruit production and ripening from July to September (Carpenter and Cottam 1982, McGraw et al. 2013). Dispersal of fruit occurs via frugivorous birds and gravity in August and September, and is followed by plant senescence and dormancy (Lewis and Zenger 1982, McGraw et al. 2013, Hruska et al. 2014).

\section{Study Site}

I took advantage of an existing, natural population of American ginseng that was located within a portion of a USDA Experimental Forest that was prescribed a patch cut timber harvest as part of a larger study. The study site was located in a USDA Experimental Forest within the central Appalachian region of the eastern deciduous forest. A specific site identifier is withheld due to the conservation concern of American ginseng, and is replaced with a non-descript identifier, 44. Site 44 was selected based on both the presence of wild American ginseng on the site and on the anticipated harvest of timber. The timber on this second growth forest was heavily harvested in the early 
twentieth century (Adams et al. 2012). The land was acquired by the USDA in 1915 and designated as an experimental forest in 1934, and consisted primarily of even-aged stands (Adams et al. 2012). Silvicultural management research was initiated in 1951 when the stand was ca. 40 years old (Schuler 2004). The site of interest, 44, was prescribed a patch cutting treatment. Patch cutting can represent a moderate- to high-level of canopy disturbance, with the disturbance severity dependent on patch opening size, total area of harvest, proximity to harvest unit, and cutting cycle. The timber on site 44 had a rotation age of 65 years, and was managed on a ten-year cutting cycle using small-patch cutting with circular openings of about 0.162 ha with a diameter of ca. $45 \mathrm{~m}$ (Schuler 2004). I therefore classify this treatment as an intermediate level canopy disturbance. I chose to focus on a site that was harvested using a patch cut, because this type of harvest lies on the upper threshold of intermediate timber harvest, and any stress observed in ginseng plants following patch cut would likely be higher than would be observed in harvest strategies that fall lower on a disturbance spectrum. The particular cutting cycle analyzed in this work occurred after the 2013 growing season in late fall.

\section{Canopy Environment}

Hemispherical images of the sky were taken above each individual or small subpopulation of tightly aggregated individuals once per growing season (June-July) to quantify the changes in canopy structure that occurred following timber harvest. Due to the short stature of the plant, the canopy is defined as the understory, mid-story, and tree canopy vegetation that extends greater than $20 \mathrm{~cm}$ aboveground, which is near the mean height of a ginseng plant (Chandler and McGraw 2015). Hemispherical photographs were taken on overcast days from a position $20 \mathrm{~cm}$ above the soil surface with the top of 
the photograph oriented northward. A Canon EOS Rebel T2i equipped with a 180-degree fisheye lens (Sigma $4.5 \mathrm{~mm}$ F2.8 EXDC) was used to capture the 18MP images. Canopy cover was then analyzed using Gap Light Analyzer software (Frazer et al. 1999) to determine percent canopy openness, defined as the percentage of open sky visible beneath the forest canopy. Percent canopy openness is determined by partitioning pixels into "sky" and "non-sky" categories and calculating the distribution of sky based on pixel categories (Frazer et al. 1999). Physical site characteristics including slope, aspect, North American averages of solar constant, cloudiness index, beam fraction, and clear-sky transmission coefficient were used to parameterize Gap Light Analyzer. While some studies indicate that PPFD and photosynthetically active radiation are not correlated with percent canopy openness under very low light conditions (Whitmore et al. 1993, Machado and Reich 1999), the majority of canopy openness values in the present study exceeded these limits. Further, other studies have established linear relationships between canopy openness and mean daily percent PPFD under higher light levels, as well as between canopy openness and global radiation (combined percentage of diffuse and direct beam total season radiation) (Machado and Reich 1999, McCarthy and Robison 2003).

Ginseng Census, Growth, and Reproduction

Thirty-four ginseng plants were located on site 44 the spring before timber harvest, and were censused for three growing seasons (2013 - 2015). Each individual was labeled using a subterranean tag to ensure accurate identification each census period. Census data were collected twice annually; once in the spring to assess plant emergence and leaf area, and once in the fall to assess reproduction. Census data collected included 
plant emergence $(\mathrm{Y} / \mathrm{N})$, leaf number, length and width of the longest leaflet on each leaf $(\mathrm{cm})$, reproductive status $(\mathrm{Y} / \mathrm{N})$, and number of seeds. Seed count is easily assessed in situ based on the shape and configuration of ginseng berries.

Survival of individuals was determined using plant emergence data. New seedlings were considered dead if they did not re-emerge the growing season after germination, while older plants were considered dead if they did not emerge for two consecutive growing seasons. The two-year observation period was necessary because established individuals with damaged shoots or roots may lie dormant for one growing season and re-emerge the following season. A G-test was performed to determine if the mortality rates at population 44 differed from the expected mean mortality rate calculated from twelve undisturbed populations whose locations spanned a substantial portion of the natural range of American ginseng, and whose abiotic site characteristics differed from the patch cut site (site 44). A logistic regression was performed to determine if the canopy openness in the summer following timber harvest (2014) affected the probability of American ginseng survival.

Leaf area was calculated for all individuals using a regression equation based on the allometric relationship between leaf area and length and width of the longest leaflet on the leaf (Souther and McGraw 2011b). Individual leaf areas were summed to yield the total leaf area for each plant. The changes in leaf area of an individual over time, relative growth rate $\left(\mathrm{RGR}_{\mathrm{LA}}\right)$, was calculated based on changes in plant leaf area between growing seasons using the formula (McGraw and Garbutt 1990):

$$
R G R_{L A}=\frac{\left(\ln L A_{2}-\ln L A_{1}\right)}{\left(t_{2}-t_{1}\right)}
$$


Leaf area of an individual ginseng plant in the present growing season is determined by carbon storage the previous growing season. Therefore, any growth effect of timber harvest that occurred during the dormant season (late fall, 2013) would not be manifest in the 2013-2014 interval, but rather in the 2014-2015 interval. Accordingly, the change in leaf area from 2013 to 2014 represents $\mathrm{RGR}_{\mathrm{LA}}$ before the timber harvest event (BT), while the change in leaf area from 2014 to 2015 represents RGR $_{\mathrm{LA}}$ after the harvest event (AT). A paired t-test was used to compare relative growth before timber harvest $\left(\mathrm{RGR}_{\mathrm{BT}}\right)$ to after harvest $\left(\mathrm{RGR}_{\mathrm{AT}}\right)$. Relative growth rate from 2013 to 2015 was also calculated to determine if there was a net increase in size over the entire study.

While the paired t-test may reflect the mean change in $\mathrm{RGR}_{\mathrm{LA}}$ in response to light, this measurement could overlook subtle variations in $\mathrm{RGR}_{\mathrm{LA}}$ present before and after the timber harvest. In order to determine if $\mathrm{RGR}_{\mathrm{LA}}$ changed as a function of variation in canopy openness in either transition period, two regressions were performed, one with relative growth rate before timber harvest $\left(\mathrm{RGR}_{\mathrm{BT}}\right)$ regressed on percent canopy openness before timber harvest (2013), and a separate one relating the same variables after timber harvest (2014). I wanted to compare changes in $R_{G R} R_{L A}$ observed at population 44 to changes in $\mathrm{RGR}_{\mathrm{LA}}$ at nearby undisturbed control populations, named "29" and " 30 " to ensure that observed changes in $\mathrm{RGR}_{\mathrm{LA}}$ at population 44 were a function of the timber harvest and not of typical year-to-year variation. The two longterm research populations used were not harvested, and were located within $20 \mathrm{~km}$ of population 44. Populations 29 and 30 were previously used to study effects of deer browse on population viability of American ginseng (McGraw and Furedi 2005), and the data from these two populations were pooled into one control for this study. A two-way 
ANOVA was used to determine if growth differed between the harvested population (population 44) and the control populations (control) over the period before (2013-2014) and after (2014-2015) the timber harvest event.

Seed production is generally positively related to total leaf area (McGraw et al. 2013) but this relationship can be altered by changes to the light environment and by the changes in internal resource availability that follow canopy disturbance (Schlessman 1985). A two-way ANOVA without replication was used to determine if the number of seeds produced by each reproductive individual present in the population differed in the growing seasons before $(2013)$ and following $(2014,2015)$ the timber harvest.

\section{Physiological Measurements and Analyses}

Light response curves were constructed from photosynthesis measurements made with a Li-Cor 6400XT gas exchange system (Li-Cor, Lincoln, NE, USA) to determine how increases in light caused by the patch cut affected gas exchange. Physiological measurements were made the growing season before timber harvest as well as the two growing seasons after timber harvest for each 2- and 3-leaved individual. All photosynthesis measurements were taken once per year in mid-season (mid-July to early August) on clear days between 11:00 a.m. and 3:00 p.m. Net photosynthesis was measured at nine PPFD levels; 0, 100, 300, 500, 700, 900, 1100, 1300, and $1500 \mu \mathrm{mol} \mathrm{m}^{-}$ ${ }^{2} \mathrm{~s}^{-1}, \mathrm{CO}_{2}$ levels were set at $390 \mu \mathrm{mol} \mathrm{CO} \mathrm{mol}^{-1}$, and cuvette temperature was set at $25^{\circ} \mathrm{C}$.

Light response curves were fit and parameter estimates were established using a non-rectangular hyperbola model (Landflux n.d., Marshall and Biscoe 1980), and values 
for $A_{\max }$ and daytime dark respiration $\left(\mathrm{R}_{\mathrm{d}}\right)$ were derived from the model fits. Separate paired t-tests were used to determine if $A_{\max }, R_{d}$, photosynthetic water use efficiency $\left(A_{n} / E\right)$ where $A_{n}$ is net carbon assimilation and $E$ is transpiration, intrinsic water use efficiency $\left(\mathrm{A} / \mathrm{g}_{\mathrm{s}}\right)$, and stomatal conductance $\left(\mathrm{g}_{\mathrm{s}}\right)$ varied in the three growing seasons surrounding timber harvest. An increase in $\mathrm{A}_{\max }$ following timber harvest would indicate that plants utilize and benefit from the additional light, while stress may be manifested as increases in respiration and stomatal closure, and decreases in water use efficiency. Two regressions were performed in order to determine if the growth of individuals as a function of $A_{\max }$ was stimulated after timber harvest relative to before harvest, where $\mathrm{RGR}_{\mathrm{BT}}$ was regressed on $\mathrm{A}_{\max }$ before timber harvest (2013), and $\mathrm{RGR}_{\mathrm{AT}}$ was regressed on $\mathrm{A}_{\max }$ after harvest (2014). 


\subsection{Results}

Canopy openness varied over the three-year study period (Fig. 3.1). Mean canopy openness increased from $17 \%$ in the growing season prior to timber harvest (2013) to $36 \%$ the growing season directly after harvest (2014); a relative increase of $112 \%$. However, as expected, canopy openness decreased to $28 \%$ two growing seasons after the timber harvest (2015) due to growth release of understory and mid-story herbs and woody plants.

Survival, Growth, and Reproduction

A G-test indicated that at $22 \%$, the mortality observed at population 44 was greater than the expected mortality at twelve undisturbed populations across American ginseng's range $(\mathrm{G}=7.286, \mathrm{p}<0.05$; data taken from Souther and McGraw 2011; Chandler and McGraw 2015). Nevertheless, a logistic regression indicated that variation in canopy openness directly after timber harvest (2014) did not affect probability of $\operatorname{survival}\left(\chi^{2}=0.17, \mathrm{p}=0.6759\right)$.

There was a marked increase in relative growth rate among individuals following the timber harvest (Table 3.1a). Plants grew significantly faster after timber harvest $\left(\mathrm{RGR}_{\mathrm{LA}}=0.62\right)$ than before timber harvest $\left(\mathrm{RGR}_{\mathrm{LA}}=-0.234\right)$. Further, there was a net increase in growth over the entire study period $\left(\mathrm{RGR}_{15-13}=0.135\right)$. Regression analyses indicated that relative growth rate did not vary as a function of canopy openness before the timber harvest $\left(\mathrm{r}^{2}=0.0162, \mathrm{p}=0.5536\right.$; Fig. 3.2a), but formed a positive linear relationship with canopy openness following the timber harvest $\left(r^{2}=0.3504, p-0.0023\right.$; Fig. 3.2b). Additionally, greater increases in canopy openness directly after harvesting did result in greater increases in growth $\left(\mathrm{r}^{2}=0.2601, \mathrm{p}=0.0155\right.$; Fig. 3.3). The two-way 
ANOVA indicated that individual growth differed between the harvested and control sites before and after the timber harvest event $(\mathrm{F}=41.6535, \mathrm{p}<0.0001$; Fig. 3.4). The growth rate of American ginseng at population 44 was far lower during the transition period before timber harvest (2013-2014) than the growth rate at comparable, undisturbed control populations (Fig. 3.4). However, this pattern was reversed after the timber harvest (2014-2015), and the growth rate at population 44 was substantially greater than the growth rate of the control populations. In fact, growth rate at population 44 after harvest was ca. twice that of the control populations (Fig. 3.4).

Although increases in relative growth rate were observed following the timber harvest, the same was not true for seed production. A two-way ANOVA without replication indicated that there was no difference in the mean number of seeds produced by reproductive individuals among pre-harvest and post-harvest years $(\mathrm{F}=0.0218, \mathrm{p}=$ $0.9785)$.

\section{Physiological Response}

Mean maximum photosynthetic rate $\left(\mathrm{A}_{\max }\right)$ of all two- and three-leaved individuals increased by $67 \%$ two growing seasons following timber harvest (2015) relative to the growing season before timber harvest (2013; Table 3.1b). Further, a trend suggests that mean $A_{\max }$ was greater two growing seasons after timber harvest (2015) than one growing season after timber harvest (2014; Table 3.1b). There were no differences in $\mathrm{A}_{\max }$ in the growing seasons directly before (2013) and after (2014) timber harvest (Table 3.1b). Similar patterns are depicted in the mean light response curves that were created only with data from individuals that were present in the population each of the three growing seasons (Fig. 3.5). 
Daytime dark respiration $\left(\mathrm{R}_{\mathrm{d}}\right)$ was greater the growing season directly after timber harvest (2014) compared to both the growing season before harvest (2013), and following harvest (2015; Table 3.1c and Table 3.2). However, $\mathrm{R}_{\mathrm{d}}$ rates pre-timber harvest (2013) and two growing seasons post-timber harvest (2015) did not differ (Table 3.1c). No differences in photosynthetic water use efficiency (WUE $\mathrm{Whoto}_{\text {; }}$ Table 3.1d) or intrinsic water use efficiency (WUE $\mathrm{intrinsic}_{\text {; }}$ Table 3.1e) were observed throughout the study period. Stomatal conductance was higher two growing seasons after the timber harvest (2015) relative to both the growing season prior to (2013) and following (2014) timber harvest (Table 3.1f and Table 3.2).

Relative growth rate did not change as a function of the variation in $\mathrm{A}_{\max }$ before timber harvest (Fig. 3.6a). However, relative growth rate tended to form a positive linear relationship with $A_{\max }$ following harvest (Fig. 3.6b). These results were consistent with the response of growth to percent canopy openness (Fig. 3.2a,b). While growth rate did not vary with canopy openness and maximum rate of photosynthesis before the timber harvest (Figs. 3.2a and 3.6a), growth rate formed a positive linear relationship with both variables following timber harvest (Figs. 3.2b and 3.6b). 


\subsection{Discussion}

Consistent with the results of Chandler and McGraw (2015), the ginseng survival rate following patch cut at site 44 was lower than rates observed at other, undisturbed populations. One mechanism that leads to decreased survival following timber harvest is the destruction and compaction of the soil profile that results both from the formation of skid roads and also from the physical dragging of timber across the soil (Chandler and McGraw 2015). Population 44 is located in a USDA research forest where care is taken to minimize soil disturbance during timber extraction through the use of minimal, permanent skid roads. As a result, the survival reported in this study was likely higher than would occur on a typical timber harvest on private lands (Chandler and McGraw 2015).

An increase in growth rate after timber harvest follows with the results of Chandler and McGraw (2015). However, the decrease in size between 2013 and 2014 (pre-timber harvest) was puzzling, and a similar trend was not observed in Chandler and McGraw (2015). A decrease in growth before timber harvest (2013-2014) may be attributed to the interaction of numerous factors including nutrient availability, surface soil moisture, and seasonal temperature and precipitation. A more open canopy in the spring after timber harvest (2014) resulted in more light in the understory, and a decrease in soil surface moisture. Drought stress may have caused developing leaves to expand less the first growing season after harvesting (2014). Nevertheless, the growth stimulation beyond that of the control populations, the net increase in relative growth rate from 2013 to 2015, along with the positive linear relationship of growth rate to canopy openness indicate that the canopy disturbance did lead to increased growth beyond 
typical year-to-year variation. Further, while seed production did not differ before and after timber harvest in this study, reproduction in American ginseng is strongly size dependent (Schlessman 1985, Charron and Gagnon 1991), and as the leaf area of individuals in the population increase, short-term increases in seed production are predicted to follow.

A comparison of the mean light response curves prior to harvest (2013) and one growing season after harvest (2014) indicated that the individuals were only partially acclimated to the higher light levels caused by timber harvest (Fig. 3.5), a pattern that may be generally applied to many understory herbs that overwinter underground and reemerge concurrent with tree canopy emergence. Acclimation in the first season after timber harvest was minimal because some aspects of leaf morphology were already preformed based on environmental conditions and carbon storage in 2013, the growing season before the harvest event. Individuals displayed signs of stress the growing season after timber harvest (2014), which included reddened leaves presumably from adaxial accumulation of anthocyanins, higher respiration, and early senescence (Neufeld and Young 2014). The second year following timber harvest (2015) plants produced leaves that were better acclimated to high light levels as a result of greater exposure to higher light during the 2014 growing season. Although not directly measured, these wellacclimated leaves likely had greater stomatal density than the leaves produced in both 2013 and 2014 (Neufeld and Young 2014), as is evidenced by greater stomatal conductance in the 2015 growing season.

American ginseng and other obligate shade herbs may be aptly classified as "slow opportunists." Delayed acclimation to higher light is a consequence of American ginseng 
and similar herbs having determinate growth and pre-formed leaves, and results in a consistent time lag behind canopy changes. By the time acclimation occurs in these plants, the understory and mid-story are closing in due to growth release of saplings and ruderal species. It is possible that the lag inherent in these understory herbs limits the duration and magnitude of light-induced growth stimulations following canopy disturbance. Similarly, shade-tolerant trees experience a lag time in the response to gap formation due to prolonged suppression and slow growth under dense shade (Canham 1989). Nevertheless, signs of acclimation to higher light levels such as increased maximum rate of photosynthesis and increased growth rate indicate that American ginseng is an opportunist that benefits from rapid, discrete increases in light availability.

This study suggests that increases in canopy openness lead to increases in carbon acquisition and subsequent growth of American ginseng; however, an analysis of a full spectrum of canopy openness was impractical and was not explored. Nonetheless, it is doubtful that physiological and growth parameters would remain positive at both the lowest and the highest levels of canopy openness. The more probable relationship of these parameters to canopy openness is parabolic with peak stimulation at some intermediate level of canopy openness (Chandler and McGraw, submitted).

Little is known about the state of the herbaceous layer in the eastern deciduous forest prior to the early 1900's when widespread timber harvests removed all but ca. 0.09\% of old-growth forests (Davis 1993, Leverett 1996, Wyatt and Silman 2014). Researchers have quantified the response of herbaceous communities to timber harvest, but confounding factors preclude broad conclusions and generalizations (Duffy and Meier 1992, Fredericksen et al. 1999, Gilliam 2002, Belote et al. 2012, Neufeld and 
Young 2014). Less research has focused on the physiological and growth response of herbaceous species to timber harvest disturbances. A separate study found that moderate to severe timber harvests are detrimental to the population maintenance of American ginseng (Anderson et al. 1993), a finding that is partially refuted in the current study and in Chandler and McGraw (2015, submitted). In fact, these results and others suggests that ginseng may still be light limited in the absence of canopy disturbances (Chandler and McGraw 2015; Chandler and McGraw, submitted), and that American ginseng growth, and growth of other similar shade obligate understory herbs, are stimulated by intermediate-intensity timber harvests. Nevertheless, care must be taken when extrapolating these results to other types of timber harvest that vary greatly in intensity and geographic extent.

Beyond individual growth parameters, Chandler and McGraw (submitted) found that asymptotic and stochastic population growth rates along with population size of American ginseng were higher when intermediate-intensity, natural disturbances were modeled (Chandler and McGraw, submitted). Increases in population growth following natural canopy disturbances may be mirrored in anthropogenic disturbances, especially if such disturbances are management-based practices that mimic the natural disturbance regimes of old-growth forests such as single-tree selection harvests and group selection harvest. Such strategies would serve the dual purpose of providing economically valuable timber and of stimulating growth of rare understory herbs such as American ginseng, an herb that is surprisingly resilient in the face of rapid environmental shifts. 


\subsection{Acknowledgements}

I would like to thank James B. McGraw, Richard Thomas, and Thomas Schuler who generously agreed to review this manuscript. For their help in the lab and the field, I thank Colin Mitchell, Kyle Gregory, Michael Elza, Anne Jarrell, and Quinn Doyle. I would also like to thank the U.S.D.A. Forest Service for access to the research site. This project was funded in part by NSF grants DEB-0613611 and DEB-1118702 to J.B.M. 


\subsection{Tables and Figures}

Table 3.1. Results of paired t-tests comparing a. relative growth rate, b. maximum rate of photosynthesis, c. daytime dark respiration rate $\left(\mathrm{R}_{\mathrm{d}}\right)$, d. photosynthetic water use efficiency, e. intrinsic water use efficiency, and f. stomatal conductance of individuals one growing season before and after timber harvest $(2013,2014)$, one growing season after and two growing seasons after timber harvest (2014, 2015), and one growing season before and two growing seasons after timber harvest $(2013,2015)$.

\begin{tabular}{lccc}
\hline Variable & $\begin{array}{c}\text { Comparison } \\
\text { Years }\end{array}$ & $|\mathrm{t}|$ & $\mathrm{p}$ \\
\hline a. RGR & Before, After & 4.35 & 0.0002 \\
b. Amax & 2013,2014 & 1.55 & 0.1653 \\
& 2014,2015 & 2.21 & 0.0916 \\
& 2013,2015 & 3.87 & 0.0062 \\
c. R $_{\mathrm{N}}$ & & & \\
& 2013,2014 & 2.78 & 0.0498 \\
& 2014,2015 & 2.85 & 0.0464 \\
d. WUE & 2013,2015 & 0.44 & 0.6834 \\
& & & \\
& 2013,2014 & 1.20 & 0.2691 \\
e. WUEto & 2014,2015 & 1.26 & 0.2772 \\
& 2013,2015 & 1.37 & 0.2075 \\
& & & \\
& 2013,2014 & 0.01 & 0.9890 \\
& 2014,2015 & 1.51 & 0.2053 \\
& 2013,2015 & 1.38 & 0.2045 \\
f. Strinsic & & & \\
conductance & 2013,2014 & 0.60 & 0.5795 \\
& 2014,2015 & 4.09 & 0.0149 \\
& 2013,2015 & 5.35 & 0.0059 \\
\hline
\end{tabular}


Table 3.2. Mean daytime dark respiration and stomatal conductance ( \pm standard errors) for individuals in each of three growing seasons: $\mathrm{BC}-2013, \mathrm{AC}_{1}-2014, \mathrm{AC}_{2}-2015$.

\begin{tabular}{ccc}
\hline Growing Season & $\begin{array}{c}\text { Daytime Dark Respiration } \\
\mu \mathrm{mol} \mathrm{CO} \mathrm{m}^{-2} \mathrm{~s}^{-1}\end{array}$ & $\begin{array}{c}\text { Stomatal Conductance } \\
\mathrm{mol} \mathrm{m}^{-2} \mathrm{~s}^{-1}\end{array}$ \\
\hline $\mathrm{BC}$ & $0.346 \pm 0.031$ & $0.056 \pm 0.003$ \\
$\mathrm{AC}_{1}$ & $0.616 \pm 0.076$ & $0.065 \pm 0.009$ \\
$\mathrm{AC}_{2}$ & $0.323 \pm 0.062$ & $0.116 \pm 0.011$ \\
\hline
\end{tabular}



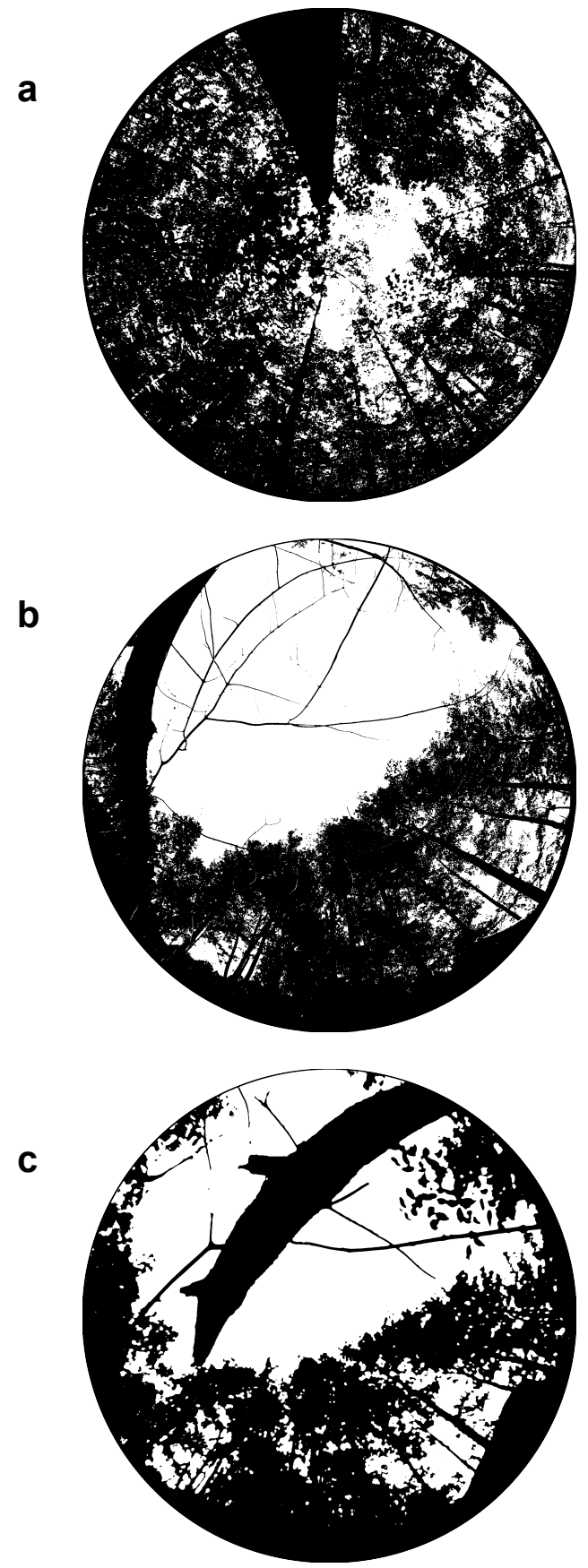

Figure 3.1. Example of hemispherical images taken above the same plant the summer before timber harvest (a; 2013), the summer after timber harvest (b; 2014), and two summers after timber harvest $(\mathbf{c} ; 2015)$. These and other hemispherical images were used 
to calculate canopy openness above each individual or small aggregation of individuals each growing season. 

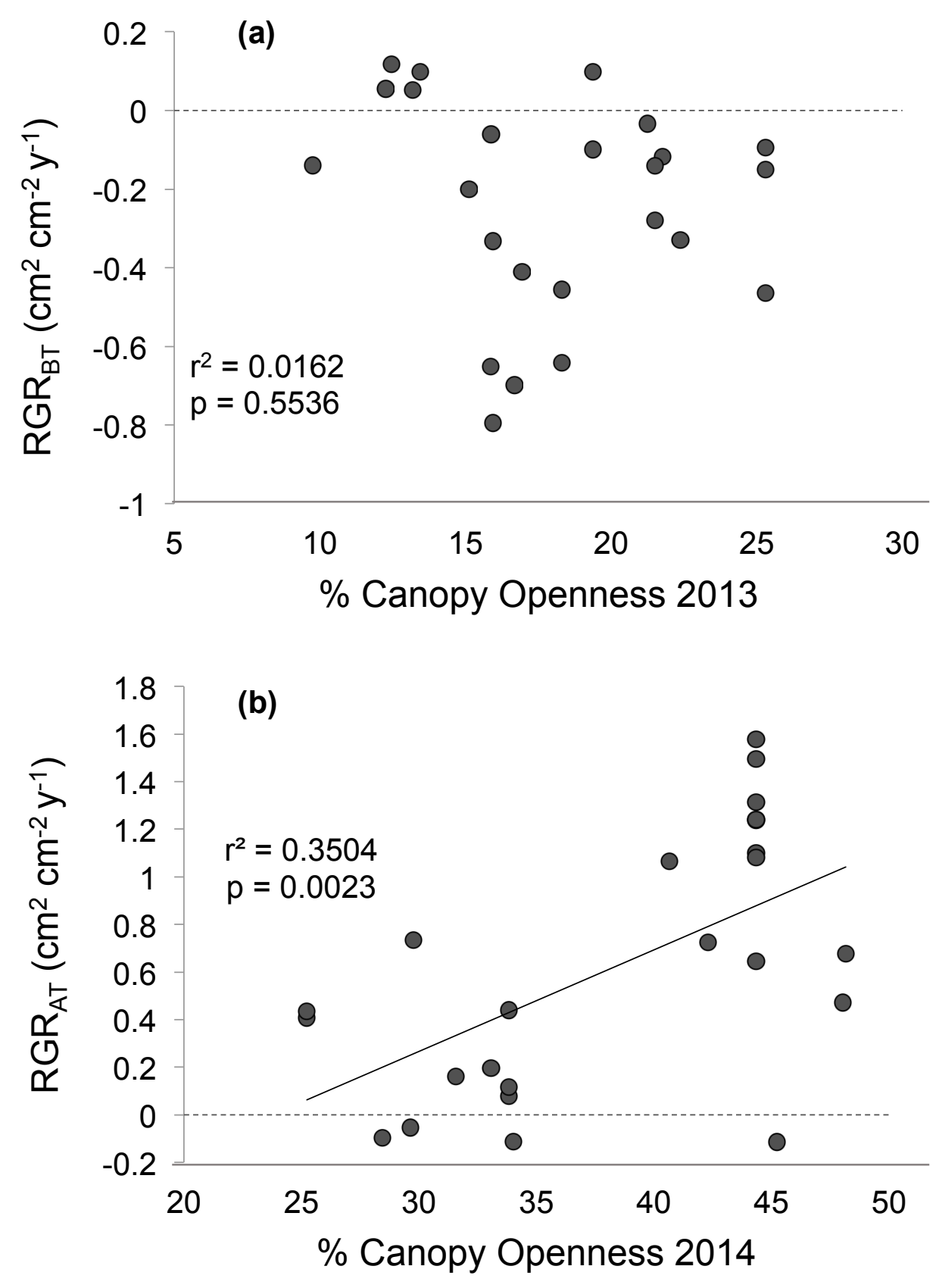

Figure 3.2. Linear regressions showing relative growth rate (RGR) of American ginseng as a function of variation in percent canopy openness (a) before timber harvest $\left(\mathrm{RGR}_{\mathrm{BT}}\right)$, and (b) after timber harvest ( RGR $\left._{\mathrm{AT}}\right)$. 


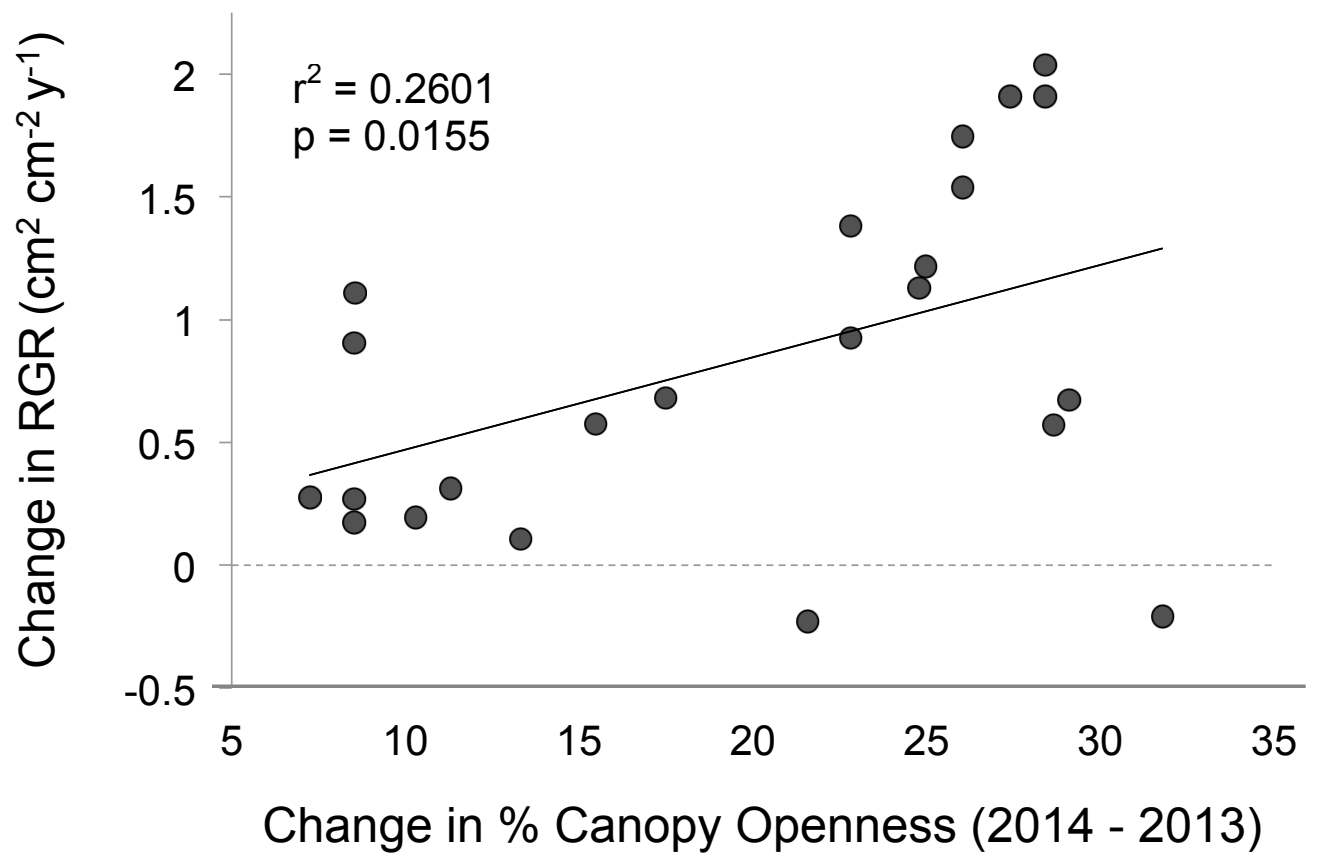

Figure 3.3. Linear regression showing change in relative growth rate after the timber harvest compared to before the timber harvest as a function of the change in percent canopy openness between the growing season prior to timber harvest (2013) and the growing season directly following timber harvest (2014) 


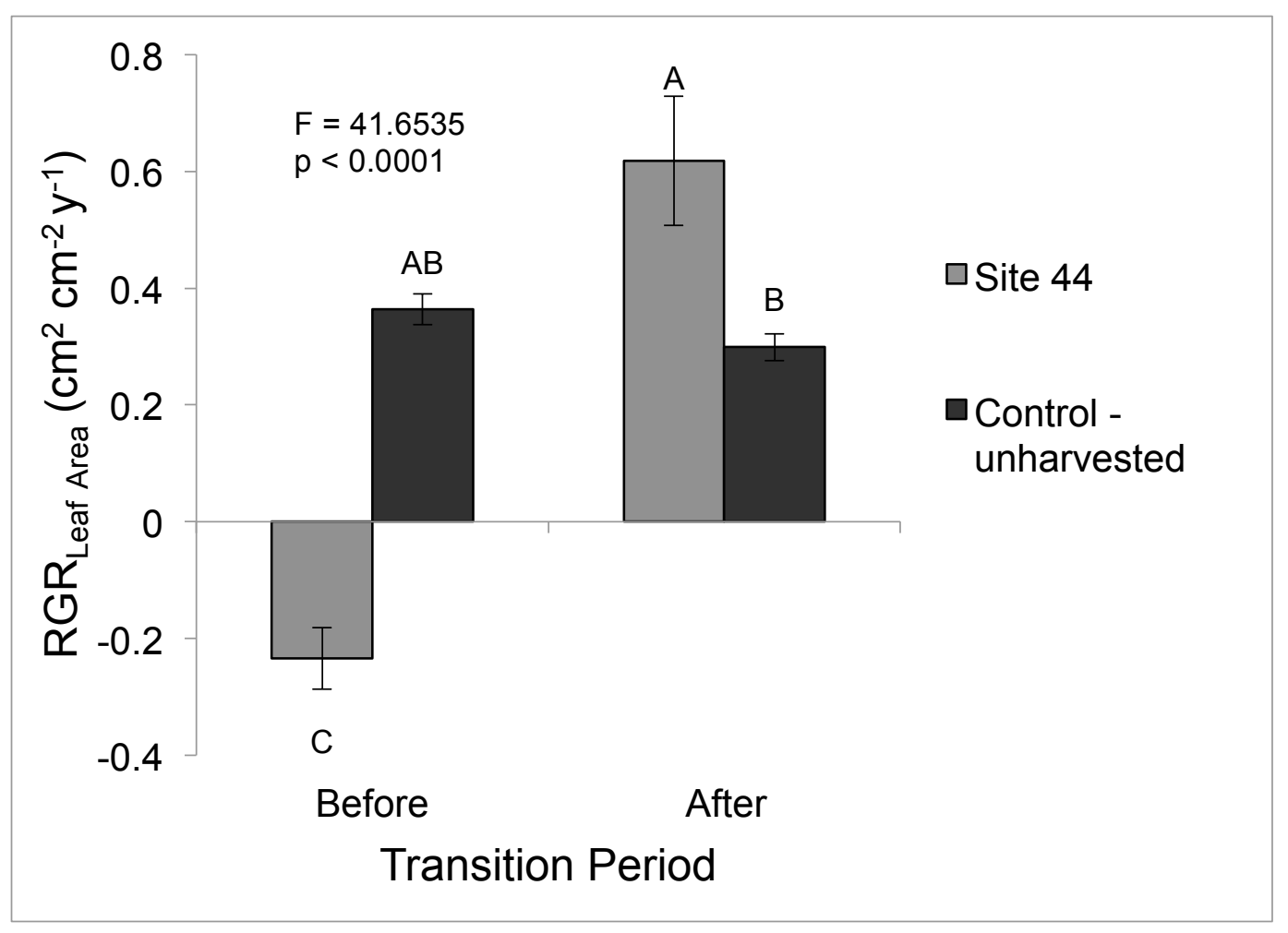

Figure 3.4. Differential effects of time period relative to timber harvest year (Before; 2013-2014, After; 2014-2015) and treatment (harvested vs. control) on the relative growth rate of American ginseng $( \pm \mathrm{SE})$. 


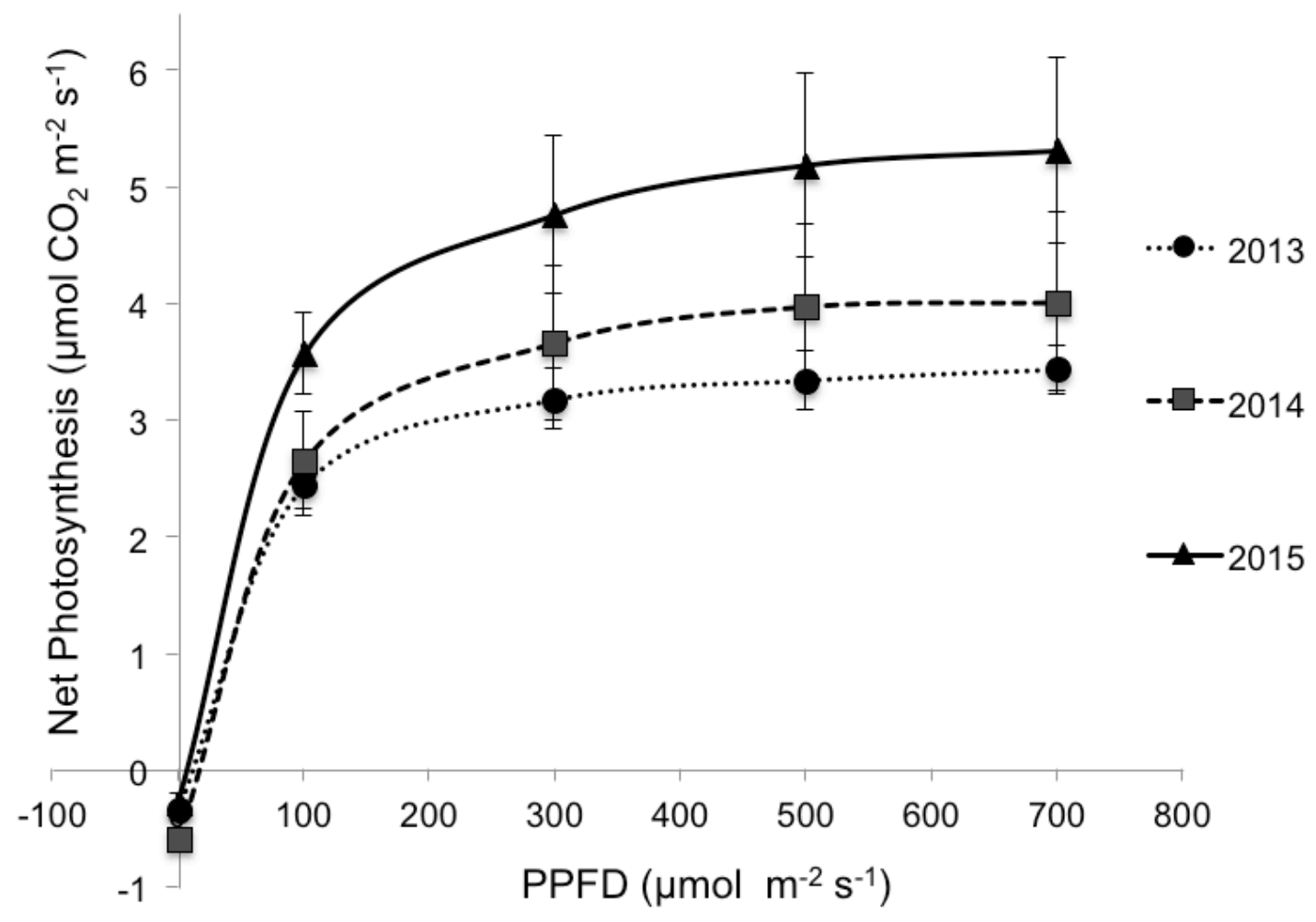

Figure 3.5. Mean light response curve $( \pm \mathrm{SE})$ depicting $A_{\text {net }}$ at each of five levels of $\operatorname{PPFD}(0,100,300,500$, and 700$)$ per year for each individual whose physiological measurements were obtainable all three of the three growing seasons. Data points from greater PPFD values are excluded, as $\mathrm{A}_{\text {net }}$ within years did not vary significantly at these levels. 

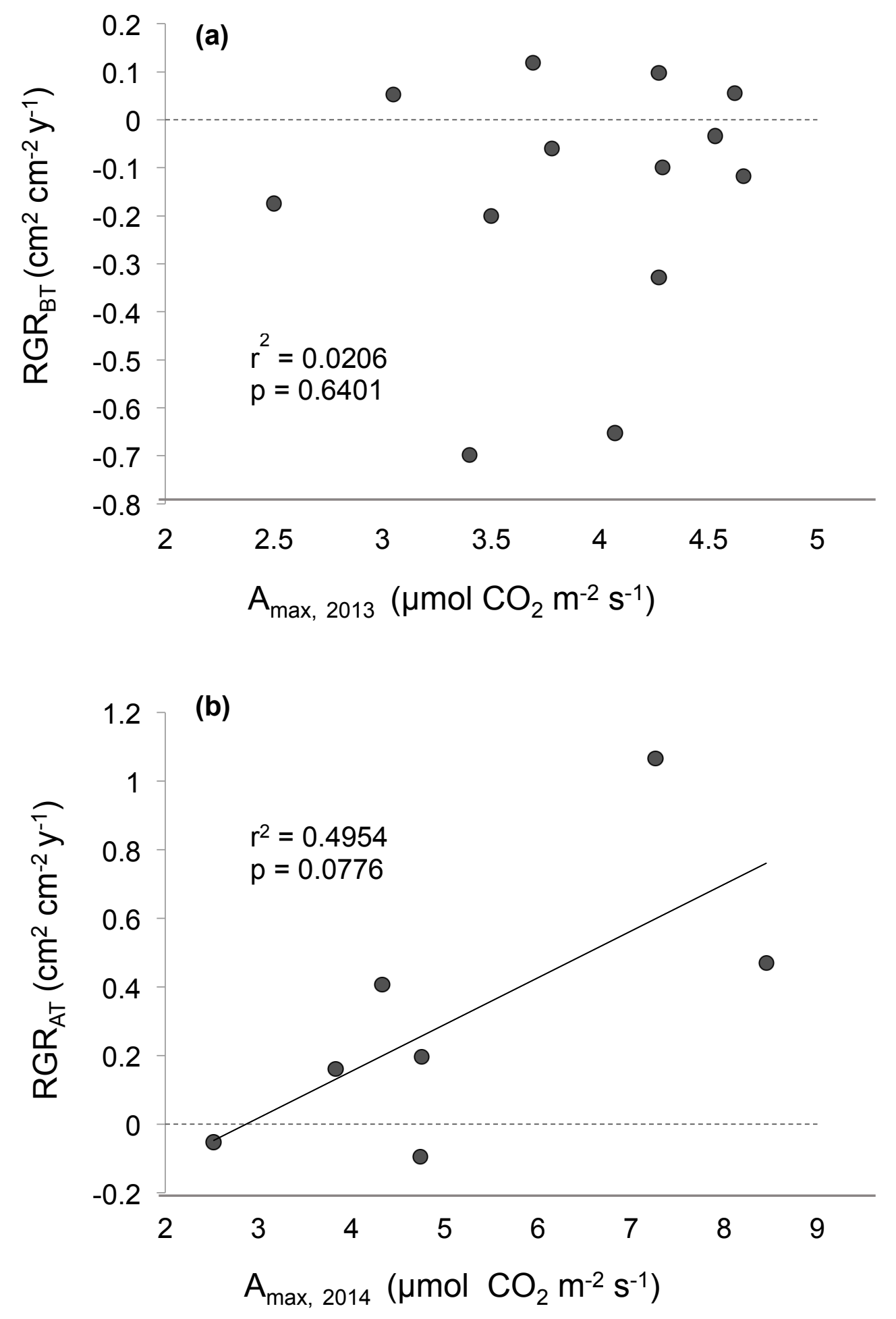

Figure 3.6. Linear regressions illustrating relative growth rate (RGR) of American ginseng as a function of maximum photosynthetic rate $\left(\mathrm{A}_{\max }\right)(\mathbf{a})$ the transition period 
prior to timber harvest $\left(\mathrm{RGR}_{\mathrm{BT}}\right)$, and (b) the transition period following timber harvest $\left(\mathrm{RGR}_{\mathrm{AT}}\right)$. 


\subsection{Literature Cited}

Adams MB, Edwards PJ, Ford WM, et al (2012) Fernow Experimental Forest: Research History and Opportunities. EFR-2 1-32.

Anderson RC, Fralish JS, Armstrong JE, Benjamin PK (1993) The ecology and biology of Panax quinquefolium L. (Araliaceae) in Illinois. Am Midl Nat 129:357-372.

Baker NR (1996) Photosynthesis and the Environment. Springer, New York

Beckage B, Clark JS, Clinton BD, Haines BL (2000) A long-term study of tree seedling recruitment in southern Appalachian forests: The effects of canopy gaps and shrub understories. Can J For Res 30:1617-1631.

Belote RT, Jones RH, Wieboldt TF (2012) Compositional stability and diversity of vascular plant communities following logging disturbance in Appalachian forests. Ecol Appl 22:502-16.

Canham CD (1988a) Growth and canopy architecture of shade-tolerant trees: Response to canopy gaps. Ecology 69:786-795.

Canham CD (1988b) An index for understory light levels in and around canopy gaps. Ecology 69:1634-1638.

Canham CD (1989) Different responses to gaps among shade-tolerant tree species. Ecology 70:548-550. doi: 10.2307/1940200

Canham CD, Denslow JS, Platt WJ, et al (1990) Light regimes beneath closed canopies and tree-fall gaps in temperate and tropical forests. Can J For Res 20:620-631. doi: $10.2307 / 1940194$

Carpenter SG, Cottam G (1982) Growth and reproduction of American ginseng (Panax quinquefolius) in Wisconsin, U.S.A. Can J Bot 60:2692-2696.

Chandler JL, McGraw JB (2015) Variable effects of timber harvest on the survival, growth, and reproduction of American ginseng (Panax quinquefolius L.). For Ecol Manage 344:1-9. doi: 10.1016/j.foreco.2015.02.007

Charron D, Gagnon D (1991) The demography of northern populations of Panax quinquefolium (American ginseng). J Ecol 79:431-445.

Chazdon R, Fetcher N (1984) Photosynthetic light environments in a lowland tropical rainforest in Costa Rica. J Ecol 72:553-564.

Chazdon RL (1988) Sunflecks and their importance to forest understory plants. In: Begon M, Fitter AH, Ford ED, Macfadyes A (eds) Advances in Ecological Research. Academic Press Limited, San Diego, pp 1-63

Chazdon RL, Pearcy RW (1991) The importance of sunflecks for forest understory plants. Bioscience 41:760-766. doi: 10.2307/1311725

Davis M. (1993) Old growth in the East: A survey. Cenozoic Society, Richmond 
Duffy DC, Meier AJ (1992) Do Appalachian herbaceous understories ever recover from clearcutting? Conserv Biol 6:196-201.

Fournier AR, Gosselin A, Proctor JTA, et al (2004) Relationship between understory light and growth of forest-grown American ginseng (Panax quinquefolius L.). J Am Soc Hortic Sci 129:425-432.

Frazer G, Canham C, Lertzman K (1999) Gap Light Analyzer.

Fredericksen TS, Ross BD, Hoffman W, et al (1999) Short-term understory plant community responses to timber-harvesting intensity on non-industrial private forestlands in Pennsylvania. For Ecol Manage 116:129-139. doi: 10.1016/S03781127(98)00452-6

Gilliam FS (2002) Effects of harvesting on herbaceous layer diversity of a central Appalachian hardwood forest. For Ecol Manage 155:33-43.

Gilliam FS, Roberts MR (1995) Impacts of forest management on plant diversity. Ecol Appl 5:911-912.

Hackney EE, McGraw JB (2001) Experimental demonstration of an allee effect in American ginseng. Conserv Biol 15:129-136.

Hruska AM, Souther S, McGraw JB (2014) Songbird dispersal of American ginseng (Panax quinquefolius). Ecoscience 21:46-55.

Knohl A, Schulze E-D, Kolle O, Buchmann N (2003) Large carbon uptake by an unmanaged 250-year-old deciduous forest in Central Germany. Agric For Meteorol 118:151-167. doi: 10.1016/S0168-1923(03)00115-1

Kursar TA, Coley PD (1993) Photosynthetic induction times in shade-tolerant species with long and short-lived leaves. Oecologia 93:165-170. doi: 10.1007/BF00317666

Landflux Photosynthetic light response curve fitting.

Le Gouallec JL, Cornic G, Blanc P (1990) Relations between sunfleck sequences and photoinhibition of photosynthesis in a tropical rain forest understory herb. Am J Bot 77:999-1006. doi: 10.2307/2444571

Leverett R (1996) Definitions and history. In: Davis M. (ed) Eastern old-growth forests: Prospects for rediscovery and recovery. Island Press, Washington, D.C., pp 3-17

Lewis WH, Zenger VE (1982) Population dynamics of the American ginseng Panax quinquefolium (Araliaceae). Am J Bot 69:1483-1490.

Liechty H, Holmes M, Reed D, Mroz G (1992) Changes in microclimate after stand conversion in two northern hardwood stands. For Ecol Manage 50:253-264.

Lorimer CG, Frelich LE (1994) Natural disturbance regimes in old-growth northern hardwoods: Implications for restoration efforts. J For 33-38.

Machado J-L, Reich PB (1999) Evaluation of several measures of canopy openness as predictors of photosynthetic photon flux density in deeply shaded conifer-dominated 
forest understory. Can J For Res 29:1438-1444. doi: 10.1139/x99-102

Manabe T, Shimatani K, Kawarasaki S, et al (2009) The patch mosaic of an old-growth warm-temperate forest: Patch-level descriptions of 40-year gap-forming processes and community structures. Ecol Res 24:575-586. doi: 10.1007/s11284-008-0528-7

Marshall B, Biscoe P (1980) A model for C3 leaves describing the dependence of net photosynthesis on irradiance. I. Derivation. J Exp Bot 31:29-39.

McCarthy BC, Robison SA (2003) Canopy openness, understory light environments, and oak regeneration. In: Characteristics of mixed oak forest ecosystems in southern Ohio prior to the reintroduction of fire. USDA Forest Service, pp 57-66

McGraw JB, Furedi MA (2005) Deer browsing and population viability of a forest understory plant. Science 307:920-922.

McGraw JB, Garbutt K (1990) Demographic growth analysis. Ecology 71:1199-1204.

McGraw JB, Lubbers AE, Van der Voort M, et al (2013) Ecology and conservation of ginseng (Panax quinquefolius) in a changing world. Ann N Y Acad Sci 62-91. doi: 10.1111/nyas. 12032

Muscolo A, Bagnato S, Sidari M, Mercurio R (2014) A review of the roles of forest canopy gaps. J For Res 25:725-736. doi: 10.1007/s11676-014-0521-7

Neufeld HS, Young DR (2014) Ecophysiology of the herbaceous layer in temperate deciduous forests. In: Gilliam FS (ed) The Herbaceous Layer in Forests of Eastern North America, 2nd edn. Oxford University Press, New York, pp 35-91

Oláh R, Masarovičová E (1997) Response of $\mathrm{CO}_{2}$ uptake, chlorophyll content, and some productional features of forest herb Smyrnium perfoliatum L. (Apiaceae) to different light conditions. Acta Physiol Plant 19:285-293.

Prévost M, Raymond P (2012) Effect of gap size, aspect and slope on available light and soil temperature after patch-selection cutting in yellow birch-conifer stands, Quebec, Canada. For Ecol Manage 274:210-221. doi: 10.1016/j.foreco.2012.02.020

Roberts MR (2004) Response of the herbaceous layer to natural disturbance in North American forests. Can J Bot 82:1273-1283. doi: 10.1139/b04-091

Roberts MR, Gilliam FS (2014) Response of the herbaceous layer to disturbance in eastern forests. In: Gilliam FS (ed) The Herbaceous Layer in Forests of Eastern North America, 2nd edn. Oxford University Press, Oxford, pp 321-340

Schlessman MA (1985) Floral Biology of American Ginseng (Panax quinquefolium). Bull Torrey Bot Club 112:129-133. doi: 10.2307/2996409

Schuler TM (2004) Fifty years of partial harvesting in a mixed mesophytic forest: Composition and productivity. Can J For Res 34:985-997. doi: 10.1139/x03-262

Smith WK, Berry ZC (2013) Sunflecks? Tree Physiol 33:233-7. doi: $10.1093 /$ treephys/tpt005 
Sousa WP (1984) The role of disturbance in natural communities. Annu Rev Ecol Syst 15:353-391.

Souther S, McGraw JB (2011) Evidence of local adaptation in the demographic response of American ginseng to interannual temperature variation. Conserv Biol 25:922-31. doi: 10.1111/j.1523-1739.2011.01695.x

Spies TA, Hemstrom MA, Youngblood A, Hummel S (2006) Conserving old-growth forest diversity in disturbance-prone landscapes. Conserv Biol 20:351-362. doi: 10.1111/j.1523-1739.2006.00389.x

Wagner A, McGraw JB (2013) Sunfleck effects on physiology, growth, and local demography of American ginseng (Panax quinquefolius L.). For Ecol Manage 291:220-227. doi: 10.1016/j.foreco.2012.11.038

Whigham D (2004) Ecology of woodland herbs in temperate deciduous forests. Annu Rev Ecol Evol Syst 35:583-621.

Whitmore TC, Brown ND, Swaine MD, et al (1993) Use of hemispherical photographs in forest ecology: Measurement of gap size and radiation totals in a Bornean tropical rain forest. J Trop Ecol 9:131. doi: 10.1017/S0266467400007112

Wyatt JL, Silman M. (2014) Long-term effects of clearcutting in the southern Appalachians. In: Gilliam FS (ed) The Herbaceous Layer in Forests of Eastern North America, 2nd edn. Oxford University Press, New York, pp 412-437 
Chapter 4. Variable Effects of Timber Harvest on the Survival, Growth, and Reproduction of American Ginseng (Panax quinquefolius L.)

Formatted for, and published in, Forest Ecology and Management.

Chandler, J.L. and McGraw, J.B. 2015. Variable effects of timber harvest on the survival, growth, and reproduction of American ginseng (Panax quinquefolius L.). For. Ecol. Manage. 344: 1-9. Elsevier B.V. doi: 10.1016/j.foreco.2015.02.007. 


\subsection{Abstract}

Timber harvest is a recurrent, widespread canopy disturbance that has long affected the eastern deciduous forest. Multi-dimensional shifts in forest dynamics occur following timber harvest, and while a great deal of research on tree response to harvesting has been performed, far less focus has been placed on herbaceous understory response to timber harvest. American ginseng (Panax quinquefolius L.) is a long-lived, economically valuable medicinal herb believed to be adapted to the dynamic light conditions of oldgrowth forests. The purpose of this study was to determine if timber harvests of varying intensity had positive, neutral, or negative effects on the survival, growth, and reproduction of wild American ginseng. Hemispherical images were used to calculate the canopy openness above ginseng plants. Population census data were used to obtain measurements of survival, relative growth rate, seed production, seed production efficiency, and new seedling emergence. Changes in survival and seed production in response to timber harvest were analyzed using log-likelihood analyses, and the responses of relative growth rate and seed production efficiency to harvest were analyzed using nested two-way ANOVAs. Initial ginseng survival varied among sites, with lowest survival at the more intensely logged site. Relative growth rate of individuals increased following harvest, with relative growth rate being greatest at sites where more tree biomass was removed. While seed production decreased the year directly following timber harvest, seed production increased over the three years after harvest. The effects of timber harvest on seed production efficiency differed among populations. While seed production increases in the years after timber harvest, this stimulation may not be realized due to sub-optimal germination conditions. Due both to decreases in survival following 
timber harvest and the unlikely continued increases in growth and seed production as the canopy fills in, some of these often-used harvesting strategies negatively affect ginseng performance. Silvicultural strategies that mimic old-growth forest structure may be better suited for the conservation of ginseng and other similar obligate understory species. 


\subsection{Introduction}

Modern forests are the products of ecological succession that occurs after natural and anthropogenic disturbance events (Oliver, 1981; Clebsch \& Busing, 1989; Seymour \& Hunter, 1999). Timber harvest is a common anthropogenic disturbance that is particularly important because of its ongoing, cyclical nature and its direct effects on forest canopy structure. A great deal of research has focused on canopy disturbances created by timber harvest (Hammond et al., 1998; Fredericksen, et al., 1999; Gilliam, 2002; Harrelson \& Matlack, 2006; Belote et al., 2009; Belote et al., 2012). However, most research involving timber harvest has focused on the study of trees (Roberts, 2004; Gilliam, 2007). Less emphasis has been placed on the herbaceous understory, even though this stratum comprises over $80 \%$ of the plant diversity in the eastern deciduous forest (Roberts, 2004; Gilliam, 2007).

The light environments of many second growth, closed-canopy eastern deciduous forests are characterized by low levels of diffuse light punctuated by spatially and temporally heterogeneous patches of more intense sunlight referred to as 'sunflecks' (Chazdon \& Pearcy, 1991; Fournier et al. 2004; Wagner \& McGraw, 2013; Smith \& Berry, 2013). Although sunflecks can contribute up to $60 \%$ of the daily photosynthesis of understory plants (Kursar \& Coley, 1993; Chazdon, 1988), light is still the primary resource limiting productivity in the understory of relatively undisturbed forests (Chazdon \& Pearcy, 1991; Beckage et al 2000; Neufeld \& Young, 2003; Whigham, 2004; Wagner \& McGraw, 2013). However, following the creation of canopy gaps by timber harvest, patches of direct sunlight reaching the understory undergo marked increases in intensity, duration, and temporal and spatial heterogeneity (Sousa, 1984; 
Chazdon \& Fetcher, 1984; Canham, 1988a and 1988b; Lawton, 1990; Roberts, 2004; Beaudet et al., 2004).

The growth and performance of understory species may initially increase with greater light availability (Chazdon and Pearcy, 1991; Fournier et al., 2004; Whigham 2004). However, the large increases in canopy openness, light intensity, and light duration caused by timber harvest may exceed a threshold leading to negative performance of shade-tolerant herbaceous plants. Exposure to direct light can be detrimental to shade species, and may lead to high leaf temperature, increased water loss, and photoinhibition (Chazdon \& Pearcy, 1991; Oláh \& Masarovičová, 1997; Fournier et al., 2004).

In addition to the changes in the light environment, the physical extraction of timber following harvest also leads to dramatic changes in the herbaceous layer, the forest floor, and soil surface properties (Demir et al. 2007). Demir et al. (2007) found that the herbaceous cover decreased substantially on skid roads following timber harvest. Decreases in herbaceous cover on skid roads result from both the immediate mortality of individuals due to removal from, or burial underneath, the skid road and from soil compaction. In a simulation that determined the effects of post-harvest light availability and soil compaction on forest herbs, Small and McCarthy (2002) found that Osmorhiza claytonii (Michx.), another shade-tolerant perennial species native to the eastern deciduous forest, experienced increased mortality and decreased growth when grown in high levels of light and compacted soils.

Some understory communities are resilient to timber harvest disturbance and canopy gap formation in terms of species composition and diversity; these communities 
are able to return to pre-disturbance composition eventually (Belote et al., 2012).

However, resiliency of a community decreases as disturbance intensity increases (Roberts \& Gilliam, 2003: Gilliam, 2007; Belote et al., 2012). Further, species that are encountered less frequently (i.e. rare species) are at greater risk of extirpation following disturbance (Belote et al., 2012). Observations of the herbaceous layer suggest that relatively short-lived pulses of energy generated by moderate canopy disturbances do not lead to sustained negative impacts or species composition shifts (Gilliam, 2002). Nevertheless, the extent to which timber harvest affects rare understory herbs is largely unknown.

American ginseng (Panax quinquefolius L.) is one rare herbaceous species whose densities and long-term population dynamics may be altered by timber harvest, especially if such disturbances are frequent and intense (Wagner \& McGraw, 2013). Due to the high demand for its root on the Asian market, ginseng is the premier medicinal, nontimber forest product in the United States (McGraw et al., 2010; McGraw, et al., 2013). Ginseng is a widespread, long-lived perennial herb that exhibits the 'slow' life history of many understory herbs present throughout the eastern deciduous forest (McGraw, et al., 2013). Historic accounts suggest that ginseng was once far more abundant than it is today; corroborating evidence includes an approximate three-fold decrease in annual ginseng export from the mid 1800's to the late 1900's (Carlson, 1986; Robbins, 1998). Overharvesting of ginseng is often described as the primary cause of reduced population size (Carlson, 1986; Nantel et al., 1996; Robbins, 1998; McGraw, 2001; McGraw et al., 2010). However, extensive changes in ginseng habitat also occurred during this time period, primarily through changes in canopy structure due to timber harvest (Charron \& 
Gagnon, 1991). The presence of wild populations of ginseng following the widespread timber harvest that occurred in the late 1800's and early 1900's suggest that ginseng is capable of surviving under sparse canopies. Additionally, the presence of ginseng in the closed canopy, second-growth forests common throughout eastern North America today suggests that ginseng is capable of surviving under a dense canopy. Although ginseng may be able to survive in these two extremes of canopy structure, ginseng performance is likely to be suboptimal at either end of this disturbance spectrum.

Wagner and McGraw (2013) investigated a suite of ginseng physiological and growth characteristics in an intact second growth eastern deciduous forest, and they hypothesized that ginseng is adapted to the dynamic light environments of old growth forests (Wagner \& McGraw, 2013); forests characterized by an overstory that varies in age, size, and species composition, and by temporally and spatially heterogeneous canopy gap formations and closures (Knohl et al., 2003; Spies et al., 2006; Manabe et al., 2009; Wagner \& McGraw, 2013). Although some aspects of American ginseng performance may benefit from smaller inputs of light energy from sunflecks (Wagner and McGraw, 2013), the effects of sudden, large canopy openings caused by timber harvest are unknown.

While research has been conducted to determine how different types of disturbances affect populations of American ginseng (McGraw and Furedi, 2005; Van der Voort and McGraw, 2006; Mooney and McGraw, 2009; Souther and McGraw, 2011), it is important to understand how an anthropogenic disturbance type such as timber harvest affects a full suite of ginseng performance metrics so that sustainable, economically-viable forest management strategies can be developed. The purpose of this study was to determine if 
timber harvest events typical of the eastern deciduous forest negatively affect the survival, growth, and reproduction of wild American ginseng. Based on the research performed by Wagner and McGraw (2013), which suggested that increased energy from sunflecks enhances the performance of ginseng, and based on observations of ginseng performance following canopy disturbance of varying intensities, we hypothesized that: 1) ginseng survival and performance would vary depending on timber harvest intensity; and 2) initial rates of ginseng survival following timber harvest would decrease, but the growth and reproduction of the individuals that did survive would increase. 


\subsection{Methods}

Study sites

Five study sites containing wild populations of American ginseng were located within the Appalachian region of the eastern deciduous forest. The timber on each of these second growth forest sites was cut during the study period, however due to the opportunistic nature of this type of work, sites differed in the type of timber harvest implemented, and in the date of the timber harvest (Fig.4.1).

Specific site locations and names are sensitive due to the economic and conservation values of American ginseng, therefore site identifiers have been replaced with generic labels. The first site $(\mathrm{CAB})$ was located within a state forest in southern West Virginia. The timber at CAB was removed using a 12" $(30.5 \mathrm{~cm})$ diameter limit harvest, and was performed in Winter 2011-2012. The second site (LAW) was located on privately owned land in southwestern Virginia. The timber on this site was also extracted in Winter 2011-2012 using a selection cut where the majority of valuable trees were extracted. The third research site (WY) is privately owned, and is also located in southwestern Virginia. The timber at WY was extracted using a selection cut, and like the previous two sites, cutting occurred in Winter 2011-2012. The remaining two research sites (F27 and F18) were located at higher elevation in central West Virginia. The timber at F27 was removed using an 18" $(45.7 \mathrm{~cm})$ diameter limit cut in Fall 2012 , while the timber on F18 was removed using a patch clearcut in Fall 2013. These five sites varied in land-use history, aspect, elevation, and slope (Fig.4.1). Nevertheless, the geographic spread and abiotic and biotic characteristics of these sites are representative of many wild American ginseng populations. These sites have been referred to numerically 
in separate studies: CAB - site 41, F27 - site 43, F18 - site 44, LAW - site 14, and WY site 18; McGraw et al. 2013, Chandler submitted, Chandler and McGraw submitted).

Three of the sites used in this study (CAB, F27, F18) were selected based upon anticipated timber harvest and based on the presence of wild ginseng within the stand. Ginseng census data on these sites were collected in the year prior to and the years following each respective timber harvest. While the timber on two of the sites (LAW and WY) was harvested without our prior knowledge, these were sites having a long history of annual ginseng censusing (up to 13 years), which provided a unique opportunity to observe the long-term effects of canopy disturbance on ginseng plants.

\section{Canopy environment}

Hemispherical images were used to quantify changes in canopy structure following timber harvest. When observing canopy openings in this study, the canopy we are referencing is the canopy above a typical-sized ginseng plant. As such, it is important to note that our definition of canopy refers to the understory, mid-story, and tree canopy. For each population, hemispherical photographs were taken on overcast days using a digital camera (Canon EOS Rebel T2i) with a 180-degree fisheye lens (Sigma 4.5mm F2.8 EX DC). The camera was situated pointing vertically upward on a tripod ca. $20 \mathrm{~cm}$ above the ground, the height of a typical adult ginseng plant. Images were taken directly above each individual ginseng plant in the population or if individuals were tightly clustered, at the center of the cluster. Images were then analyzed using Gap Light Analyzer (GLA) software (Frazer et al., 1999). Specific site characteristics (slope, aspect, and geographic location) as well as North American averages of solar constant, cloudiness index, beam fraction, and clear-sky transmission coefficient were used to 
parameterize the GLA program. Gap Light Analyzer processes hemispherical images by partitioning pixels into "sky" and "nonsky" categories, and then calculating the distribution of sky brightness based on these pixel categories (Fournier et al., 2004), yielding an estimate of percent canopy openness.

\section{Census}

Ginseng plants were labeled using a subterranean tag so that each individual could be unequivocally identified each census year. For each population, census data were collected twice annually, once in the spring and once in the fall. Data collected on each individual included the presence or absence of the individual, the number of leaves, leaflet arrangement (typically $3-7$ leaflets per leaf), stem height $(\mathrm{cm})$, leaflet lengths $(\mathrm{cm})$, leaflet widths $(\mathrm{cm})$, reproductive status (Reproductive: $\mathrm{Y} / \mathrm{N})$, and number of seeds.

Survival was determined yearly for every individual in each population. Two criteria were used to establish death of an individual: (1) new seedlings were considered dead if they did not re-emerge one growing season after their initial emergence, (2) all other individuals were considered dead if they did not emerge for two consecutive growing seasons. The waiting period was necessary because if plant tops are damaged, the plant may re-emerge one year later after being dormant for a growing season.

The leaf area of each individual was calculated using a previously established regression equation based on the allometric relationship of leaf area to leaflet width and leaflet length (Souther and McGraw, 2011; Wagner and McGraw, 2013). Relative growth rate $\left(R_{G R}\right)$, the change in leaf area of an individual over time, was calculated based on the changes in total leaf area from year-to-year using the formula: 


$$
R G R_{L A}=\frac{\left(\ln L A_{2}-\ln L A_{1}\right)}{\left(t_{2}-t_{1}\right)}
$$

Leaf area of a ginseng plant in the given year is determined by nutrient acquisition and carbon storage of the year prior. Therefore, the effects of a dormant-season timber harvest event on ginseng leaf area would not be evident in the first growing season directly following the cut, but rather in the second. Because of this, we included the year in which the cut occurred as a 'before cut' year when making RGR comparisons.

To assess reproduction, we determined whether each individual produced seeds and counted the total number of seeds at the fall census. In addition, we measured seed production efficiency; the number of seeds produced by an individual per unit leaf area. Total plant leaf area is related to total seed production (Schlessman, 1985), but efficiency may also be affected by changes in light level, and subsequent changes in internal resource availability.

Analyses

\section{Canopy Openings}

Since the intensity of cutting varied among populations, the canopy openness above ginseng plants was estimated for the year before and the years following timber harvest to quantify the overstory change due to timber harvest. For two sites in which the timing of the cut was known in advance (F27 and F18), canopy characteristics were characterized both prior to and following timber harvest. However, at three sites (CAB, LAW, WY) images were not captured prior to timber harvest because harvest implementation was not known in advance (Fig.4.1). For CAB and LAW, a forested reference site was located ca. 100 meters from the original site to compare the cut site to 
an uncut reference. No reference site with similar aspect and slope was available for WY, and thus WY was removed from this analysis.

\section{Survival}

To determine whether survival prior to cutting differed from survival after cutting (three-year survival prior, compared to two-year survival after cutting), a loglikelihood analysis was performed. Two populations (LAW and WY) were used in this analysis because of available pre-cutting long-term census data.

To determine whether survival in the first year following timber harvest $\left(\mathrm{AC}_{1}\right)$ differed among populations (LAW, F27, WY, and CAB), a loglikelihood analysis was performed. Each of these populations experienced a unique silvicultural treatment, and while there were other differences among the sites, the magnitude of the differences in logging practices was very likely a contributing factor to survival differences.

\section{Relative Growth Rate (RGR)}

To determine if the shift in relative growth rate caused by cutting (one year before vs. one year after harvest) differed among four populations (LAW, WY, CAB F27), a two-way nested ANOVA was performed with population and time-relative-to-harvest as the main effects, and individual nested within population. The main effect of timerelative-to-harvest $\left(\mathrm{BC}\right.$ vs. $\left.\mathrm{AC}_{1}\right)$ was the primary term of interest in the model.

We then wanted to determine if relative growth rate prior to cutting differed from relative growth rate after cutting (three years before vs. two years after timber harvest) on two sites for which we had long-term growth data (LAW and WY). For each individual, the natural log of leaf area was regressed over the year, and the overall RGR for the time 
periods before timber harvest and after timber harvest was calculated as the slope of the line. A two-way nested ANOVA was performed with population and time-relative-toharvest (three years before harvest vs. two years after harvest) as the main effects and individual nested within population. As with the previous analysis, time-relative-totimber harvest was the variable of interest.

\section{Seed Production, Seed Production Efficiency (SPE), and New Seedling Emergence}

To determine if the proportion of flowering individuals producing seeds differed the year prior to and the year after timber harvest, a log-likelihood analysis was performed using all five populations (Fig. 4.1). A second log-likelihood analysis was performed comparing the proportion of flowering individuals producing seeds at $\mathrm{CAB}$ and LAW the year before timber harvest $(\mathrm{BC})$ and three years after timber harvest $\left(\mathrm{AC}_{1}\right.$, $\mathrm{AC}_{2}$, and $\mathrm{AC}_{3}$ ) to determine if seed production varied for multiple years after a harvest event

Using only individuals that produced seeds, a two-way nested ANOVA was performed to determine if there were differences in the seed production efficiency the two years surrounding the timber harvest event, and if so, if this effect differed among populations. The LAW, F27, F18, and CAB populations were used in this study. A Tukey-Kramer HSD post hoc test was used to determine differences in means.

A second analysis of seed production efficiency took advantage of the early cutting date in two of the populations (CAB and $\mathrm{LAW}$ ) to determine if there was a difference in seed production efficiency over multiple pre- and post-cut years (one year prior to cut and three years after cut), and if so, if this effect differed between 
populations. A two-way nested ANOVA was performed with time-relative-to-harvest and population as main effects, and individual was nested within population.

In order to determine if new seedling emergence was affected by timber harvest and to separately determine if new seedling emergence depended upon population, a 2way ANOVA without replication was performed with time period (before cut and after cut) and population as the main effects. A Tukey-Kramer HSD post hoc test was used to determine differences in means. 


\subsection{Results}

\section{Canopy Openings}

As expected, pre-cut/reference canopy openness above ginseng plants was lower than all years following timber harvest for each population (Fig. 4.2), and patterns in canopy openness varied among populations. At CAB, which had a $12 "(30.5 \mathrm{~cm})$ diameter limit cut, canopy openness above ginseng plants increased by $81 \%$ in the season following timber harvest relative to the reference, but decreased the two years following. A similar pattern was observed at F27, which had an 18" $(45.7 \mathrm{~cm})$ diameter limit cut. In the first year after the cut at F27, canopy openness increased $133 \%$ relative to pre-cut, however, the absolute canopy openness $(21 \%)$ was still the lowest of any population in the year after the cut. In the first year after timber harvest, the canopy at LAW (selection cut) was only opened up by $10 \%$ compared to the reference, but remained open in the years following harvest, likely due to additional cuts that were occurring in the vicinity. The canopy above ginseng plants at F18 (patch clearcut) was opened by $112 \%$ following timber harvest, leading to a ginseng canopy that was more open than all other populations (36\%), but the late cut date on F18 precluded additional canopy analyses.

Survival

The effect of timber harvest on survival did not differ between populations (LAW and $\left.\mathrm{WY}) ; \chi_{\text {time-relative-to-cut x population }}^{2}=2.75, \mathrm{p}=0.6011\right)$. However, for both populations survival did decrease in the two years after timber harvest (Fig. $4.3 ; \chi^{2}$ time-relative-to-cut $=$ $15.47, \mathrm{p}=0.0038$ ) with the probability of survival decreasing from ca. $90 \%$ the year before cut to ca. $75 \%$ two years after cut. 
The proportion of individuals surviving the first year following timber harvest $\left(\mathrm{AC}_{1}\right)$ differed among populations (Fig. $\left.4.4 ; \chi_{\text {population }}^{2}=41.138, \mathrm{p}<0.0001\right)$. The lowest post-cut survival was from $\mathrm{CAB}$, one of the populations that incurred the most intense timber harvest. In fact, the proportion of individuals surviving one year after timber harvest at $\mathrm{CAB}$ was ca. half that of all other populations.

\section{Relative Growth Rate (RGR)}

Among individuals present both one year before and one year after timber harvest, there was a marked increase in RGR after timber harvest (Fig. $4.5 \mathrm{~A} ; \mathrm{F}_{\text {cut }}=60.02$, $\mathrm{p}<0.0001$ ). Additionally, as with the proportion of individuals surviving one year after timber harvest, mean RGR varied among populations (Fig. 4.5B; $F_{\text {population }}=9.19, \mathrm{p}<$ 0.0001). Nevertheless, the effect of timber harvest on RGR did not depend on the population from which the ginseng plants originated $\left(\mathrm{F}_{\text {cut } x \text { population }}=0.59, \mathrm{p}=0.6252\right)$.

In accordance with the increase in short-term RGR following timber harvest, the long-term RGR of individuals from the LAW and WY populations also depended on the time period relative to timber harvest $\left(\mathrm{Fig} 4.5 \mathrm{C} ; \mathrm{F}_{\text {time-relative-to-cut }}=11.69, \mathrm{p}=0.0011\right)$. Mean relative growth rate of individuals was over three times greater in the two years following timber harvest as it was in the three years prior to timber harvest.

Seed Production, Seed Production Efficiency (SPE), and New Seedling Emergence

Among all five populations, the proportion of flowering individuals that produced seeds decreased the year after timber harvest $\left(\chi_{\text {cut }}^{2}=10.917, p=0.0010\right)$. Approximately $50 \%$ of all flowering plants present in the populations one year before timber harvest produced seeds, while only $33 \%$ of flowering plants produced seeds the year following 
timber harvest. In the separate, long-term analysis of seed production at two populations ( $\mathrm{CAB}$ and $\mathrm{LAW}$ ), the proportion of flowering individuals producing seeds was dependent on the year relative to timber harvest (Fig. $4.6 ; \chi_{\text {year-relative-to-cut }}^{2}=38.216, \mathrm{p}<0.0001$ ). Similar to the result obtained in the previous short-term analysis of SPE, the proportion of flowering individuals declined the year following timber harvest in these long-term populations. However, the proportion of flowering individuals producing seeds increased each year following timber harvest, and three years after harvest, the proportion of individuals producing seeds surpassed the pre-timber harvest value.

The effect of timber harvest on seed production efficiency one year before and one year after harvest depended upon the population (Fig. $4.7 \mathrm{~A} ; \mathrm{F}_{\text {cut }}$ population $=4.6924, \mathrm{p}$ $=0.0051)$. The SPE at two of the populations (F27 and CAB) increased markedly the year following timber harvest, while SPE at LAW and F18 remained unchanged. Likewise, the analysis of seed production efficiency in the CAB and LAW populations one year before harvest and three years after harvest showed a differential effect of timerelative-to-harvest and population on seed production efficiency (Fig. 4.7B; $\mathrm{F}_{\text {time-relative-to- }}$ cut x population $=3.5543, \mathrm{p}=0.0159)$. The seed production efficiency $(\mathrm{SPE})$ at $\mathrm{CAB}$ increased by ca. $40 \%$ the first year after timber harvest $\left(\mathrm{AC}_{1}\right)$ and decreased to preharvest SPE rates by the third year after timber harvest $\left(\mathrm{AC}_{3}\right)$. Meanwhile, no change in SPE was seen in the LAW population in any of the years following timber harvest.

Among all populations, new seedling emergence was reduced by ca. $70 \%$ following timber harvest events $(\mathrm{F}=5.92, \mathrm{p}=0.0333)$. In addition, populations differed in seedling emergence rates $(F=6.96, p=0.0048)$ with the greatest number of new seedling emergence occurring at LAW, and the least at WY. 


\subsection{Discussion}

In the absence of disturbance, American ginseng survival rates tend to be high (Charron and Gagnon, 1991). In fact, a separate study showed that the average survival probability of juvenile and adult ginseng plants in twelve undisturbed ginseng populations was $87 \%$ (data taken from Souther and McGraw, 2011). In the present study, the average proportion of individuals surviving in all populations was only $69 \%$ the year after harvest, and $76 \%$ two years after harvest in two of the long-term populations (LAW and WY). These results indicate that, in general, timber harvest negatively affects survival of American ginseng, with survival dependent on the amount of canopy removed and the mode of timber removal.

Based on field observations, the disturbance to the forest floor that resulted from timber harvest led to significant mortality in places where the soil profile was destroyed or compacted by equipment. Skid roads that are placed on cut sites to facilitate movement of timber result in the displacement and compaction of soil, and Demir et al. (2007) noted a reduction in herbaceous cover on skid roads. Furthermore, forest floor damage and the resulting plant mortality can occur simply by moving the timber across the ground during extraction, especially if the harvest is performed during a time period when the soil profile is easily disturbed (i.e. when soil is not frozen). Mortality of entire ginseng clusters within populations due to soil disturbance was observed on multiple sites throughout this study.

The relative growth rate of surviving ginseng plants increased markedly in the years following timber harvest, and this increase was likely due to the sudden increase in light availability once the canopy was opened. Greater canopy openness would stimulate 
photosynthesis, leading to greater carbon storage and overall increases in leaf area the following year (Wagner and McGraw, 2013), although tests to support this mechanism were not performed. Though increases in light are beneficial to plant growth to some critical level, long-duration sunflecks and sunflecks with high PPFD can lead to high leaf temperatures, wilting, and photoinhibition in some plant species (LeGouallec et al., 1990; Oláh and Masarovićová, 1997; Chazdon and Pearcy, 1991). In the present study, observations of thickened leaves and chlorosis following timber harvest indicated that the ginseng plants were stressed, but the continued increases in relative growth rate two years following timber harvest suggest that net carbon assimilation across a growing season was not reduced. Wagner and McGraw (2013) found that ginseng growth rate increased with increases in both the percent photosynthetic photon flux density from sunflecks and the duration of the longest sunfleck. The results of the present study support these earlier findings (Wagner and McGraw, 2013), and suggest that ginseng growth is stimulated by increases in light caused by canopy openings. However, it is important to note that other changes in ginseng habitat following timber harvest, such as nutrient availability and soil moisture, could have also affected ginseng performance.

Although ginseng mortality can be high following timber harvest, subsequent increases in incident photosynthetically active radiation and leaf area may lead to positive gains in the belowground portion of the surviving ginseng plants. Anecdotal evidence obtained from ginseng harvesters suggests that in the years following harvest, occasionally very large plants may be found a few years after heaving cutting. Such increases in root size could be economically beneficial since roots are sold by weight. 
However, it is unclear whether the increase in root mass of the surviving portion of ginseng plants is enough to offset losses due to mortality.

Initial observed decreases in ginseng seed production were likely caused by desiccation of ginseng inflorescences (flowering clusters) due to the higher light, lower humidity, and higher temperatures at the forest floor in the first growing season following timber harvest. The leaf area of ginseng increased following timber harvest, and although not observed in the first growing season after harvest, increases in seed production probability eventually followed suit, as was expected with increased plant size (Schlessman, 1985).

While in some cases the seed production efficiency increased after timber harvest, the increases were population dependent, and were not long-lived. We propose that the increases in seed production efficiency at $\mathrm{CAB}$ and not at LAW can be explained at least in part by the fact that far more tree biomass was removed from $\mathrm{CAB}$. As a result, the biological demand for nitrogen decreased and decomposition likely increased (as reviewed by Roberts and Gilliam, 1995), leading to a larger pulse of nitrogen available for uptake by other plants at $\mathrm{CAB}$.

Although canopy removal stimulated seed production and in some cases seed production efficiency, the effects of this stimulation may not be realized due to low seed germination rates. While germination rates were not directly accounted for in this study, it was found that new seedling emergence decreased significantly following timber harvest. Wagner and McGraw (2013) found that ginseng seed germination had a negative linear relationship to both sunfleck duration and \% PPFD from sunflecks. The inverse relationship of seed germination and light was attributed to two possible, yet 
contradictory, causes. First, growth of other plants in the area was stimulated by sunflecks, and these plants were overtopping ginseng seeds, leading to light levels too low to induce germination (Wagner and McGraw, 2013). Second, seeds present in areas of high sunfleck activity were desiccating due to higher incident light (Wagner and McGraw, 2013). In the present study, increases in herb- and shrub-layer cover and desiccation of seeds was observed following timber harvest. Moreover, American ginseng seed banks are not long-lived (Charron and Gagnon, 1991, Cruse-Sanders and Hamrick, 2004). As a result, we do not expect that the majority of seeds in the seed bank will be viable long enough to make a large contribution to population size once germination conditions improve.

In their study of short-term understory response to timber harvest, Fredericksen et al. (1999) determined that increases in ground- and shrub-layer cover occured following harvest, and that the cover of these strata increased with increasing timber harvest intensity. Our results that quantify the mean changes in canopy openness above ginseng plants in the years before and after harvest support the findings of Fredericksen et al. (1999) in that the ground- and shrub-layer canopies at the intensely harvested CAB population filled in more densely in the years following harvest than the less intenselycut sites (LAW and F27). As the ground- and shrub-layers begin filling in after timber removal, ginseng plants and other similar herbaceous species will be overtopped and heavily shaded, and it is possible that growth and seed production may decline as a result. Therefore, it is doubtful that the stimulation of growth and reproduction caused by timber harvest will persist for a long period of time following a harvesting event. 
Studies have found that short-term understory diversity is typically not affected by timber harvest (Fredericksen et al. 1999; Belote et al. 2012; Duguid and Ashton, 2013), but may be affected by site-specific characteristics such as resource availability and heterogeneity (Fredericksen et al. 1999; Duguid and Ashton, 2013). While richness and diversity of forests can remain unchanged following timber harvest, this stasis may be the result of influxes and/or increases in ruderal species rather than the retention of the mid- to late-successional species that were originally on the site (Meier et al. 1995; Small and McCarthy 2002, Duguid and Ashton, 2013). As a result, biodiversity measures that do not make distinctions about the nature of diversity (i.e. early successional species vs. late successional species) do not accurately account for the retention of rare species like American ginseng and other similar herbs following timber harvest. The site-specific nature of herbaceous response to timber harvest makes in-depth studies of species' response to varying timber harvest techniques necessary (Roberts and Gilliam, 1995), and the present study provides an understanding of the fate of American ginseng populations following varying types (intensities) of timber harvest. To our knowledge, the present study is the first to examine in detail variation in the survival, growth, and reproduction response of a single, long-lived, economically valuable herbaceous plant species to timber harvest in the eastern deciduous forest.

Chamberlain et al. (2013) determined that in eighteen states in the eastern United States, the annual revenue value of wild ginseng (ranging from \$26.9 million to $\$ 43.4$ million) is significantly less than the annual stumpage value of hardwood timber extracted from these same states ( $\$ 1.27$ billion). Nevertheless, American ginseng is an important source of supplemental income in rural Appalachia (Chamberlain et al. 2013). 
Additionally, the habitat of American ginseng is shared by many other herbaceous species that are harvested for their medicinal qualities such black cohosh (Actaea racemosa L.), bloodroot (Sanguinaria canadensis L.), and goldenseal (Hydrastis canadensis L.). All of these medicinal, herbaceous species are important both in terms of their impacts on annual income in Appalachia and on forest biodiversity (Chamberlain et al. 2013). The insights gained concerning the response of American ginseng to timber harvest translate to these similar understory herb species, and allow predictions to be made about the response of these other economically-valuable species to timber harvest events.

Timber harvest strategies typical of many privately owned woodlots in the eastern deciduous forest are driven primarily by the economic value of timber products. In West Virginia's recent past, for example, the majority of timber harvests were not based in silvicultural theory, but instead consisted of large-scale removals of sawtimber-size trees through diameter-limit harvesting (Fajvan et al. 1988). American ginseng is believed to be adapted to the spatial and temporally heterogeneous light environments typical of old growth forests (Wagner and McGraw 2013). Therefore, theoretically, ginseng populations could benefit from silvicultural management techniques that minimize forest floor disturbance and mimic old-growth canopy structure. These types of harvest will perhaps be less detrimental to the initial survival of American ginseng and other similar understory herbs, and may allow for increases in growth and seed production due to spatially heterogeneous increases in light availability.

\section{Conclusions}


Based on the results of this study, growth of individual American ginseng plants may benefit from the formation of canopy gaps caused by timber harvest, but harvest needs to be performed in a manner that preserves the soil profile and increases the initial chances of ginseng survival. While seed production increases following timber harvest events, the germination rates may actually decrease due to the excess light availability in the understory (Wagner and McGraw 2013), minimizing the effect of this reproductive stimulation. Some current silvicultural strategies such as single-tree selection and group selection mimic the structure of old-growth forests (Lorimer \& Frelich, 1994; Goebel \& Hix, 1996); environments to which American ginseng and perhaps other understory shade-species are adapted. These silvicultural strategies that mimic old growth forest structure are perhaps a good fit for land managers who have multi-dimensional goals involving continued production of valuable timber, maintenance of forest biodiversity, and conservation and stewardship of ecologically and economically valuable understory herbs such as American ginseng. 


\subsection{Acknowledgements}

For their extremely hard work and dedication both in the field and in the lab, we thank Amy Hruska, Alix Wagner, Jessica Turner, Zac Zacavish, Michael Elza, Anne Jarrell, Kyle Gregory, Quinn Doyle, Kenny Smith, Chris Walter, and Mark Burnham. We also thank prior field crews for gathering the long-term data that was used in this study as well as the landowners for allowing us to census on their properties. This project was funded in part by NSF grants DEB-0613611 and DEB-1118702 to J.B.M. 


\subsection{Tables and Figures}

Site Characteristics

Year

\begin{tabular}{|c|c|c|c|c|c|c|c|c|c|}
\hline & $\mathrm{N}$ & Aspect & $\begin{array}{l}\text { Mean } \\
\text { Slope }\end{array}$ & $\begin{array}{l}\text { Elev. } \\
\text { (m) }\end{array}$ & $\begin{array}{l}\text { Pre- } \\
2011\end{array}$ & 2011 & 2012 & 2013 & 2014 \\
\hline $\begin{array}{c}30.5 \mathrm{~cm} \\
\text { DLH } \\
\text { (CAB) }\end{array}$ & 84 & $0^{\circ}$ & $9.5^{\circ}$ & 373 & & $\begin{array}{c}\mathrm{LA} \\
\frac{\mathrm{RGR}_{\mathrm{bc}}}{\mathrm{SP}}\end{array}$ & $\begin{array}{c}\stackrel{\mathrm{LA}^{\mathrm{RGR}} \underset{\mathrm{ac} 1}{\mathrm{SP}}}{\longrightarrow} \\
\mathrm{HP}\end{array}$ & $\begin{array}{c}\mathrm{LA} \underset{\mathrm{SP}}{\stackrel{\mathrm{RGR}_{\mathrm{ac} 2}}{\longrightarrow}} \mathrm{HP} \\
\mathrm{HP}\end{array}$ & $\begin{array}{l}\text { LA } \\
\text { SP } \\
\text { HP }\end{array}$ \\
\hline $\begin{array}{c}\text { Selection } \\
\text { Harvest } \\
\text { (LAW) }\end{array}$ & 291 & $300^{\circ}$ & $16.2^{\circ}$ & 663 & $\mathrm{LA}_{\mathrm{SP}}^{\stackrel{\mathrm{RGR}_{\mathrm{bc}}}{\longrightarrow}}$ & LA $\frac{\mathrm{RGR}_{\mathrm{bc}}}{\mathrm{SP}}$ & $\begin{array}{c}\stackrel{\mathrm{LA}}{\stackrel{\mathrm{RGR}_{\mathrm{ac} 1}}{\longrightarrow}} \underset{\mathrm{SP}}{\mathrm{HP}}\end{array}$ & $\begin{array}{c}\mathrm{LA} \underset{\mathrm{SP}}{\stackrel{\mathrm{RGR}_{\mathrm{ac} 2}}{\longrightarrow}} \\
\mathrm{HP}\end{array}$ & $\begin{array}{l}\text { LA } \\
\text { SP } \\
\text { HP }\end{array}$ \\
\hline $\begin{array}{c}\text { Selection } \\
\text { Harvest } \\
\text { (WY) }\end{array}$ & 38 & $280^{\circ}$ & $28^{\circ}$ & 908 & $\mathrm{LA}_{\mathrm{SP}}^{\stackrel{\mathrm{RGR}_{\mathrm{bc}}}{\longrightarrow}}$ & $\begin{array}{c}\mathrm{LA} \\
\mathrm{RG} \\
\mathrm{RP}\end{array}$ & $\begin{array}{c}\stackrel{\mathrm{LA}}{\stackrel{\mathrm{RGR}_{\mathrm{ac} 1} 1}{\longrightarrow}} \underset{\mathrm{SP}}{\mathrm{HP}}\end{array}$ & $\begin{array}{c}\mathrm{LA} \underset{\mathrm{SP}}{\stackrel{\mathrm{RGR}_{\mathrm{ac} 2}}{\longrightarrow}} \mathrm{HP}\end{array}$ & $\begin{array}{l}\text { LA } \\
\text { SP }\end{array}$ \\
\hline $\begin{array}{c}45.7 \mathrm{~cm} \\
\text { DLH } \\
\text { (F27) }\end{array}$ & 80 & $168^{\circ}$ & $16^{\circ}$ & 689 & & & $\begin{array}{c}\mathrm{LA}_{\mathrm{RGR}} \\
\mathrm{RP} \\
\mathrm{HP}\end{array}$ & $\left\{\begin{array}{c}\mathrm{LA} \underset{\mathrm{SP}}{\mathrm{RGR}} \\
\mathrm{HP}\end{array}\right.$ & $\begin{array}{l}\text { LA } \\
\text { SP } \\
\text { HP }\end{array}$ \\
\hline $\begin{array}{l}\text { Patch Cut } \\
\text { (F18) }\end{array}$ & 33 & $355^{\circ}$ & $7.7^{\circ}$ & 841 & & & & $\begin{array}{c}\mathrm{LA} \stackrel{\mathrm{RGR}_{\mathrm{bc}}}{\mathrm{SP}} \\
\mathrm{HP}\end{array}$ & $\begin{array}{l}\text { LA } \\
\text { SP } \\
\text { HP }\end{array}$ \\
\hline
\end{tabular}

Figure 4.1. Characteristics of each population are listed on the left, including initial population size (growing season prior to timber harvest). For each population, a jagged vertical line indicates the timing of the timber harvest. Remaining symbols indicate recorded data. LA represents leaf area, SP represents seed production, HP represents the collection of hemispherical photographs, and $\mathrm{RGR}_{\mathrm{x}}$ represents the calculation of relative growth rate. $R_{G R}$ rc represents the RGR prior to the cut, $R_{\text {GR }}$ acl represents the RGR one year after the cut, and $R_{\text {GR }}$ ac2 represents RGR two years following the cut. F18 was excluded from pre- vs. post-cut analyses of survival and RGR due to the late date of cutting, however some variables could be included for this population, effectively increasing replication, so it is included in those analyses. Likewise, WY, F27, and F18 were excluded from some measures of reproduction due to small sample size and/or late date of cutting, however data from these populations were included for more short-term analyses. 


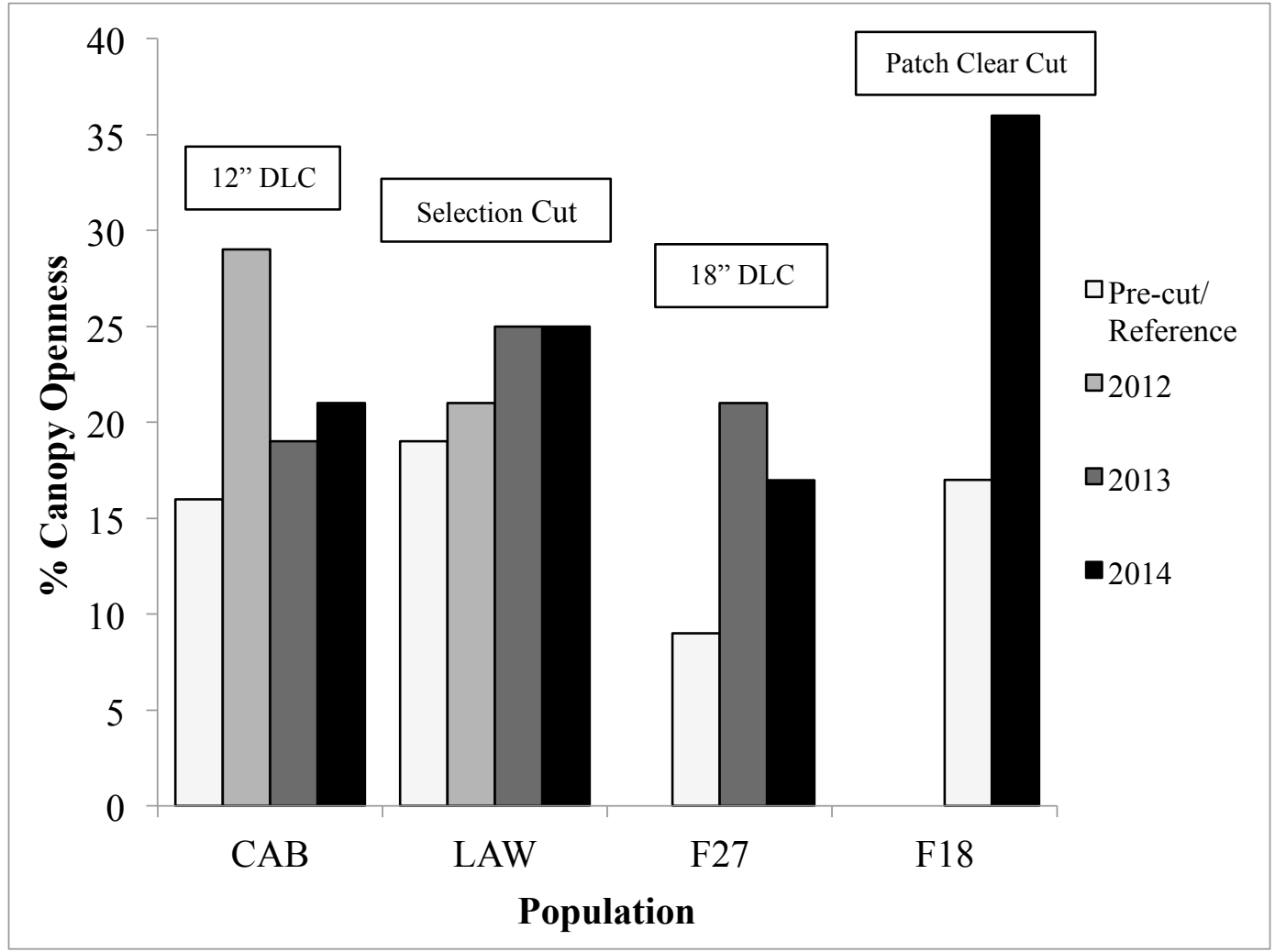

Figure 4.2. Canopy openness as measured by hemispherical images taken above the American ginseng plants at four populations: CAB [12” $(30.5 \mathrm{~cm})$ diameter limit cut], F27 [18" (45.7 cm) diameter limit cut], LAW (selection cut), and F18 (patch clearcut). 


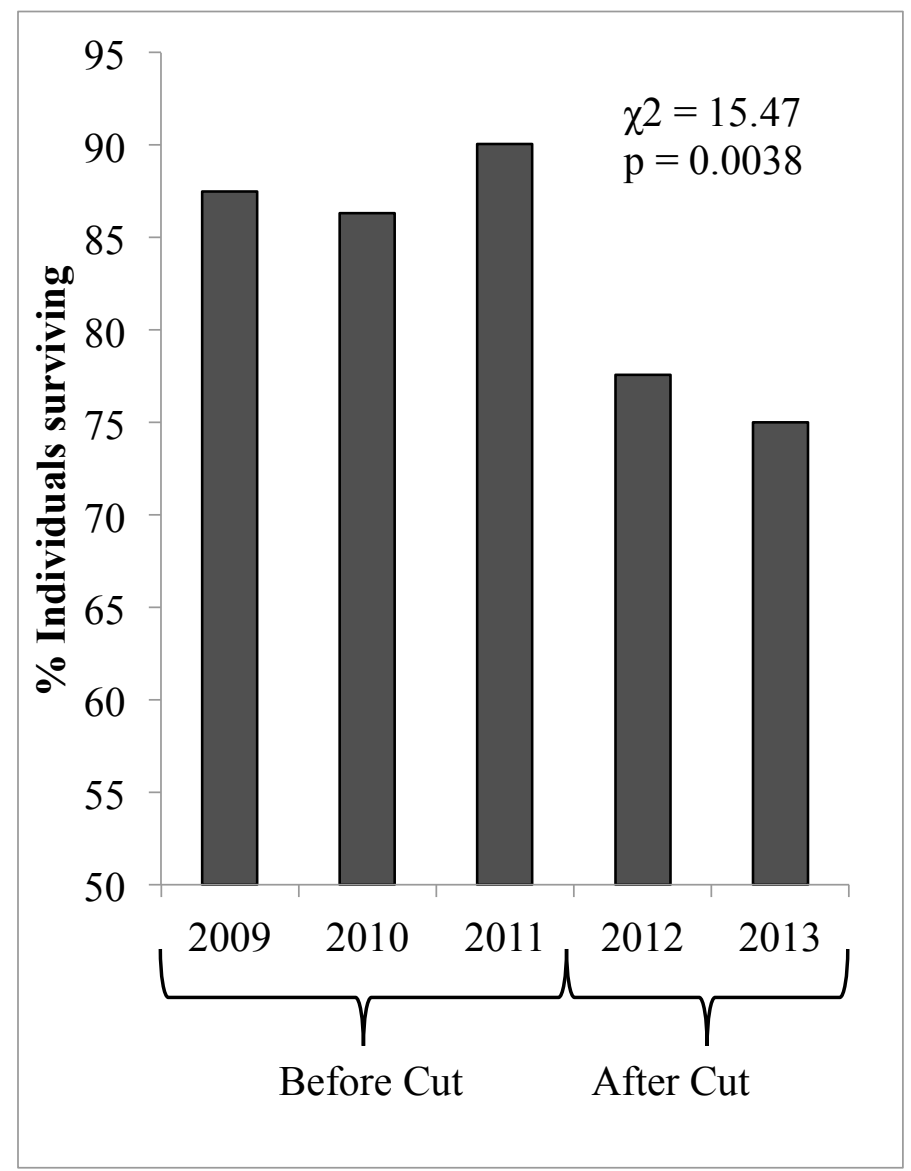

Figure 4.3. The proportion of individuals surviving in two of the long-term ginseng populations (LAW and WY). 


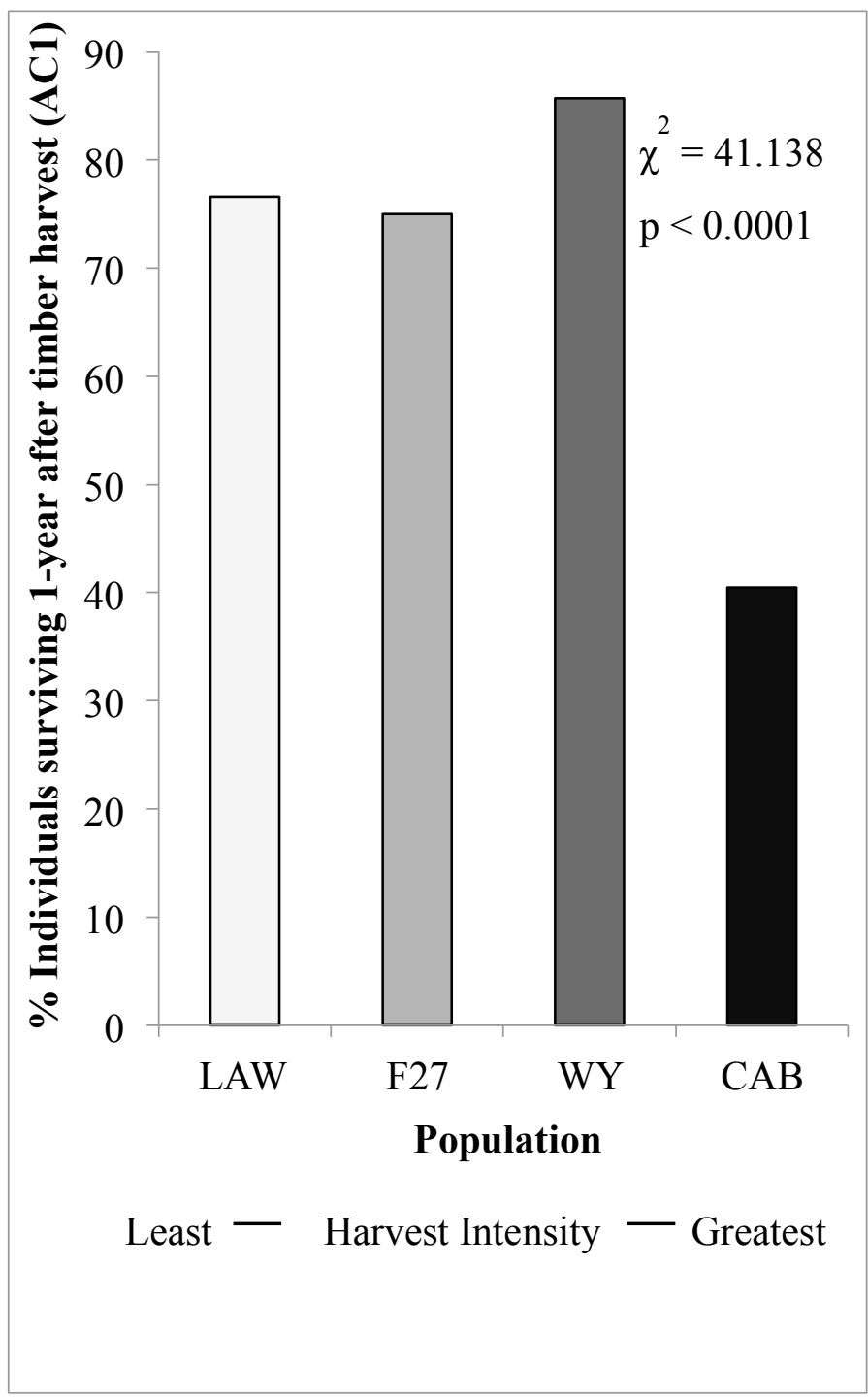

Figure 4.4. The proportion of individuals surviving the first year after timber harvest at four ginseng populations. 


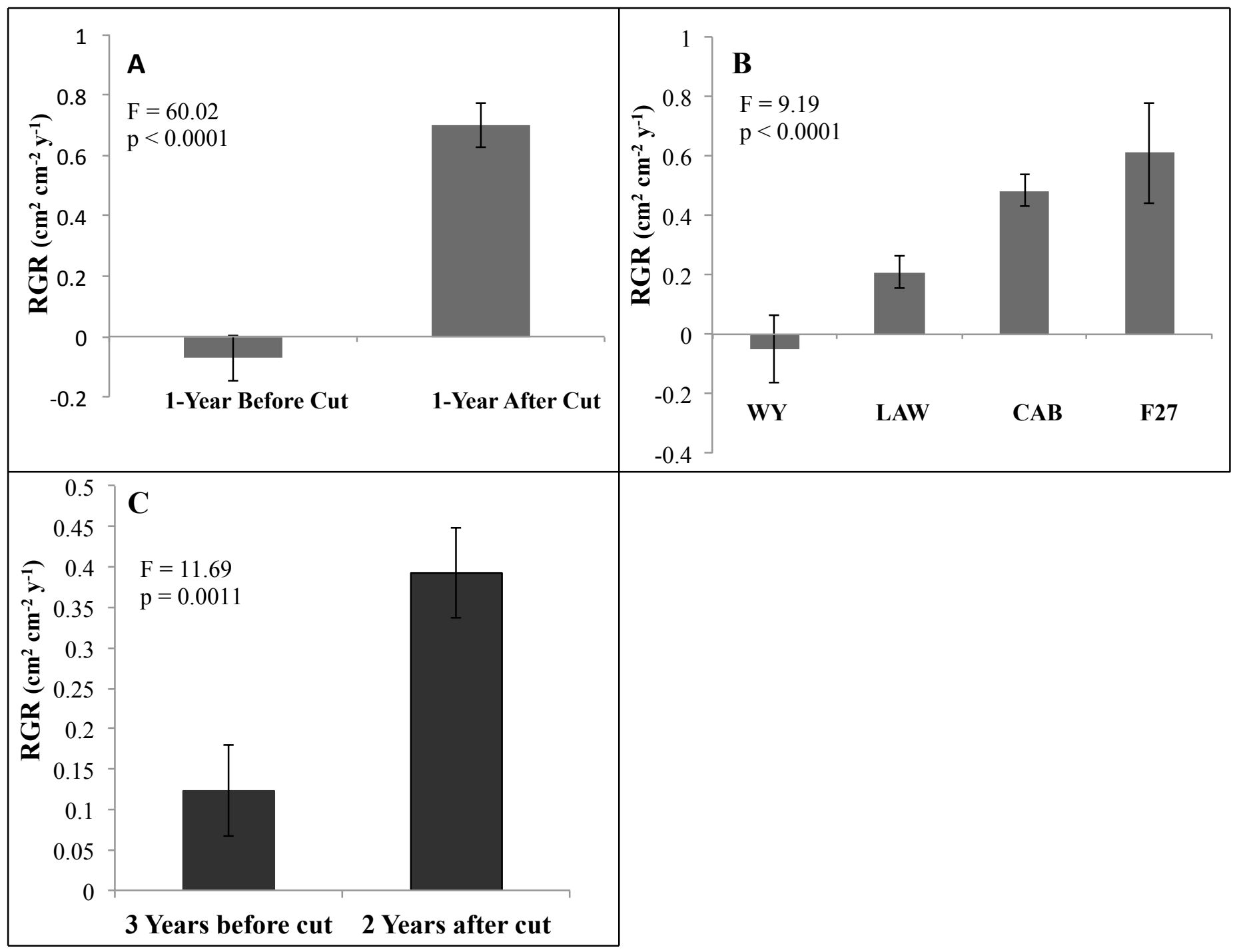

Figure 4.5. A) Relative growth rate (RGR) of individuals present both one year before and one year after the timber harvest at four populations (WY, LAW, CAB, and F27) B) Relative growth rate of individuals in four populations, independent of the harvesting events. C) Relative growth rate three years before cut and two years after cut at two long-term populations (LAW and WY). 


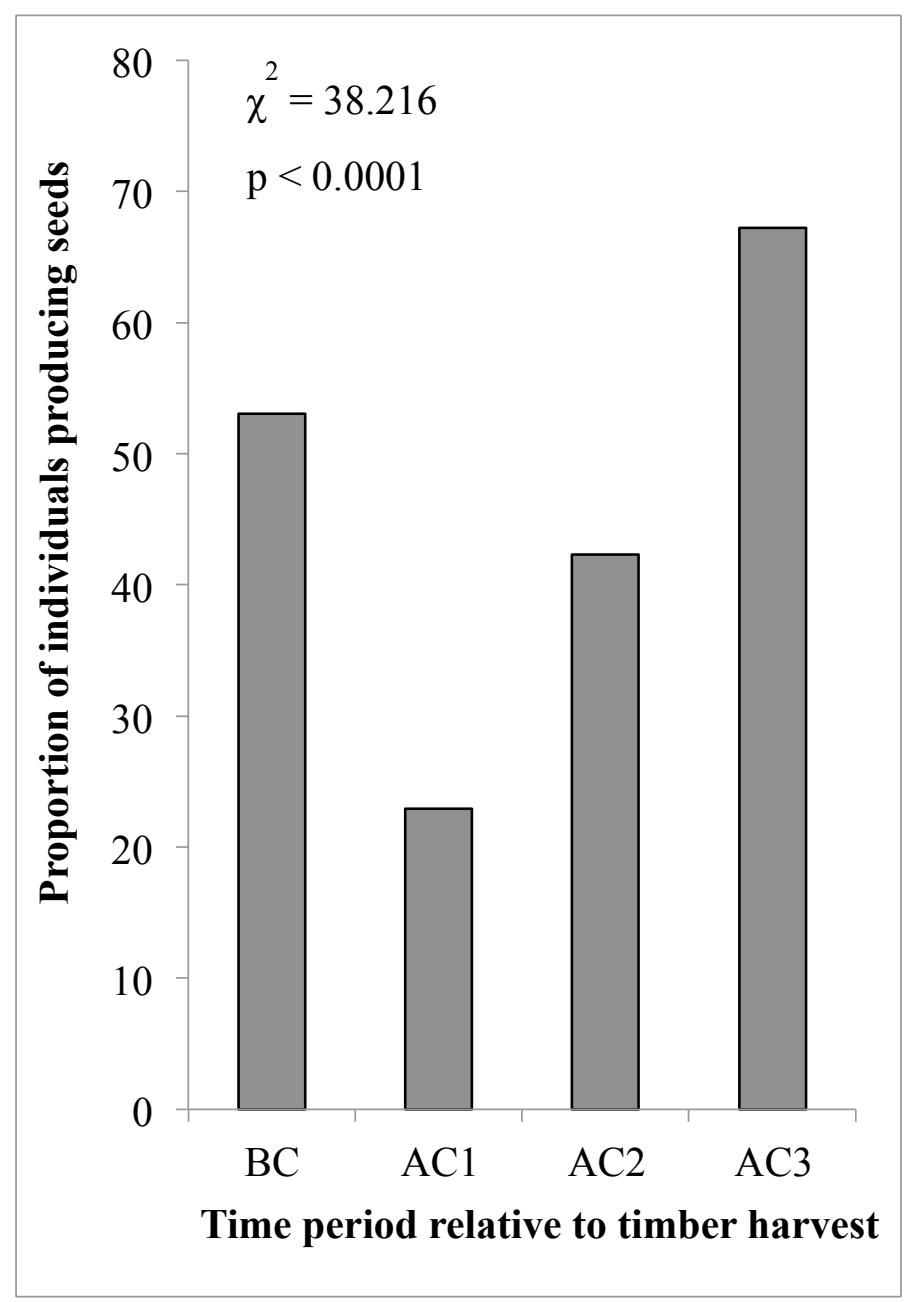

Figure 4.6. The proportion of individuals that produced seeds each year relative to timber harvest at two of the long-term populations (CAB and LAW). 


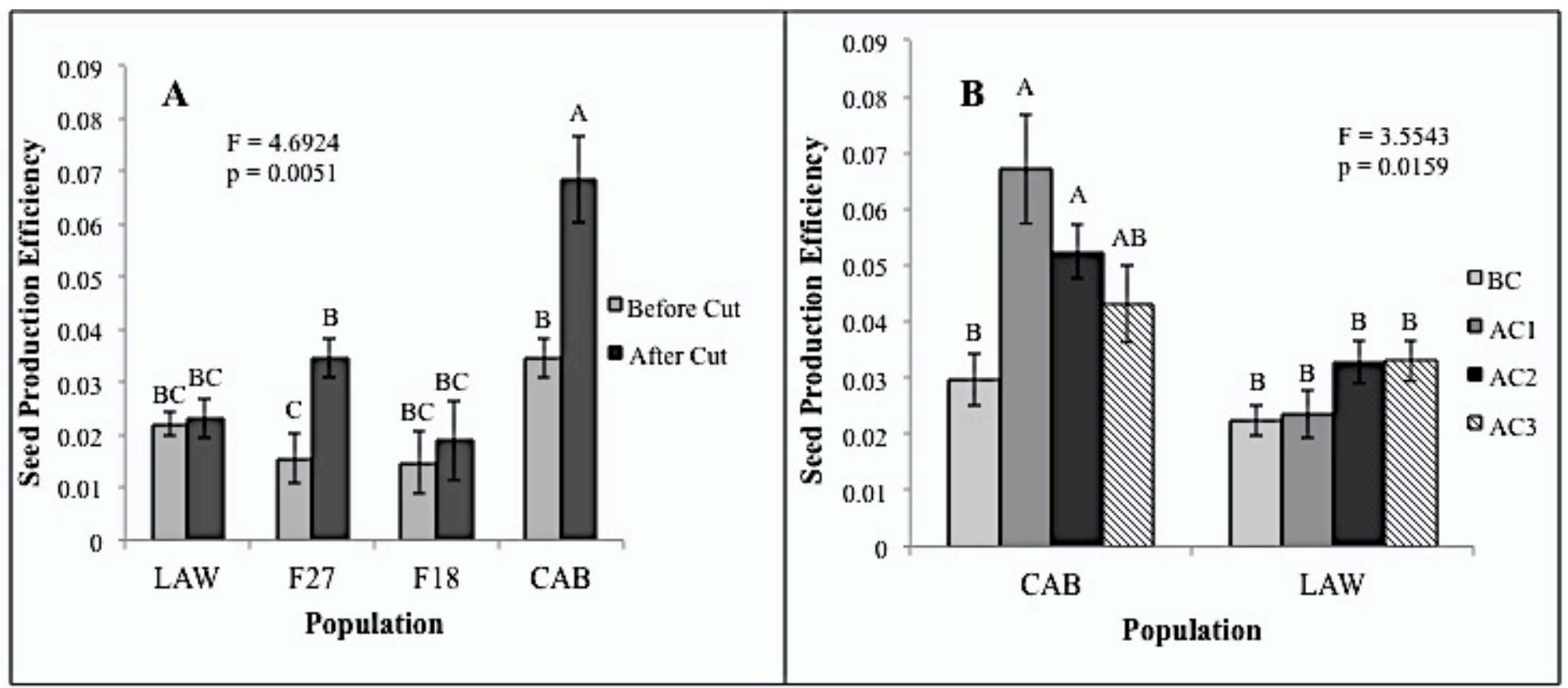

Figure 4.7. A) Short-term differential effects of timber harvest and population on seed production efficiency. B) Long-term differential effects of timber harvest and population on seed production efficiency $\left(\mathrm{BC}\right.$ - before cut, $\mathrm{AC}_{1}$ - one year after cut, $\mathrm{AC}_{2}-$ two years after cut, $\mathrm{AC}_{3}$ - three years after cut). 


\subsection{Literature Cited}

Beaudet M, Messier C, and Leduc A. 2004. Understorey light profiles in temperate deciduous forests: Recovery process following selection cutting. Journal of Ecology 92: 328-338. DOI: 10.1111/j.0022-0477.2004.00869.x

Beckage B, Clark J, Clinton B, and Haines B. 2000. A long-term study of tree seedling recruitment in southern Appalachian forests: The effects of canopy gaps and shrub understories. Canadian Journal of Forest Research 30(10): 1617-1631. DOI: $10.1139 / \mathrm{x} 00-075$

Belote R, Sanders N, and Jones R. 2009. Disturbance alters local-regional richness relationships in Appalachian forests. Ecology 90(10): 2940-2947. DOI: 10.1890/081908.1

Belote R, Jones R, and Wieboldt T. 2012. Compositional stability and diversity of vascular plant communities following logging disturbance in Appalachian forests. Ecological Applications 22(2): 502-516. DOI: 10.1890/11-0925.1

Canham C. 1988a. Growth and canopy architecture of shade-tolerant trees: Response to canopy gaps. Ecology 69(3): 786-795. DOI: 10.2307/1941027

Canham C. 1988b. An index for understory light levels in and around canopy gaps. Ecology 69(5): 1634-1638. DOI: 10.2307/1941664

Carlson A. 1986. Ginseng-America's botanical drug connection to the Orient. Economic Botany 40: 233-249. DOI: 10.1007/BF02859148

Chamberlain JL, Prisley S, and McGuffin M. 2013. Understanding the relationships between American ginseng harvest and hardwood forest inventory and timber harvest to improve co-management of the forests of eastern United States. Journal of Sustainable Forestry 32(6): 605-624. DOI: 10.1080/10549811.2013.798828.

Charron D and Gagnon D. 1991. The demography of northern populations of Panax quinquefolius (American ginseng). Journal of Ecology 79:431-445. DOI: $10.2307 / 2260724$

Chazdon R. 1988. Sunflecks and their importance to forest understory plants. Advances in Ecological Research 18: 1-63.

Chazdon R and Fetcher N. 1984. Photosynthetic light environments in a lowland tropical rainforest in Costa Rica. Journal of Ecology 72: 553-564. DOI: $10.2307 / 2260066$

Chazdon R and Pearcy R. 1991. The importance of sunflecks for forest understory plants. Bioscience 41(11): 760-766. DOI: $10.2307 / 1311725$ 
Clebsch E and Busing R. 1989. Secondary succession, gap dynamics, and community structure in a southern Appalachian cove forest. Ecology 70(3): 728-735. DOI: $10.2307 / 1940223$

Cruse-Sanders JM and Hamrick JL. 2004. Spatial and genetic structure within populations of wild American ginseng (Panax quinquefolius L., Araliaceae). Journal of Heredity 95(4): 309-321. DOI: 10.1093/jhered/esh046

Demir M, Makineci E, and Yilmaz E. 2007. Investigation of timber harvesting impacts on herbaceous cover, forest floor and surface soil properties on skid road in an oak (Quercus petrea L.) stand. Building and Environment 42(3): 1194-1199. DOI: 10.1016/j.buildenv.2005.11.008

Duguid MC and Ashton MS. 2013. A meta-analysis of the effect of forest management for timber on understory plant species diversity in temperate forests. Forest Ecology and Management 303: 81-90. DOI: 10.1016/j.foreco.2013.04.009

Fajvan MA, Grushecky ST, and Hassler CC. 1998. The effects of harvesting practices on West Virginia's wood supply. Journal of Forestry 96(5): 33-39.

Fournier A, Gosselin A, Proctor J, Gauthier L, Khanizadeh S, and Dorais M. 2004. Relationship between understory light and growth of forest-grown American ginseng (Panax quinquefolius L.). Journal of the American Society for Horticultural Science 129(3): 425-432.

Frazer G, Canham C and Lertzman K. 1999. Gap light analyzer (GLA) Version 2.0 Imaging software to extract canopy structure and gap light transmission indices from true-color fisheye photographs: users' manual and program documentation. 36p. Burnaby, BC, Canada: Simon Fraser University.

Fredericksen TS, Ross BD, Hoffman W, Morrison ML, Beyea J, Johnson BN, Lester MB, and Ross E. 1999. Short-term understory plant community responses to timberharvesting intensity on non-industrial private forestlands in Pennsylvania. Forest Ecology and Management 116(1-3): 129-139.

Gilliam FS. 2002. Effects of harvesting on herbaceous layer diversity of a central Appalachian hardwood forest in West Virginia, USA. Forest Ecology and Management 155: 33-43. DOI: 10.1016/S0378-1127(01)00545-X

Gilliam FS. 2007. The ecological significance of the herbaceous layer in temperate forest ecosystems. BioScience 57(10): 845-858. DOI: 10.1641/B571007

Goebel P and Hix D. 1996. Development of mixed-oak forests in southeastern Ohio: a comparison of second-growth and old-growth forests. Forest Ecology and Management 84: 1-21. DOI: 10.1016/0378-1127(96)03772-3 
Hammond D, Smith D, Zedaker S, Wright D, and Thompson J. 1998. Floral diversity following harvest on southern Appalachian mixed oak sites. In Proceedings of the Ninth Southern Biennial Silvicultural Research Conference (Vol. SRS 20, pp. 461465). Clemson, SC: USDA Forest Service General Technical Report.

Harrelson S and Matlack G. 2006. Influence of stand age and physical environment on the herb composition of second-growth forests, Strouds Run, Ohio, USA. Journal of Biogeography 33: 1139-1149. DOI: 10.1111/j.1365-2699.2006.01489.x

Knohl A, Schulze E, Kolle O, and Buchmann N. 2003. Large carbon uptake by an unmanaged 250-year-old deciduous forest in Central Germany. Agricultural and Forest Meteorology 118: 151-168. DOI: 10.1016/S0168-1923(03)00115-1

Kursar T and Coley P. 1993. Photosynthetic induction in shade-tolerant species with long and short-lived leaves. Oecologia 93: 165-170. DOI: 10.1007/BF00317666

Lawton R. 1990. Canopy gaps and light penetration into a wind-exposed tropical lower montane rain forest. Canadian Journal of Forest Research 20: 659-667. DOI: 10.1139/x90-088

LeGouallec JL, Cornic G, Blanc P. 1990. Relations between sunfleck sequences and photoinhibition of photosynthesis in a tropical forest understory herb. American Journal of Botany 77: 999-1006.

Lorimer C and Frelich L. 1994. Natural disturbance regimes in old-growth northern hardwoods: Implications for restoration efforts. Journal of Forestry 92: 33-38.

Manabe T, Shimatani K, Kawarasaki S, Aikawa S and Yamamoto S. 2009. The patch mosaic of an old-growth warm-temperate forest: Patch-level descriptions of 40-year gap-forming processes and community structures. Ecological Research 24: 575-586. DOI: $10.1007 / \mathrm{s} 11284-008-0528-7$

McGraw JB. 2001. Evidence for decline in stature of American ginseng plants from herbarium specimens. Biological Conservation 98: 25-32. DOI: 10.1016/S00063207(00)00138-5

McGraw JB and Furedi MA. 2005. Deer browsing and population viability of a forest understory plant. Science 307: 920-922. DOI: 10.1126/science.1107036

McGraw JB, Souther S and Lubbers A. 2010. Rates of harvest and compliance with regulations in natural populations of American ginseng (Panax quinquefolius L.). Natural Areas Journal 30: 202-210. DOI: 10.3375/043.030.0207 
McGraw JB, Lubbers A, Van der Voort M, Mooney E, Furedi M, Souther S, Turner JB, and Chandler J. 2013. Ecology and conservation of ginseng (Panax quinquefolius) in a changing world. In The Year in Ecology and Conservation Biology (pp. 1-30). New York: Annals of the New York Academy of Sciences. DOI: 10.1111/nyas.12032

Meier AJ, Bratton SP, Duffy DC. 1995. Possible ecological mechanisms for loss of vernal-herb diversity in logged eastern deciduous forests. Ecological Applications 5: 935-946. DOI: $10.2307 / 2269344$

Mooney EH and McGraw JB. 2009. Relationship between age, size and reproduction in populations of American ginseng, Panax quinquefolius (Araliaceae), across a range of harvest pressures. Ecoscience 16: 84-94. DOI: 10.2980/16-1-3168

Nantel P, Gagnon D and Nault A. 1996. Population viability analysis of American ginseng and wild leek harvested in stochastic environments. Conservation Biology 10: 608-621. DOI: 10.1046/j.1523-1739.1996.10020608.x

Neufeld H and Young D. 2003. Ecophysiology of the herbaceous layer in temperate deciduous forests. In F. Gilliam, \& M. Roberts, The Herbaceous Layer in Forests of Eastern North America (pp. 38-90). New York: Oxford University Press.

Oláh R and Masarovičová E. 1997. Response of CO2 uptake, chlorophyll content, and some productional features of forest herb Smyrnium perfoliatum L. (Apiaceae) to different light conditions. Acta Physiologiae Plantarum 19: 285-293. DOI: 10.1007/s11738-997-0004-y

Oliver C. 1981. Forest development in North America following major disturbances. Forest Ecology and Management 3(3): 153-168. DOI: 10.1016/0378-1127(80)900134

Roberts MR. 2004. Response of the herbaceous layer to natural disturbances in North American forests. Canadian Journal of Botany 82: 1273-1283. DOI: 10.1139/b04091

Roberts MR and Gilliam FS. 1995. Disturbance effects on herbaceous layer vegetation and soil nutrients in Populus forests of northern lower Michigan. Journal of Vegetation Science 6: 903-912. DOI: 10.2307/3236405

Roberts MR and Gilliam FS. 2003. Response of the herbaceous layer to disturbance in eastern forests. In F. Gilliam, \& M. Roberts (Eds.), The herbaceous layer in forests of eastern North America (pp. 302-320). New York: Oxford University Press.

Robbins C. 1998. American ginseng: The root of North America's medicinal herb trade. Washington, DC: TRAFFIC. 
Schlessman M. 1985. Floral biology of American ginseng (Panax quinquefolium). Bulletin of the Torrey Botanical Club 112(2): 129-133. DOI: 10.2307/2996409

Seymour R and Hunter M. 1999. Principles of ecological forestry. In M. Hunter, Maintaining biodiversity in forest ecosystems (pp. 22-61). New York: Cambridge University Press.

Small CJ, and McCarthy BC. 2002. Effects of simulated post-harvest light availability and soil compaction on deciduous forest herbs. Canadian Journal of Forest Research 32: 1753-1762. DOI: 10.1139/x02-099

Smith W and Berry Z. 2013. Sunflecks? Tree Physiology 00: 1-5. DOI: $10.1093 /$ treephys/tpt005

Sousa W. 1984. The role of disturbance in natural communities. Annual Review of Ecology, Evolution, and Systematics 15: 353-391.

Souther S. and McGraw JB. 2011. Evidence of local adaptation in the demographic response of American ginseng to interannual temperature variation. Conservation Biology 25(5): 922-931. DOI: 10.1111/j.1523-1739.2011.01695.x

Spies T, Hemstrom M, Youngblood A, and Hummel S. 2006. Conserving old-growth forest diversity in disturbance-prone landscapes. Conservation Biology 20: 351-362. DOI: $10.1111 / \mathrm{j} .1523-1739.2006 .00389 . x$

Van der Voort ME and McGraw JB. 2006. Effects of harvester behavior on population growth rate affects sustainability of ginseng trade. Biological Conservation 130: 505-516. DOI: 10.1016/j.biocon.2006.01.010

Wagner A and McGraw J. 2013. Sunfleck effects on physiology, growth, and local demography of American ginseng (Panax quinquefolius L.). Forest Ecology and Management 291: 220-227. DOI: 10.1016/j.foreco.2012.11.038

Whigham D. 2004. Ecology of woodland herbs in temperate deciduous forests. Annual Review of Ecology, Evolution, and Systematics 35: 583-621. 
Chapter 5. Demographic Response of a Model Obligate Understorey Herb to Canopy Disturbances in a Mixed Mesophytic Forest

Formatted for, and in revision for re-submission to, Journal of Ecology 


\subsection{Abstract}

1) Natural and anthropogenic forest disturbances range from discrete disturbance events to chronic disturbances that occur over longer timescales. An understorey plant's ability to exploit alterations to the light environment caused by canopy disturbance leads to changes in population dynamics. The purpose of this work was to determine if population growth of a species adapted to low light increases in response to additional light inputs caused by canopy disturbance, or alternatively, declines due to long-term selection under low light conditions.

2) To address this question, we quantified the demographic response of an understorey herb to three contrasting forest canopy disturbances (ice storms, tent caterpillar defoliation and lightning strikes) that encompass a significant range of disturbance severity. We used a model shade-adapted understorey species, Panax quinquefolius, to parameterize stage-based matrix models. Asymptotic growth rates, stochastic growth rates and simulations of transient dynamics were used to quantify the population-level response to canopy disturbance. Life table response experiments were used to partition the underlying controls over differences in population growth rates.

3) Population growth rates at all three disturbed sites increased immediately after the canopy disturbance relative to the period prior to disturbance. Stochastic population models revealed that growth rates increased significantly in simulations that included disturbance matrices relative to those simulations that excluded disturbance. 
Additionally, transient models indicated that population size (n) was larger for all three populations when the respective disturbance matrix was included in the model.

4) Synthesis Obligate shade species may be adapted to take advantage of canopy gaps and light influx to a degree, and this adaptation may be due to long-term selection under dynamic old growth forest canopies. We propose a model whereby population performance is represented by a parabolic curve where performance is maximized under intermediate levels of canopy disturbance. This study provides new evidence to aid our understanding of the population-level response of understorey herbs to disturbances whose frequency and intensity are predicted to increase as global climates continue to shift. 


\subsection{Introduction}

Forest disturbances occur as a result of both natural and anthropogenic influences, and range from discrete disturbance events (e.g. insect defoliation, windthrow, hurricanes and ice storms) to long-term environmental changes such as climate shifts (White and Pickett 1985). Disturbance influences the structure and function of individual plants, populations and forest communities, and can differentially affect the various strata within forested systems (White 1979, Roberts and Gilliam 2014). Canopy disturbances are recurring sources of heterogeneity that lead to multi-dimensional shifts in forest understorey dynamics.

Climate change directly and indirectly affects forest systems by altering the frequency, intensity, duration, and extent of natural disturbance regimes across the landscape (Baker 1995, Turner et al. 1998, Dale et al. 2001, IPCC 2007a, Ryan et al. 2008, Bentz et al. 2010, Babst et al. 2014). A suite of understorey environmental characteristics are altered by canopy disturbance, including light availability, temperature, humidity, surface soil moisture, nutrient availability and evapotranspiration (Liechty et al. 1992, Roberts 2004, Muscolo et al. 2014, Roberts and Gilliam 2014). Insect defoliation, ice storms and lightning strikes are three common types of natural canopy disturbances that can lead to profound changes both in the light dynamics of the understorey and also in other abiotic understorey characteristics such as nutrient inputs, woody debris accumulation and inter- and intra-specific competition (Roberts 2004, Roberts and Gilliam 2014). Further, the frequency and intensity of these types of disturbances are increasing as climates shift (Dale et al. 2001, IPCC 2007a, Kunkel et al. 2008, Dukes et al. 2009, Babst et al. 2014). 
Light is the primary resource that limits photosynthesis, growth and seedling establishment in relatively undisturbed forest understories (Chazdon and Pearcy 1991, Beckage et al. 2000, Whigham 2004b, Wagner and McGraw 2013, Neufeld and Young 2014). Sunflecks play a critical role in the development and success of understorey herbs by contributing up to $85 \%$ of the total photosynthetic photon flux density (PPFD) and up to $60 \%$ of an understorey plant's daily photosynthesis and net carbon gain (Chazdon 1988, Chazdon and Pearcy 1991, Kursar and Coley 1993, Wagner and McGraw 2013). Wagner and McGraw (2013) found that microsites with higher sunfleck activity triggered an increase in light saturated photosynthetic rates as well as an increase in individual growth rates in Panax quinquefolius L. (American ginseng). However, this positive response is not ubiquitous. Elatostema repens, a tropical understorey herb, experienced photoinhibition and a reduction in carbon gain when exposed to irradiance greater than $700 \mu \mathrm{mol} \mathrm{m} \mathrm{s}^{-1}$ (Le Gouallec et al. 1990). Intense and long lasting canopy disturbances could lead to high leaf temperature, increased water loss and eventual photoinhibition in obligate understorey herbs that do not possess physical avoidance mechanisms and physiological adaptations to high light (Chazdon and Pearcy 1991, Oláh and Masarovičová 1997, Fournier et al. 2004, Roberts and Gilliam 2014). While many studies have documented a range of physiological responses to sunflecks, fewer have examined the longer-term consequences for plant growth, survival, reproduction and ultimately population dynamics.

Population growth rate $(\lambda)$ is an integrated measure of plant survival, growth and fertility (Caswell 1989). Wagner and McGraw (2013) proposed that since the survival, growth and reproduction of $P$. quinquefolius are largely size dependent, the changes in 
growth brought about by light variability in sunflecks could predict the fate of $P$. quinquefolius subpopulations, however their work did not scale up responses to the population-level (Wagner and McGraw 2013). The present study builds upon the findings above by determining how the vital rates of an obligate understorey plant, $P$. quinquefolius, vary in response to quantities and durations of light that exceed even those found in sunflecks. The 'slow' life history traits that characterize $P$. quinquefolius are typical of many perennial understorey herbs (McGraw et al. 2013), making $P$. quinquefolius a good model species for understanding canopy disturbance effects generally.

The overarching goal of this research was to determine if a species found primarily in low light understorey environments benefits demographically from additional inputs of light from canopy disturbances, or alternatively, due to long-term selection under low light conditions, such disturbances bring about a population decline. Secondly, we wanted to know if the demographic response was consistent across different canopy disturbance types, regardless of severity, duration, and effects beyond light enhancement. To address these goals, we analyzed the demographic consequences of three contrasting canopy disturbances observed over the history of studying thirty natural P. quinquefolius populations over a period of up to 18 years from a sample of 461 population-years of data. 


\subsection{Methods}

\section{STUDY SPECIES}

Panax quinquefolius is a long-lived, obligate understorey herb found throughout much of the eastern United States and in southern portions of Canada (McGraw et al. 2013). Panax quinquefolius emerges from winter dormancy and begins elongation and leaf expansion in late April or early May, prior to complete closure of the tree canopy (Lewis and Zenger 1982, Hackney and McGraw 2001). Flowering occurs in June and July, followed by fruit production and ripening from July to September (Carpenter and Cottam 1982, McGraw et al. 2013). Dispersal of fruit via gravity and frugivorous birds (Lewis and Zenger 1982, Hruska et al. 2014) takes place in August and September and is followed by plant senescence, as is common in many understorey herbs (McGraw et al. 2013). Panax quinquefolius seeds require a stratification period following dispersal, which is also similar to many other perennial herbs. The stratification period for $P$. quinquefolius is typically twenty-one months, but germination after 33 or 45 months is also possible (McGraw et al. 2013). Newly emerged $P$. quinquefolius seedlings consist of a one-leaf plant with three leaflets. In the years that follow, individuals produce additional leaves with varying numbers of leaflets (Lewis and Zenger 1982, Anderson et al. 1993). Fruit production can occur in plants that have two leaves, but is more common in plants at the three- to four-leaf stage (Furedi 2004).

A previous study of the response of natural populations to spatial variation in forest floor sunflecks suggested that $P$. quinquefolius is adapted to the light regimes of old growth forests (Wagner \& McGraw 2013). Old growth forests are characterized by an overstorey with well-developed canopy layers as well as temporally and spatially 
heterogeneous gap formation and closure (Knohl et al. 2003, Spies et al. 2006, Manabe et al. 2009, Wagner and McGraw 2013). A separate study that focused on the response of P. quinquefolius to timber harvest found that initial $P$. quinquefolius survival decreased following canopy removal, while the growth rate of surviving individuals increased (Chandler and McGraw 2015). Nevertheless, the net demographic effect of natural canopy disturbances on P. quinquefolius was unknown.

\section{STUDY AREAS}

We took advantage of natural canopy disturbance events that occurred at five long-term research sites, each containing natural populations of $P$. quinquefolius. Due to the economic and conservation values of P. quinquefolius, generic site descriptors (NY, WKY, EKY) have replaced actual location names. While the canopy disturbances were noted during censuses, we did not anticipate a comparative study of canopy disturbance effects; therefore, with the exception of EKY, changes in photosynthetic photon flux density and other indirect effects of the disturbances were estimated only qualitatively.

\section{NY - Forest Tent Caterpillar Defoliation}

The affected range, frequency and intensity of some phytophagous insect outbreaks are predicted to increase with the changes in temperature and precipitation associated with climate change (Williams and Liebhold 1995, Harrington et al. 1999, Logan et al. 2003, Battisti et al. 2006, Dukes et al. 2009, Klutsch et al. 2009, Bentz et al. 2010). An example of this is the recent widespread tree mortality observed in the western United States caused by bark beetle outbreak (Bentz et al. 2009). Another example is forest tent caterpillars (FTC; Malacosoma disstria), which feed on leaves of an array of 
broadleaf trees (Dukes et al. 2009). Insect defoliation thins the tree canopy, thus allowing more sunlight to reach the understorey until refoliation occurs. Soil nutrient inputs increase as well due to frass deposition (Hunter 2001, Frost and Hunter 2004). This study site was located in eastern New York (NY), U.S.A. In May-June, 2006, heavy FTC defoliation resulted in the loss of $>50 \%$ of the deciduous canopy cover for several weeks in mid-growing season. Refoliation occurred gradually in July and August.

\section{WKY - Ice Storm}

Like insect defoliation, ice storms are common recurrent disturbance events in many temperate forests (Irland 2000, Darwin et al. 2004, Roberts 2004, Vowels 2012). Ice storms can cause breakage of tree limbs, crowns and even boles, leading to abrupt changes in tree stand and canopy structure (Irland 2000). The duration of an ice storm's influence on the understorey can vary depending upon storm severity. Roberts and Gilliam (2014) predicted that small canopy gaps created by ice storms would create a light environment that favors shade-tolerant understorey plants, while larger canopy gaps would favor shade intolerant species. Three western Kentucky, U.S.A. (WKY) study sites containing $P$. quinquefolius populations experienced heavy damage from ice storms in January, 2009. A protracted freezing rain event deposited ca. $5 \mathrm{~cm}$ of ice, leading to loss of tree limbs and whole crowns (Vowels 2012). In contrast to the FTC defoliated site, WKY populations experienced longer-lasting canopy gaps and deposition of extensive down woody debris.

\section{EKY - Lightning Strike}


Climate models predict increases in the frequency of severe thunderstorms (Trapp et al. 2007, Brooks 2013). Severe thunderstorms may produce hail, tornado activity and, more frequently, lightning strikes, any of which can affect tree canopy integrity. Lightning is the most common of these in temperate deciduous forests, and can produce a variety of structural and physiological damages (Taylor 1971). In contrast to ice storms, lightning strikes tend to affect the canopy of single trees or small groups of trees in multiple ways, with effects ranging from little tree damage to loss of tree limbs to mortality of single trees or groups of trees (Taylor 1971).

In late spring, 2012, lightning killed two dominant trees within a single $P$. quinquefolius population in eastern Kentucky, U.S.A. (EKY), opening the canopy over portions of the population. A LI-COR LI-189 light meter (LI-COR Environmental, Nebraska, USA) was used in summer 2015 to measure PPFD $\left(\mu \mathrm{mol} \mathrm{m}{ }^{-2} \mathrm{~s}^{-1}\right)$ along four transects that extended in each cardinal direction from the center of the canopy gap. Light measurements were taken at $0,2,4,6,8,10$ and 12 meter intervals from the origin. These transects were designed to determine if individuals within the EKY population were either in the "affected" area or the "unaffected" area of the canopy, based on the light availability in the understorey. Light levels dropped sharply at eight meters and beyond, thus the individuals that fell within the eight-meter radius of the origin were deemed affected by the canopy gap, while unaffected individuals fell outside the same radius.

The three different types of disturbance events (NY-defoliation, WKY-ice storm and EKY-lightning strike) bracketed a substantial range of severity. Defoliation at the NY population represented a low severity disturbance affecting a large area, ice damage 
to the tree canopy at WKY represented a more intense, long lasting disturbance affecting a large area, while lightning damage at EKY represented a relatively low to medium intensity disturbance affecting only a small area. These sites have been referred to differently in separate studies: NY - site 10, WKY - sites 4, 7, and 8, EKY - site 3; McGraw et al. 2013).

\section{PANAX QUINQUEFOLIUS CENSUS}

Panax quinquefolius plants were labeled with an aluminum tag so that each individual could be accurately identified each census year. Census data were collected twice annually; once in the spring to assess emergence and leaf area, and once in the fall to assess reproduction. We collected data on plant emergence, leaf number, length and width of the longest leaflet on each leaf $(\mathrm{cm})$, reproductive status (Reproductive: Y/N) and number of seeds produced.

Individual survival was determined by observing plant emergence. Two criteria were used to establish death of a plant: 1) new seedlings were considered dead if they did not re-emerge the growing season following their initial emergence; 2) All older plants were considered dead if they did not emerge for two consecutive growing seasons. The two-year waiting period was necessary because plants whose roots or shoots have been damaged may lie dormant for one growing season and re-emerge the following season.

Leaf area was calculated using a previously established regression equation based on the allometric relationship between total leaf area and length and width of the longest leaflet on each leaf (Souther and McGraw 2011b). Leaf area of all leaves was summed to yield total leaf area of an individual. 


\section{ASYMPTOTIC POPULATION GROWTH RATE}

Separate population projection matrices (Caswell 2001) were parameterized for each of the three disturbance types for the nine transition periods between growing seasons from 2004 to 2013. To obtain a sample size sufficient for demographic analyses, the three small WKY populations, which were all within $50 \mathrm{~km}$ of each other, were pooled.

Data from annual censuses and seed cage experiments were used to parameterize elements of nine-stage transition matrices (Fig. 5.1) for each population for each transition period ( $t$ to $t+1$; from $2004-2013$ ). The matrices included four seed age classes and five post-germination stage classes. Matrix transition elements $\left(\mathrm{a}_{\mathrm{ij}}\right)$ represented the number of class $i$ individuals derived from class $j$ individuals over the span of one year. Seed classes represented viable seeds present in the soil at the spring census; therefore they were $9,21,33$, and 45 months old. To parameterize the seed bank transition probabilities in each matrix $\left(\mathrm{a}_{21}, \mathrm{a}_{32}, \mathrm{a}_{43}\right)$, mean seed survival was estimated from mean values obtained from two serial seed cage experiments performed on these populations (McGraw and Furedi 2005, Souther and McGraw 2011b). Because it was impractical to repeat these studies annually, seed survival transitions within the seed bank were assumed to be constant for a given population across years.

Stage 5 in the matrix represented 1-leaf plants. The probability of a seed germinating and producing a 1-leaf new plant (transitions $\mathrm{a}_{51}, \mathrm{a}_{52}, \mathrm{a}_{53}$ and $\mathrm{a}_{54}$ ) was calculated as:

$$
a_{5 j}=\frac{G_{i}}{S_{j}}
$$


where $G_{i}$ equals the mean number of germinants $(t+1)$ and $S_{j}$ equals the mean number of viable seeds at time t.

Because the photosynthetic capacity and reproductive effort of $P$. quinquefolius depends more on leaf area than age, analyses of $P$. quinquefolius have used stage-based demographic models (Charron and Gagnon 1991, Nantel et al. 1996, Van der Voort and McGraw 2006, McGraw et al. 2013). We also used a stage-based matrix to represent post-germination growth of individuals. The first post-germination growth stage included all 1-leaf plants (stage 5). The placement of one-leaf individuals into a separate non-adult class is appropriate because, unlike adults, flowering is extremely rare for oneleafed individuals. The partitioning of individuals into adult stages (small - stage 6, medium - stage 7, large - stage 8 and extra-large - stage 9) was determined by dividing adults into four groups of comparable size (n) based on the leaf area of each adult individual. Transition probabilities $\left(\mathrm{a}_{\mathrm{ij}}\right)$ within stages 5-9 represented stage stasis $\left(\mathrm{a}_{\mathrm{ij}}\right.$, where $i=j)$, growth to a larger stage $\left(a_{i j}\right.$ where $\left.i>j\right)$ or reduction to a smaller stage $\left(a_{i j}\right.$ where $\mathrm{i}<\mathrm{j}$ ). The seed stratification requirement (over 2 winters) precluded direct transition from a reproductive individual (stages 6, 7, 8 and 9) to a 1-leaf plant (stage 5).

The fertilities of each individual stage six through nine $\left(a_{16}, a_{17}, a_{18}, a_{19}\right)$ were determined as follows:

$a_{i j}=v \frac{\sum S_{j}}{n_{j}}$

where $v$ is a constant (0.9289), representing the proportion of seeds remaining viable from dispersal to the next growing season (9 months; Souther \& McGraw 2011b), $\mathrm{S}_{\mathrm{j}}$ is the number of seeds produced in August of year $t$ by individuals in stage $j(j=6,7,8$ and 
9) and $n_{j}$ is the total number of individuals in stage $\mathrm{j}$ at the spring census of year $\mathrm{t}$

(Caswell 2001). For each transition period in each disturbance type, the finite rate of population growth $(\lambda)$ was calculated as the dominant eigenvalue of the transition matrix (A) (Caswell 2001).

To provide replication and allow comparisons of population growth rate between transition periods, pseudovalues $\left(\phi_{i}\right)$ of the finite rate of population increase were determined (McGraw 1989, Vavrek et al. 1996, Chandler et al. 2015). The mean pseudovalue of $\lambda\left(\bar{\phi}_{i}\right)$ provides an unbiased estimate of $\lambda$, and pseudovalues can be used as replicates for statistical analyses and estimates of standard errors (McGraw 1989; Vavrek et al. 1996; Chandler et al. 2014). For each matrix that was assembled, to determine a $\phi_{i}$, each individual $i$ within the matrix was removed stepwise, and a new $\lambda$ minus individual $i$ was determined. Each missing individual's contribution to overall population growth was then calculated as the pseudovalue $\left(\phi_{i}\right)$ of population growth rate as follows:

$\phi_{i}=n \lambda_{a l l}-(n-1) \lambda_{-i}$

where $n$ is the total number of individuals, $\lambda_{-i}$ is the population growth rate when individual $(i)$ is removed and $\lambda_{\text {all }}$ is the population growth rate when all individuals are included (McGraw 1989, Vavrek et al. 1996, Chandler et al. 2015). Pseudovalues of lambda $\left(\phi_{i}\right)$ were then used to compare population growth one transition period prior to the disturbance and one transition period after the disturbance for each disturbance type. Normality was improved by transformation when possible, and non-parametric Welch's ANOVAs were used when normality could not be improved. 


\section{LIFE TABLE RESPONSE EXPERIMENTS}

Life table response experiments (LTREs) are retrospective analyses that can evaluate the influence that environmental factors have on population-level responses by decomposing the underlying controls over population growth rate difference (Caswell 2001). In the present implementation, LTREs were performed to determine the change in transition parameters $\left(\mathrm{a}_{\mathrm{ij}}\right)$ most responsible for the observed differences in population growth rate $(\lambda)$ one transition period before and one transition period after the defoliation at the NY population, the ice storm damage at the WKY population and the lightning strike at the EKY population.

\section{STOCHASTIC POPULATION GROWTH RATE}

By employing iterative simulations, stochastic demographic models can be used to evaluate how variations in vital rates caused by environmental change can affect population growth (Morris and Doak 2002, Hunter et al. 2010). Stochastic population growth rates $\left(\lambda_{\mathrm{s}}\right)$ were calculated for each of the populations using both Tuljapurkar's approximation and simulations (Morris and Doak 2002, MathWorks 2015). We first calculated stochastic population growth rate by executing 50,000 simulations that used only the eight matrices in which the disturbance of interest did not occur (minus disturbance). Each A matrix in these simulations had an equal probability of selection. We performed another set of simulations in which the disturbance matrices were included (plus disturbance). The probability of selecting the disturbance matrices was equivalent to the observed disturbance probabilities. We calculated the observed probability of each of the three disturbances occurring in a given place at a give time by dividing the number of occurrences observed by the total population years of data collected at all thirty of our 
long-term research sites $(\mathrm{n}=461)$. The probability of disturbance was then subtracted from the total probability, one, and the remainder was equally divided such that matrix selection was equally probable among the remaining eight undisturbed matrices.

\section{TRANSIENT POPULATION DYNAMICS}

Natural disturbances and other stochastic environmental events disrupt the stable state of a population (Hastings 2001, Koons et al. 2005, Ezard et al. 2010, Tremblay et al. 2015). Transient population dynamics can be used to determine how populations vary as a function of these disturbances, in the absence of a stable stage distribution (Hastings 2001; Koons et al. 2005; Ezard et al. 2010; Tremblay, Raventos \& Ackerman 2015). Transient population models were constructed in an effort to determine what, if any, effect these disturbance events had on short-term population dynamics. Previouslydeveloped MATLAB code (Box 7.3; Morris \& Doak 2002) was used as a basis of stochastic simulations. An average matrix was formed from the undisturbed matrices for each disturbance type, and the initial population state vector was calculated as the right eigenvector of the average matrix. The numbers of individuals in the aboveground stages were relativized to $\mathrm{N}=100$ and were added to the total seed count to yield initial population size. For each disturbance type, we first projected population size fifteen years into the future by running 10,000 simulations using only the matrices in which the disturbance of interest did not occur (- disturbance). Each A matrix in these simulations had an equal probability of selection each year. Then, we re-ran the projections with a single 'disturbance matrix' introduced at $\mathrm{t}=5$ to produce estimates of mean population size multiple years before and after disturbance. Mean population sizes (+/-s.e.) were 
plotted for the two sets of projections for each of the three disturbance types to visualise the transient effects.

\section{DISCRETE STAGE-MODEL VS. INTEGRAL PROJECTION MODEL}

We considered formulating the adult components of our population projection model using an integral projection model approach which uses regression models to assess how an individual's state influences survival, growth, and reproduction and which has certain advantages over discrete-stage models (Ramula et al. 2009). However, for the purposes of this study we elected to use a model with four seed age classes, one seedling class, and four discrete adult classes for the following reasons: (1) the seedling (1 leaf) class has distinct survival and growth patterns as it is in the establishment phase, where rooting depth and microsite determine early success, (2) the smallest adult class rarely produced seeds, and therefore allocation and growth had distinctive behavior warranting a separate class from other adults, (3) in comparing pre- and post-disturbance matrices with an LTRE, we felt the underlying causes of $\lambda$ 's would be more clearly shown with a smaller set of meaningful size classes, (4) due to its 'slow' life history and relatively low level of size variation, discrete stages adequately capture the broad patterns of betweenyear environmental effects and (5) prior demographic work with this species used this approach, and we wanted to make comparisons of our findings concerning natural disturbances with those previous studies of deer browse (McGraw and Furedi 2005), harvest (Van der Voort and McGraw 2006) and climate change (Souther and McGraw 2011a, 2011b, 2014); thus, we did not want to confound methodological differences in making these comparisons. 


\subsection{Results}

\section{ASYMPTOTIC POPULATION GROWTH RATE}

\section{NY - FOREST TENT CATERPILLAR DEFOLIATION}

The results from the FTC defoliation study supported the general pattern of population growth stimulation by canopy gap formation. A one-way ANOVA indicated that growth rate increased by $16.8 \%$ one year after defoliation relative to one year before defoliation $(\mathrm{F}=9.2636, \mathrm{p}=0.0024$; Fig. 5.2a). Mean population growth rates were $>1$ in both transition periods, indicating that population sizes were increasing throughout the study period (Fig. 5.2a).

The LTRE revealed that change in the parameters reflecting greater growth from large to extra large individuals $\left(\Delta \mathrm{a}_{98} ; 0.4152\right)$ and enhanced reproduction of extra large individuals $\left(\Delta \mathrm{a}_{19} ; 4.2857\right)$ contributed the most to $\Delta \lambda$ (Table 5.1a). The reduction in stasis of large adults $\left(\Delta \mathrm{a}_{88}=-0.4086\right)$ and small adults $\left(\Delta \mathrm{a}_{66}=-0.4037\right)$ led to a negative $\Delta \lambda$, indicating that stasis in these stages occurred more before defoliation than after defoliation (Table 5.1a). Generally, the probabilities of an individual regressing or remaining static in stage were greater before defoliation. Conversely, the probability of individuals transitioning to larger stages was typically greater following defoliation. Transitions from the small adult stage $\left(\mathrm{a}_{56}, \mathrm{a}_{66}, \mathrm{a}_{76}, \mathrm{a}_{86}\right.$ and $\left.\mathrm{a}_{96}\right)$ contributed the most to overall $\Delta \lambda\left(\sum \Delta \lambda_{i 6}=0.0547\right.$; Table 5.2a), reinforcing the importance of growth stimulation for enhanced population growth. Greater fertility of all reproductive stages $\left(a_{16}, a_{17}, a_{18}\right.$, $\mathrm{a}_{19}$ ) following defoliation contributed positively to $\Delta \lambda$, with increases being the most pronounced in the largest size class. 


\section{WKY - ICE STORM}

Consistent with the pattern observed for forest tent caterpillars, a one-way Welch's ANOVA indicated that mean population growth rate $\left(\bar{\phi}_{i}\right)$ increased by $23.1 \%$ in the transition period following the ice storm relative to the transition period prior $(\mathrm{F}=$ $5.7522, \mathrm{p}=0.0171$; Fig. $5.2 \mathrm{~b}$ ). While population size decreased by $9.4 \%$ in the transition period prior to the disturbance $(\lambda=0.906)$, population growth increased by $17.9 \%(\lambda=$ 1.179) in the transition period that encompassed the disturbance (Fig. 5.2b).

Similar to the results obtained from the NY population, changes in matrix elements quantifying stasis and regression in size generally produced a negative $\Delta \lambda$, indicating that these probabilities were higher before the ice storm than afterwards at WKY populations (Table 5.1b). This pattern was especially pronounced in the stasis of 1-leaf plants $\left(\Delta \lambda \mathrm{a}_{55}=-0.0829\right)$. An exception was the stasis of extra-large individuals (a99), which was higher after the canopy was opened by the ice storm. Growth to a larger stage class was more commonly observed following the ice storm (Table 5.1b), as indicated by positive $\Delta \lambda \mathrm{a}_{\mathrm{ij}}$ for those transitions. Growth from large individuals to extra large individuals $\left(\Delta \mathrm{a}_{98}=0.5653\right)$ was much greater following the ice storm $\left(\Delta \lambda \mathrm{a}_{98}=\right.$ 0.0731). Overall, the change in fates of medium-sized adults $\left(a_{57}, a_{67}, a_{77}, a_{87}, a_{97}\right)$ contributed the greatest positive $\Delta \lambda$ among all stages (Table 5.2b). Fertility was higher for all reproductive stages $\left(\mathrm{a}_{17}, \mathrm{a}_{18}\right.$ and $\left.\mathrm{a}_{19}\right)$ following the ice storm, but the enhanced fertility of extra large individuals produced the largest $\Delta \lambda$ observed in this study $\left(\Delta \mathrm{a}_{19}=\right.$ 2.3323, $\Delta \lambda \mathrm{a}_{19}=0.0985 ;$ Table 5.1b).

EKY - LIGHTNING STRIKE 
Population size was increasing $(\lambda>1)$ in transition periods both before and after the lightning strike at the EKY population (Fig. 5.2c). However, a one-way Welch's ANOVA revealed a trend which suggested that population growth rate was higher in the transition period following the lightning strike than the transition period prior, resulting in a relative increase of $7.4 \%(\mathrm{~F}=3.3583, \mathrm{p}=0.0674$; Fig. $5.2 \mathrm{c})$. While this increase was smaller than the previous two disturbance types, the pattern was the same.

The LTRE revealed that growth of one-leaf plants to small adults was greater following the lightning strike $\left(\Delta \mathrm{a}_{65}=0.1443\right)$, and resulted in the largest $\Delta \lambda$ among all transitions $\left(\Delta \lambda \mathrm{a}_{65}=0.0632\right.$; Table 5.1c). Further, the sum of transitions from the one leaf plant stage $\left(\mathrm{a}_{55}, \mathrm{a}_{65}\right.$ and $\left.\mathrm{a}_{75}\right)$ contributed the most to overall $\Delta \lambda\left(\sum \Delta \lambda_{i 5}=0.462\right.$; Table 5.2c). Fertility was generally higher for reproductive stages $\left(a_{16}, a_{17}\right.$ and $\left.a_{18}\right)$ following the lightning strike (Table 5.1c). However, the fertility of the extra large individuals $\left(\mathrm{a}_{19}\right)$ was slightly lower following the lightning strike (Table 5.1c), a result that contradicts those of the other disturbed populations.

In the lowest severity canopy disturbance, lightning strike, the sum of transitions from the smallest stage class was most important in the $\Delta \lambda$ (Table 5.2c). Conversely, as the severity of canopy disturbance increases, the sum of transitions from increasingly larger stage classes had the greatest influence on the $\Delta \lambda$ (Table 5.2a-b).

\section{STOCHASTIC POPULATION GROWTH RATE}

Stochastic population growth rates $\left(\lambda_{\mathrm{s}}\right)$ increased significantly, albeit slightly, in all populations when the disturbance matrices were included (Fig. 5.3a,b,c). We infer that these canopy disturbances are capable of increasing population growth even at the 
current frequency of disturbance within American ginseng populations. The inclusion of the defoliation disturbance matrix increased $\lambda_{\mathrm{s}}$ by $2.6 \%$ at the NY population relative to the model that did not include the disturbance matrix (Fig. 5.3a). Stochastic population growth rate increased by $2.2 \%$ at the WKY population when the ice storm was included in the model compared to when the disturbance was excluded (Fig. 5.3b). Stochastic population growth rate increased by $1.1 \%$ at the EKY population when the lightning strike disturbance matrix was included in the model relative to when the disturbance matrix was excluded (Fig. 5.3c). The latter was the smallest increase in $\lambda_{\mathrm{s}}$ observed among all populations and disturbance types.

\section{TRANSIENT POPULATION DYNAMICS}

No differences in population size were observed between models with and without disturbance at year 5, which is the state of the population after multiplication by each respective disturbance matrix (Fig. 5.4a,b,c). However, the simulations including a disturbance matrix exhibited a significant increase in population size in year 6 (Fig. 5.4a,b,c). Contrasts in mortality and fertility were observed among the three populations that help to explain the lack of immediate year 5 numerical response (Fig. 5.5a,b). Fertility was higher in the NY and WKY disturbance matrix compared to the average undisturbed matrix, however this increased fertility was offset by higher mortality (Fig. 5.5a,b). The opposite was observed in the EKY population where both mortality and fertility were lower in the disturbed matrix than in the average undisturbed matrix (Fig. $5.5 \mathrm{a}, \mathrm{b})$. Nevertheless, there was a consistent shift in stage class distribution from the predisturbance period (year 4) to the post-disturbance period (year 5) among all populations (Fig. 5.6). There was a decrease in the proportion of individuals that comprised the 
smallest aboveground stage (stage five) between the pre-disturbance period (year 4) and post-disturbance period (year 5), coupled with an increase in the proportion of individuals that comprised the largest aboveground stage (stage nine) in the same period (Fig. 5.6). The observed shift to larger adults in the post-disturbance year led to stimulations in seed production between years 5 and 6 , thus explaining the rapid increases in population sizes observed in that interval. Population size increased at a relatively stable rate in the simulations that did not include a disturbance matrix (Fig. 5.4a,b,c). Further, while the size of the disturbed populations remained larger than their undisturbed counterparts following the disturbance year (year 6 and beyond), the rate of growth eventually returned to the same stable rate as observed in the undisturbed simulations (Fig. 5.4a,b,c). These results indicate that canopy disturbances can alter population dynamics in the short term and lead to increases in the overall population size that are sustained in a relatively undisturbed environment. 


\subsection{Discussion}

The post-disturbance patterns observed in all three populations supports a general pattern of light-gap stimulated population growth, whether examining asymptotic or stochastic population growth rates. Further, transient population models revealed that after fifteen years, population size was substantially higher in models that included one disturbance matrix at $\mathrm{t}=5$ compared to those that were comprise solely of undisturbed matrices, an increase that is caused by shifts in stage distribution to larger stage classes that are capable of producing more seeds. These results provide support for the idea that shade-tolerant herbs may be adapted to take advantage of canopy gap formation to a certain degree. These life history responses may reflect long-term selection under dynamic canopies typical of old growth forests.

The brief FTC defoliation event at the NY population elicited the strongest growth response, likely due to a combination of increases in light resources and redistribution of nutrients from canopy leaves to the understorey in the form of frass deposition (Hunter 2001, Frost and Hunter 2004). In the year following defoliation, a few 4-leaf plants transitioned to the unusually large 5-leaf stage $(<1$ in 10,000 plants attain this size; McGraw, unpublished data). While the canopy opening at NY was brief, the open canopy at the WKY populations lasted for multiple transition periods due to breakage of tree limbs and trunks from ice load.

The sum of transitions from larger stage classes had the greatest influence on the $\Delta \lambda$ at the two populations (NY and WKY) that incurred the most severe canopy disturbance. Larger plants appeared better able to withstand the stress caused by canopy disturbance than smaller plants. While population growth rate was stimulated by the ice 
storm, leaves of plants that remained were noticeably thickened and showed signs of photooxidation (Chandler and McGraw, personal observations). Additionally, although fertility of surviving individuals increased directly following the ice storm, many of the berries that were produced desiccated prior to dispersal (Chandler and McGraw, personal observation), limiting both seed viability and the potential for long-distance dispersal via frugivorous birds (Hruska et al. 2014; Elza, Slover \& McGraw 2015). Further, the aboveground portion of the plants at the WKY populations began senescing earlier in the fall than plants in many other routinely censused populations that were not included in this study (Chandler and McGraw, personal observation), a pattern also observed in Panax ginseng grown under high irradiance (Parmenter and Littlejohn 2000).

Nevertheless, the potential increases in photosynthesis and carbon storage for plants subjected to higher light levels appears to have more than compensated for the earlier senescence (Parmenter and Littlejohn 2000) and other signs of physiological stress.

While population growth rate did increase in response to a lightning strike, the increase was not as pronounced as in the other types of disturbance. One explanation for the smaller response is that only a small portion of the population was directly affected by the canopy gap, while the remainder experienced an undisturbed forest overstorey. Nevertheless, the growth stimulation of even a small portion of the population led to overall increases in population growth, indicating that even modest changes in light availability can result in significant stimulation of population growth.

Simulations in this study were performed under the assumption that each respective disturbance had only short-term effects on $P$. quinquefolius, as a single matrix continuously classified the disturbance period. However, in reality, the effects of all 
three disturbances could have persisted beyond one growing season in the form of residual soil nutrients from frass deposition and downed woody debris, and in the form of canopy openness that was sustained for longer than one transition period in the WKY and EKY populations. As such, these results are conservative and may underestimate the stimulation of population growth following intermediate canopy disturbances.

The intensity and frequency of natural forest disturbance events are predicted to change, most often increasing, as climates shift (Ryan et al. 2008). An understanding of both direct and indirect effects of climate change will be important in determining plant demographic responses (Souther et al. 2012, Sletvold et al. 2013, McGraw et al. 2013). In fact, Souther et al. (2012) suggest that increases in the frequency and intensity of extreme weather events, along with indirect effects of climate change such as light availability, soil moisture and disease may be more important than increases in temperature. Souther and McGraw (2011a) quantified the response of $P$. quinquefolius to a late frost event that occurred after emergence and found that survival, growth and reproduction decreased in plants that were exposed to the damaging frost. These results contrasted the results in the present study, which found increases in population growth following canopy disturbance. However, this contrast was expected since the mechanisms through which these disturbances affect $P$. quinquefolius differ. Nevertheless, these results reinforce the notion that populations respond differentially to varying types of disturbance. Previous research has shown that secondary effects of climate change, such as species interaction and competition, may have strong, and often negative, influences on population performance (Sletvold et al. 2013, Scanga 2014). While species interactions and competition undoubtedly changed following the 
disturbances studied here, these shifts did not result in discernable decreases in population growth.

The positive response of $P$. quinquefolius to canopy disturbance could be mitigated by an increase in harvesting. Panax quinquefolius has been the premier wildharvested herb in North America for the past two centuries (McGraw et al. 2013). Typical harvesters focus on the extraction of large, more apparent individuals from a population (Mooney and McGraw 2009), the same individuals whose growth transitions and fertilities drove much of the increase in $\lambda$ that was observed following canopy disturbance in this study. The destructive harvest of large individuals following disturbances would lead to long-term changes in demography, including a population largely composed of smaller, non-reproductive individuals. A separate study modeled $P$. quinquefolius population growth under various harvest scenarios and found that population size decreased between 8\% and 15\% (Van der Voort and McGraw 2006). Souther and McGraw (2014) found that the extinction risk predicted by models that included the interaction of both harvest and climate shift was far greater than the individual additive effects of harvest and climate change. Changes in population structure via enhanced harvest may result as the climate continues to shift and secondary canopy disturbances become more commonplace throughout eastern North America. The positive response of $P$. quinquefolius to canopy disturbance could also be mitigated by deer browse, which is a type of disturbance that affects many species of understorey herbs (Côté et al. 2004). Previous work indicated that current levels of deer browse have negative effects on population viability by increasing mortality, and reducing growth and fecundity (McGraw and Furedi 2005). These studies indicate that continued deer browse 
and potential increases in harvest could pose serious threats to population growth of medicinal, non-timber forest products in a shifting climate (Souther and McGraw 2014).

Based on the results of the current study combined with the findings of a study of timber harvest effects (Chandler and McGraw 2015), the demography of $P$. quinquefolius can be viewed as a parabolic function of canopy openness (Fig. 5.7). Although Chandler and McGraw (2015) did not directly assess population growth rate $(\lambda)$, they analyzed mortality, growth, and seed production of $P$. quinquefolius following various timber harvest events, metrics that are components of demographic models. Populations located under very dense evergreen canopies are expected to perform poorly relative to populations located in deciduous forest that consist of low levels of diffuse light punctuated by sunflecks. Similarly, the populations most likely to elicit the highest population growth rates are those whose canopy has been disturbed by some intermediate level of natural disturbance or disturbance-based silvicultural treatments that mimic old growth forest disturbance regimes (North and Keeton 2008). Individual photosynthesis, growth, and oftentimes seed production increases following moderate canopy disturbances such as those reviewed here, and these increases will similarly affect population growth (Chandler \& McGraw 2015; Chandler in press). At the highest values of canopy openness, which are represented by high-grade and clearcut timber harvest operations, overall population performance again decreases, and transient effects would be the opposite of those observed in the present study. However, anecdotal evidence suggest that a few large individuals do persist following these high levels of canopy disturbance (Chandler and McGraw 2015). The disturbance types illustrated by this model do not represent a complete list of possible canopy disturbances, and further, the 
amount of canopy openness that falls within each of the canopy disturbances is variable. Nevertheless, this conceptual model suggests that, although $P$. quinquefolius and understorey species like it are adapted to a low understorey light environment, this guild is able to exploit moderate increases in light availability, and population performance increases as a result.

Different types of disturbances affect forests in different ways and to different degrees. Nevertheless, some of the most common types of forest canopy disturbances are linked to climate, and predictions indicate that changes in forest disturbance regimes will be exacerbated by future climate shifts (Ryan et al. 2008, Babst et al. 2014). In addition to insect defoliation, ice storms and lightning strikes, other climate-mediated disturbances that have the potential to alter the growth rates of understorey plants include frost damage caused by emergence of plants prior to the passing of frost risk (Cannell and Smith 1986, Linkosalo et al. 2000, Jönsson et al. 2004, Souther and McGraw 2011a), wildfire (Babst et al. 2014), drought, herbivory (Parmesan 2006) and pests and disease (Parmesan 2006).

Panax quinquefolius is a long-lived obligate understorey herb that exhibits the same slow life history as many other obligate understorey species (McGraw et al. 2013). By using $P$. quinquefolius as a model species, we are able to better understand potential population level responses of similar understorey plants to disturbances whose frequency and intensity are predicted to increase as global climates continue to shift. Our results suggest that this shade-adapted herb is able to utilize and benefit from the additional light produced by canopy disturbance. While this study was observational in nature, the inferences we offer were based on consistent, shared patterns of response. In contrast to this research, many studies conclude that climate change and the interaction of climate 
change with other anthropogenic forces presages negative effects on natural plant populations (Thomas et al. 2004, Parmesan 2006, Souther and McGraw 2011b, Bellard et al. 2012). We conclude that more frequent, moderate canopy disturbances could provide herb populations a temporary stimulus in population growth, resulting in larger population size and greater insulation from demographic stochasticity. Small populations of understorey plants could benefit from increases in the frequency of moderate canopy disturbances that are predicted to occur as climates continue to shift. 


\subsection{Acknowledgements}

A special thank you to Amy Hruska and Jessica Turner, as well as previous graduate students and field crews, for their help in gathering the long-term data that was used in this study. Additionally, we thank the landowners for graciously allowing us to census ginseng populations on their properties. For their help reviewing this manuscript, we thank Christopher Walter, Mark Burnham, Leigh Ann Scholtz and Michael Elza. This project was funded in part by NSF grants DEB-0613611 and DEB-1118702 to J.B.M. 


\subsection{Tables and Figures}


Table 5.1. (a-c) Results of Life Table Response Experiments (LTRE) comparing matrices for the two transition periods surrounding a FTC defoliation event at the NY population (a), matrices for the two transition periods surrounding an ice storm at the WKY populations (b) and matrices for the two transition periods surrounding a death of canopy trees due to lightning strike at the EKY population (c). Transitions that contributed significantly to $\Delta \lambda$ are depicted in bold.

\begin{tabular}{|c|c|c|c|c|c|c|c|c|c|}
\hline \multirow{3}{*}{$\begin{array}{c}\text { Vital Rates } \\
\qquad\left(a_{i j}\right)\end{array}$} & \multicolumn{3}{|c|}{ a) NY - FTC Defoliation } & \multicolumn{3}{|c|}{ b) WKY - Ice Storm } & \multicolumn{3}{|c|}{ c) EKY - Lightning Strike } \\
\hline & \multicolumn{3}{|c|}{ Post-disturbance - Pre-disturbance } & \multicolumn{3}{|c|}{ Post-disturbance - Pre-disturbance } & \multicolumn{3}{|c|}{$\underline{\text { Post-disturbance - Pre-disturbance }}$} \\
\hline & $\Delta \mathrm{a}_{\mathrm{ij}}$ & $\mathrm{s}_{\mathrm{ij}}$ & $\Delta \lambda$ & $\Delta \mathrm{a}_{\mathrm{ij}}$ & $S_{i j}$ & $\Delta \lambda$ & $\Delta \mathrm{a}_{\mathrm{ij}}$ & $S_{i j}$ & $\Delta \lambda$ \\
\hline$a_{55}$ & -0.2074 & 0.1691 & -0.0351 & $-\mathbf{0 . 3 3 9 3}$ & 0.2444 & -0.0829 & -0.0938 & 0.1691 & -0.0159 \\
\hline$a_{65}$ & 0.1146 & 0.3482 & 0.0399 & -0.0223 & 0.3034 & -0.0068 & 0.1443 & 0.4375 & 0.0632 \\
\hline$a_{75}$ & 0.0437 & 0.4918 & 0.0215 & 0.1306 & 0.4472 & 0.0584 & -0.0015 & 0.7463 & -0.0011 \\
\hline$a_{85}$ & 0 & 0.6991 & 0 & 0.0707 & 0.5690 & 0.0402 & 0 & 0.9074 & 0 \\
\hline$a_{95}$ & 0 & 0 & 0 & 0.0202 & 0.7414 & 0.0150 & 0 & 1.1916 & 0 \\
\hline $\mathrm{a}_{16}$ & 0.1661 & 0.0269 & 0.0045 & 0 & 0 & 0 & 0.0399 & 0.0304 & 0.0012 \\
\hline$a_{56}$ & 0.0111 & 0.0641 & 0.0007 & -0.2251 & 0.0642 & -0.0144 & -0.0879 & 0.0604 & -0.0053 \\
\hline$a_{66}$ & -0.4037 & 0.1319 & -0.0533 & -0.2900 & 0.0796 & -0.0231 & -0.0364 & 0.1563 & -0.0057 \\
\hline$a_{76}$ & 0.0824 & 0.1863 & 0.0153 & 0.0779 & 0.1174 & 0.0091 & 0.0505 & 0.2667 & 0.0135 \\
\hline$a_{86}$ & 0.2477 & 0.2648 & 0.0656 & 0.2121 & 0.1494 & 0.0317 & 0.0343 & 0.3242 & 0.0111 \\
\hline$a_{96}$ & 0.0723 & 0.3640 & 0.0263 & 0.1515 & 0.1946 & 0.0295 & 0.0152 & 0.4258 & 0.0065 \\
\hline$a_{17}$ & 0.0884 & 0.0125 & 0.0011 & 0.1451 & 0.0534 & 0.0077 & 0.3262 & 0.0158 & 0.0052 \\
\hline$a_{57}$ & 0 & 0 & 0 & -0.0862 & 0.0937 & -0.0081 & 0 & 0.0314 & 0 \\
\hline$a_{67}$ & -0.1551 & 0.0615 & -0.0095 & -0.1758 & 0.1163 & -0.0204 & 0.1084 & 0.0813 & 0.0088 \\
\hline$a_{77}$ & -0.1359 & 0.0869 & -0.0118 & -0.2603 & 0.1714 & -0.0446 & -0.1694 & 0.1387 & -0.0235 \\
\hline$a_{87}$ & 0.0436 & 0.1235 & 0.0054 & 0.0289 & 0.2182 & 0.0063 & -0.0129 & 0.1686 & -0.0022 \\
\hline$a_{97}$ & 0.2487 & 0.1698 & 0.0422 & 0.4344 & 0.2842 & 0.1235 & 0.1097 & 0.2214 & 0.0243 \\
\hline$a_{18}$ & 1.5839 & 0.0154 & 0.0245 & 0.0900 & 0.0243 & 0.0022 & 0.5986 & 0.0154 & 0.0092 \\
\hline$a_{58}$ & 0 & 0.0368 & 0 & 0.0213 & 0.0426 & 0.0009 & 0 & 0.0306 & 0 \\
\hline$a_{68}$ & -0.0161 & 0.0758 & -0.0012 & -0.1167 & 0.0529 & -0.0062 & 0.0426 & 0.0792 & 0.0034 \\
\hline$a_{78}$ & -0.0292 & 0.1071 & -0.0031 & -0.3936 & 0.0780 & -0.0307 & -0.0687 & 0.1351 & -0.0093 \\
\hline $\mathrm{a}_{88}$ & -0.4086 & 0.1522 & -0.0622 & -0.0671 & 0.0993 & -0.0067 & -0.0491 & 0.1643 & -0.0081 \\
\hline $\mathrm{a}_{98}$ & 0.4152 & 0.2092 & 0.0869 & 0.5653 & 0.1293 & 0.0731 & 0.1566 & 0.2158 & 0.0338 \\
\hline$a_{19}$ & 4.2857 & 0.0223 & $\mathbf{0 . 0 9 5 7}$ & 2.3323 & 0.0422 & 0.0985 & -1.1644 & 0.0189 & -0.0220 \\
\hline$a_{69}$ & 0.0208 & 0.1097 & 0.0023 & -0.0952 & 0.0920 & -0.0088 & -0.0142 & 0.0972 & -0.0014 \\
\hline$a_{79}$ & -0.0217 & 0.1550 & -0.0034 & -0.2857 & 0.1356 & -0.0387 & 0 & 0.1657 & 0 \\
\hline$a_{89}$ & -0.0670 & 0.2203 & -0.0148 & 0.0571 & 0.1725 & 0.0099 & -0.0425 & 0.2015 & -0.0086 \\
\hline$a_{99}$ & 0.0272 & 0.3028 & 0.0082 & 0.3143 & 0.2248 & 0.0706 & 0.0182 & 0.2646 & 0.0048 \\
\hline
\end{tabular}


Table 5.2. (a-c). Sum of the change in lambda for each vital rate one transition year before and after insect defoliation at the NY population (a), ice storm at the WKY populations (b) and tree death due to lightning strike at the EKY population (c). Each represents a sum of transitions from a single stage to any of four other stages $\left(\mathrm{a}_{\mathrm{i} 5}, \mathrm{a}_{\mathrm{i} 6}, \mathrm{a}_{\mathrm{i}}\right.$, $\left.\mathrm{a}_{\mathrm{i} 8}, \mathrm{a}_{\mathrm{i} 9}\right)$. Sum of transitions that most contributed to $\Delta \lambda$ are depicted in bold.

\begin{tabular}{|c|c|c|c|}
\hline & a) NY - FTC Defoliation & b) WKY - Ice Storm & c) EKY - Lightning Strike \\
\hline $\begin{array}{l}\text { Vital Rates } \\
\qquad\left(\mathrm{a}_{\mathrm{ii}}\right)\end{array}$ & $\begin{array}{c}\text { Post-disturbance }- \text { Pre-disturbance } \\
\sum \Delta \lambda \underset{\substack{\text { growth } \\
\text { transitions }}}{\Delta}\end{array}$ & $\begin{array}{c}\text { Post-disturbance - Pre-disturbance } \\
\sum \Delta \lambda \underset{\substack{\text { growth } \\
\text { transitions }}}{\Delta}\end{array}$ & $\begin{array}{l}\text { Post-disturbance }- \text { Pre-disturbance } \\
\qquad \Delta \lambda_{\substack{\text { growth } \\
\text { transitions }}}\end{array}$ \\
\hline$a_{i 5}$ & 0.0264 & 0.0239 & 0.0462 \\
\hline$a_{i 6}$ & 0.0547 & 0.0328 & 0.0201 \\
\hline$a_{i 7}$ & 0.0263 & 0.0566 & 0.0074 \\
\hline$a_{i 8}$ & 0.0203 & 0.0305 & 0.0198 \\
\hline$a_{i 9}$ & -0.0076 & 0.0330 & -0.0051 \\
\hline
\end{tabular}




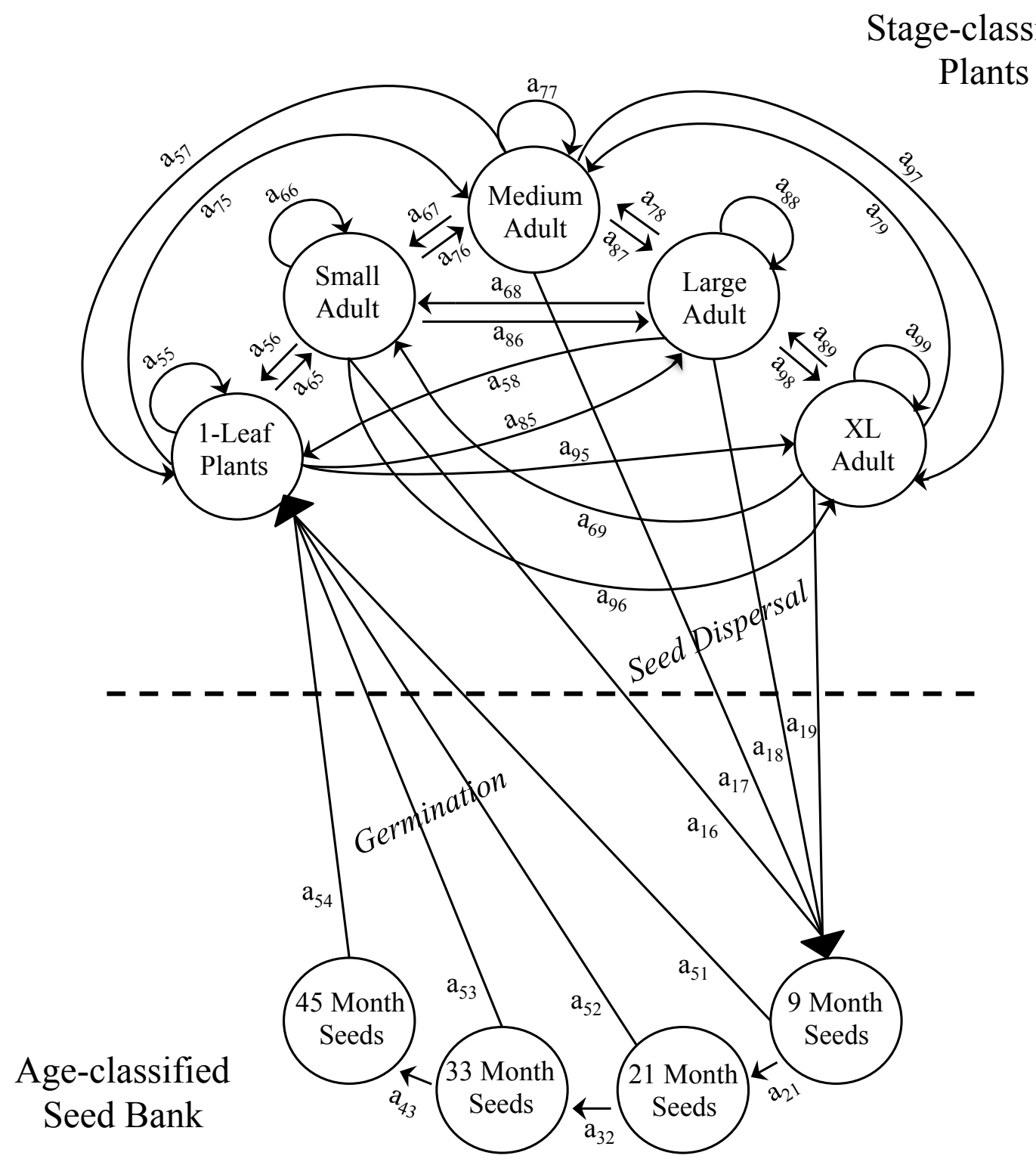

Figure 5.1. Life-cycle stages used for demographic modeling and analysis. The seed bank classes (stages 1-4) was based on seed ages, while the stage-classified portion of the model was based on leaf number for one leaf plants (stage 5) or leaf area for adults (stages 6-9). Arrows indicate all possible life-stage transitions. Stage transition probabilities $\left(\mathrm{a}_{\mathrm{ij}}\right)$ represent the number of individuals $(i)$ in each stage at the spring census in year $t+1$ per individual size $(j)$ at the spring census in year $t$. 
(a)

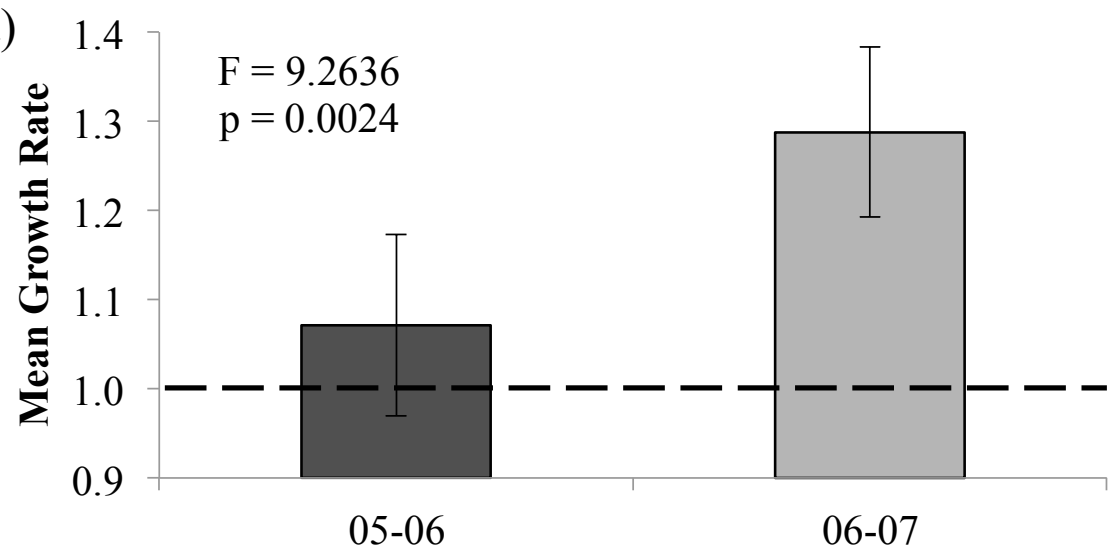

(b)
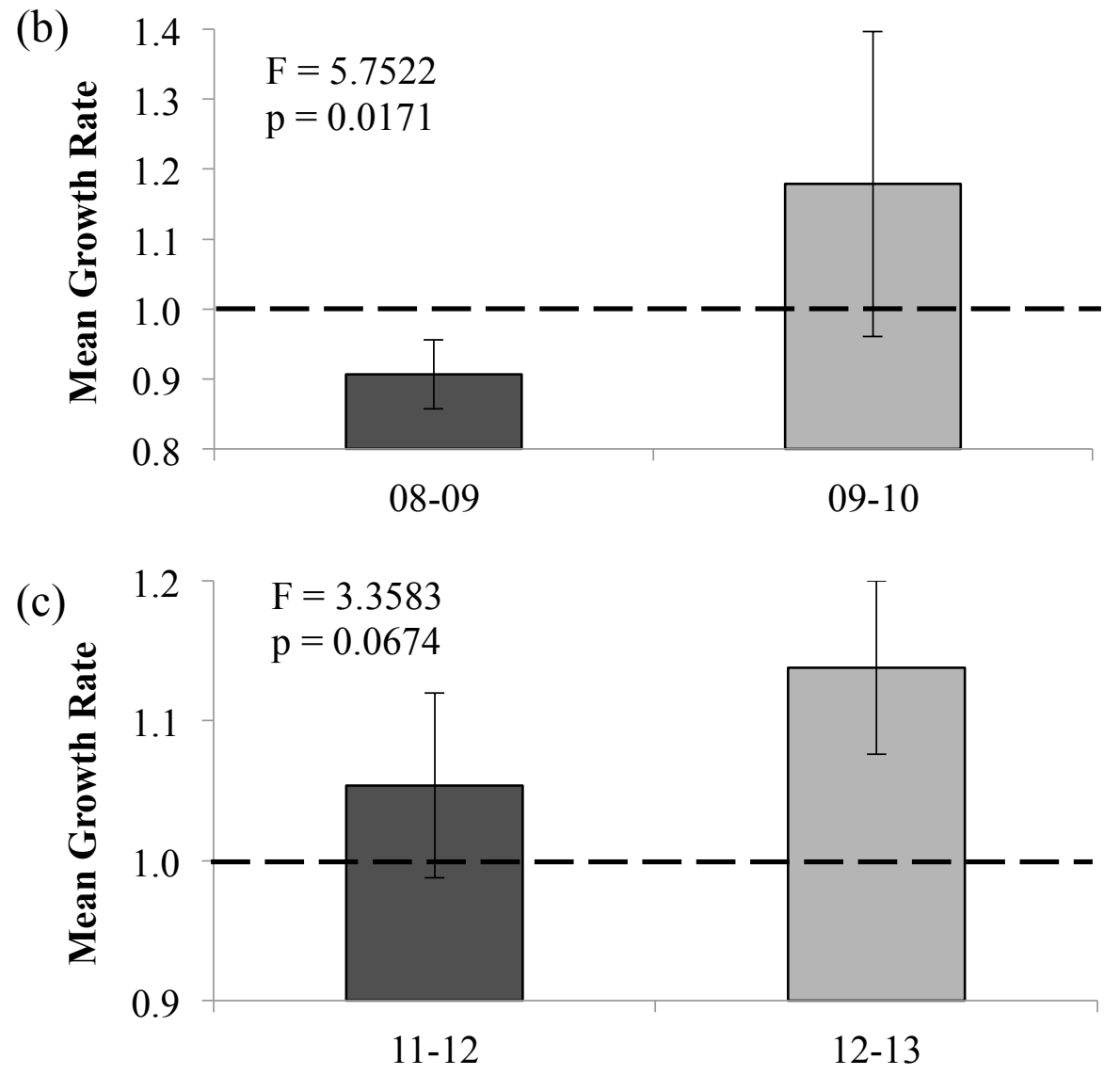

Transition Years

Figure 5.2. Mean population growth rate $\left(\bar{\phi}_{i}\right)$ for the transition period not affected by canopy disturbance and for the subsequent transition period affected by canopy disturbance for: the NY population that incurred forest tent caterpillar defoliation (a), the WKY populations whose canopies were damaged by a severe ice storm (b) and the EKY population whose canopy was damaged by a lightning strike (c). The horizontal dashed line represents $\lambda=1$, above which populations are growing and below which populations are decreasing. 

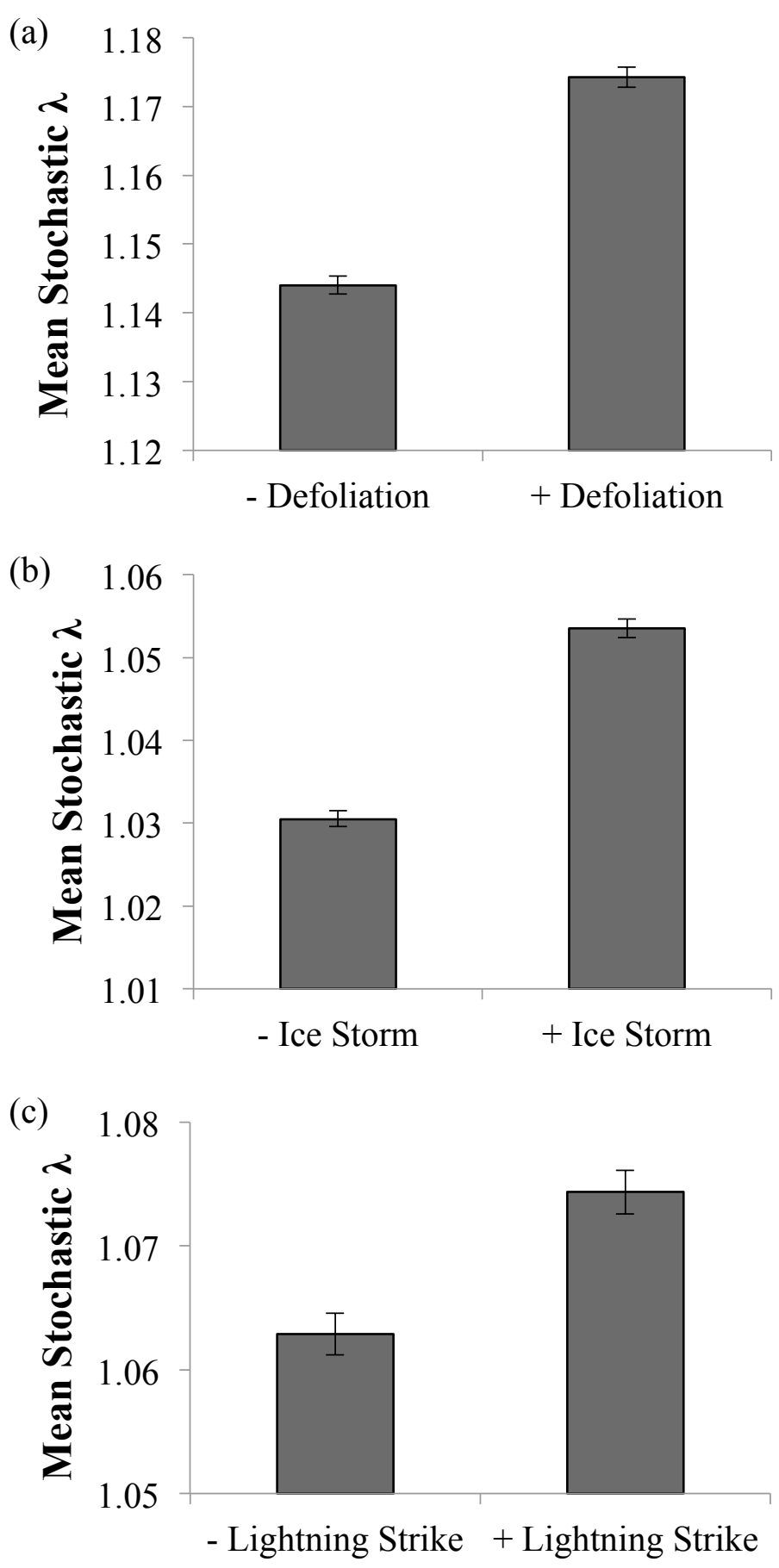

Figure 5.3. Mean stochastic population growth rates (+/- 95\% C.I.) for: the NY population that incurred forest tent caterpillar defoliation (a), the WKY populations whose canopies were damaged by a severe ice storm (b) and the EKY population whose canopy was damaged by a lightning strike (c). 
(a)

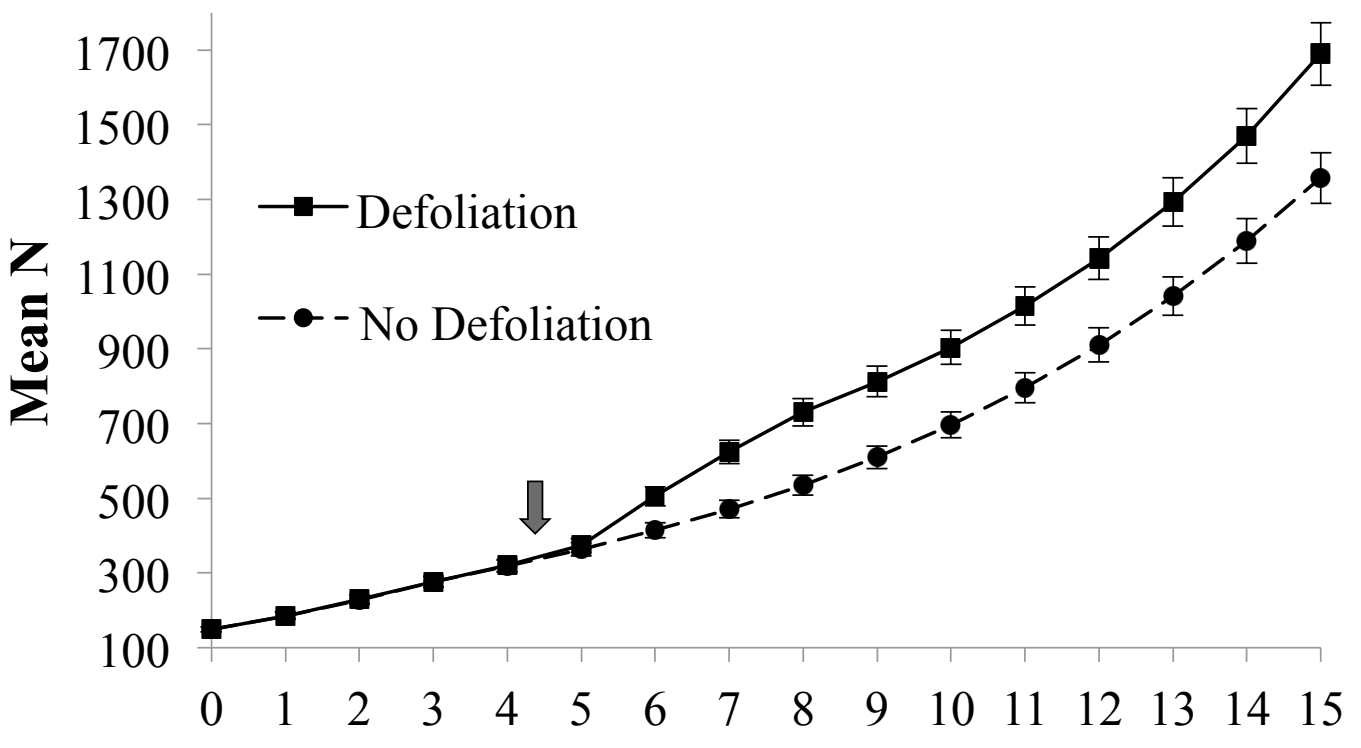

(b)

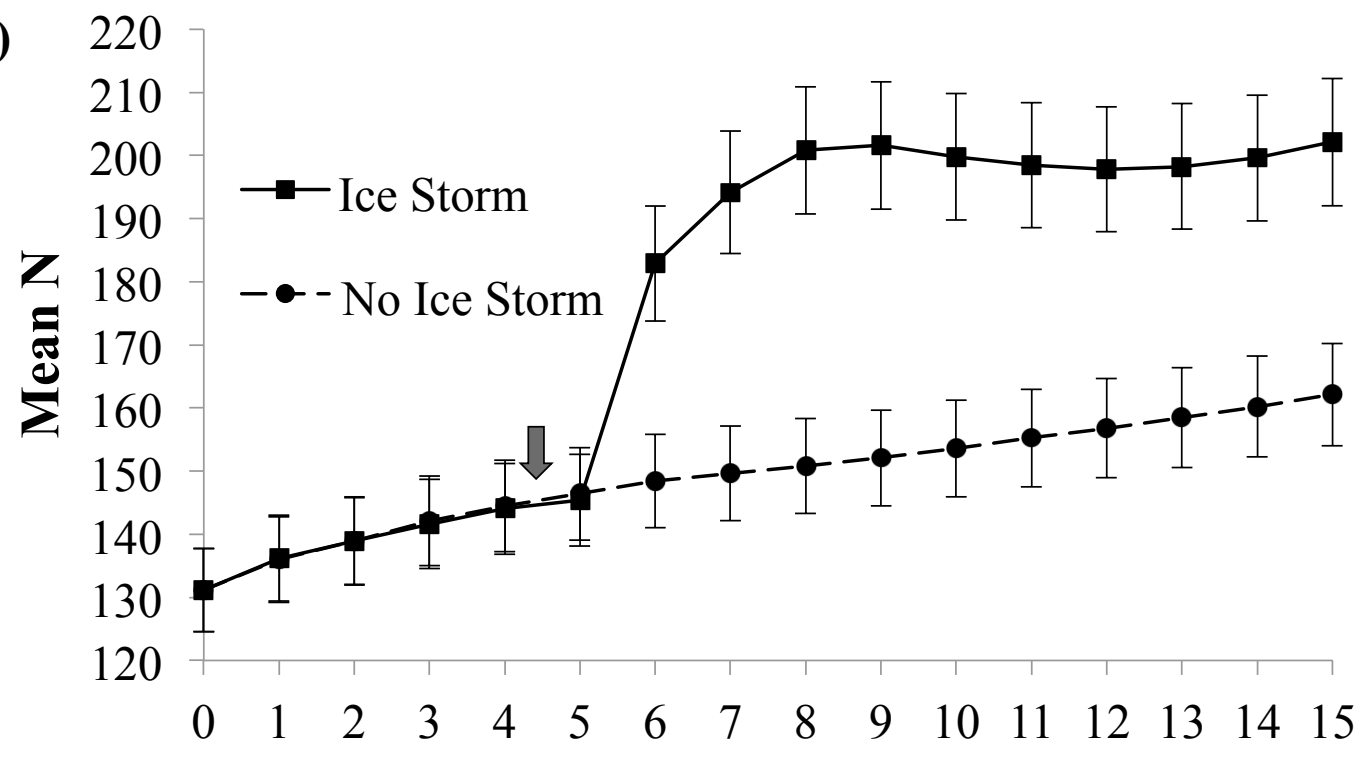

(c)

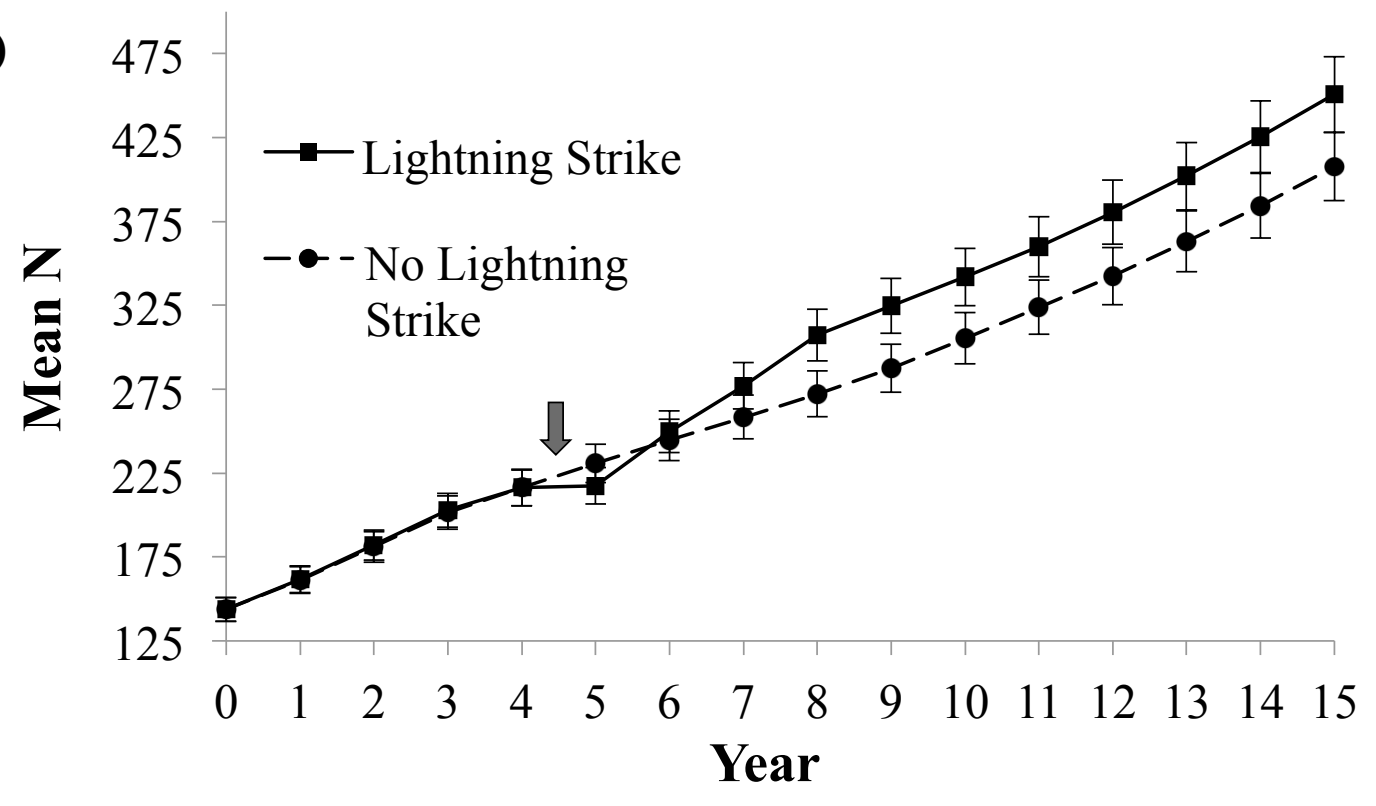


Figure 5.4. Mean population size projected over fifteen years using transient population dynamic simulations for the NY population that incurred forest tent caterpillar defoliation (a), the WKY populations that incurred canopy damage from an ice storm (b) and the EKY population that incurred canopy damage from a lightning strike (c). For each of the three disturbance types, 10,000 runs were performed with the disturbance matrices included in the model and 10,000 runs were performed with the disturbance matrices excluded. Vertical arrow represents the insertion of the post disturbance matrix reflecting the canopy opening. 
(a)

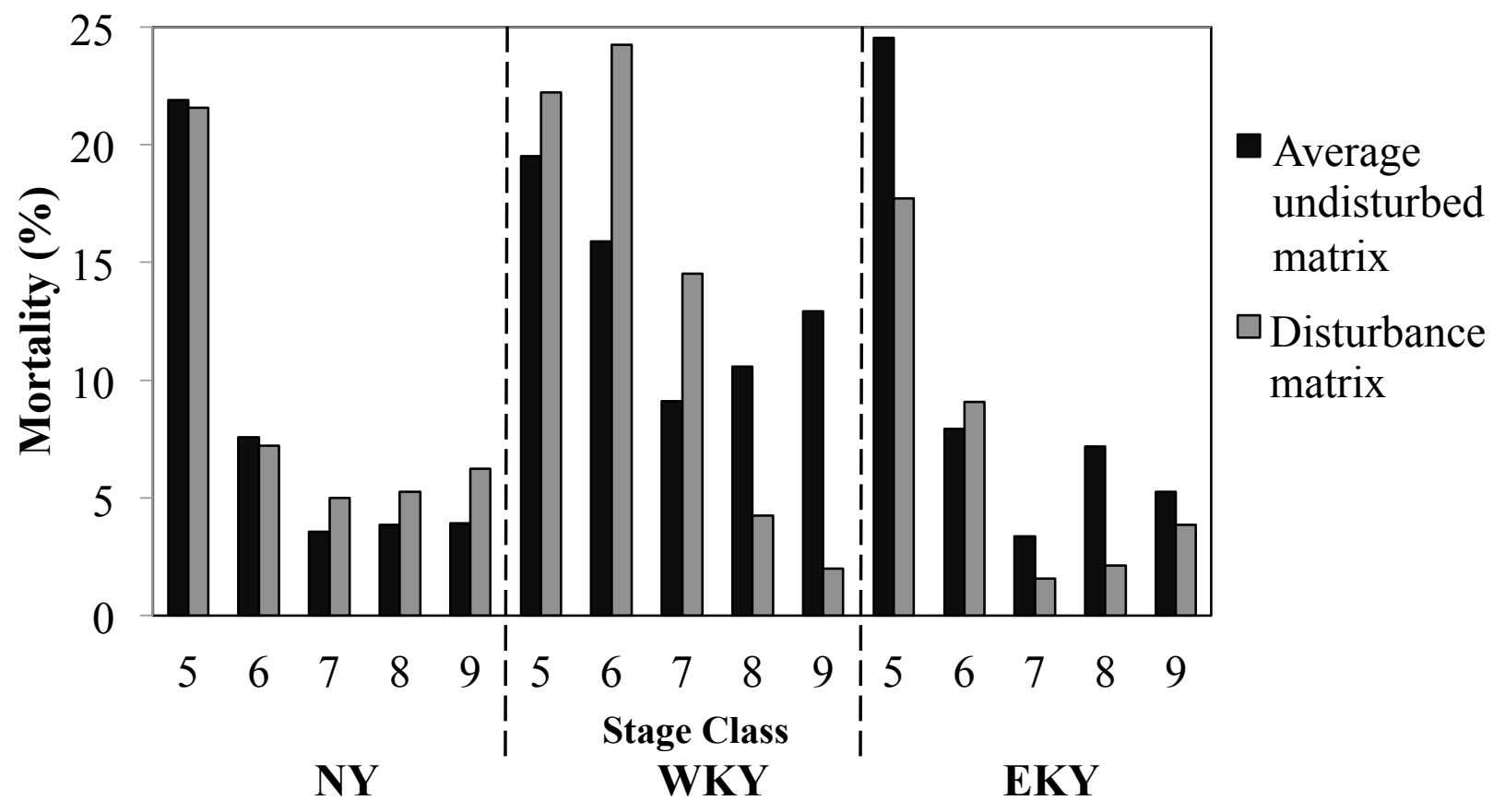

(b)

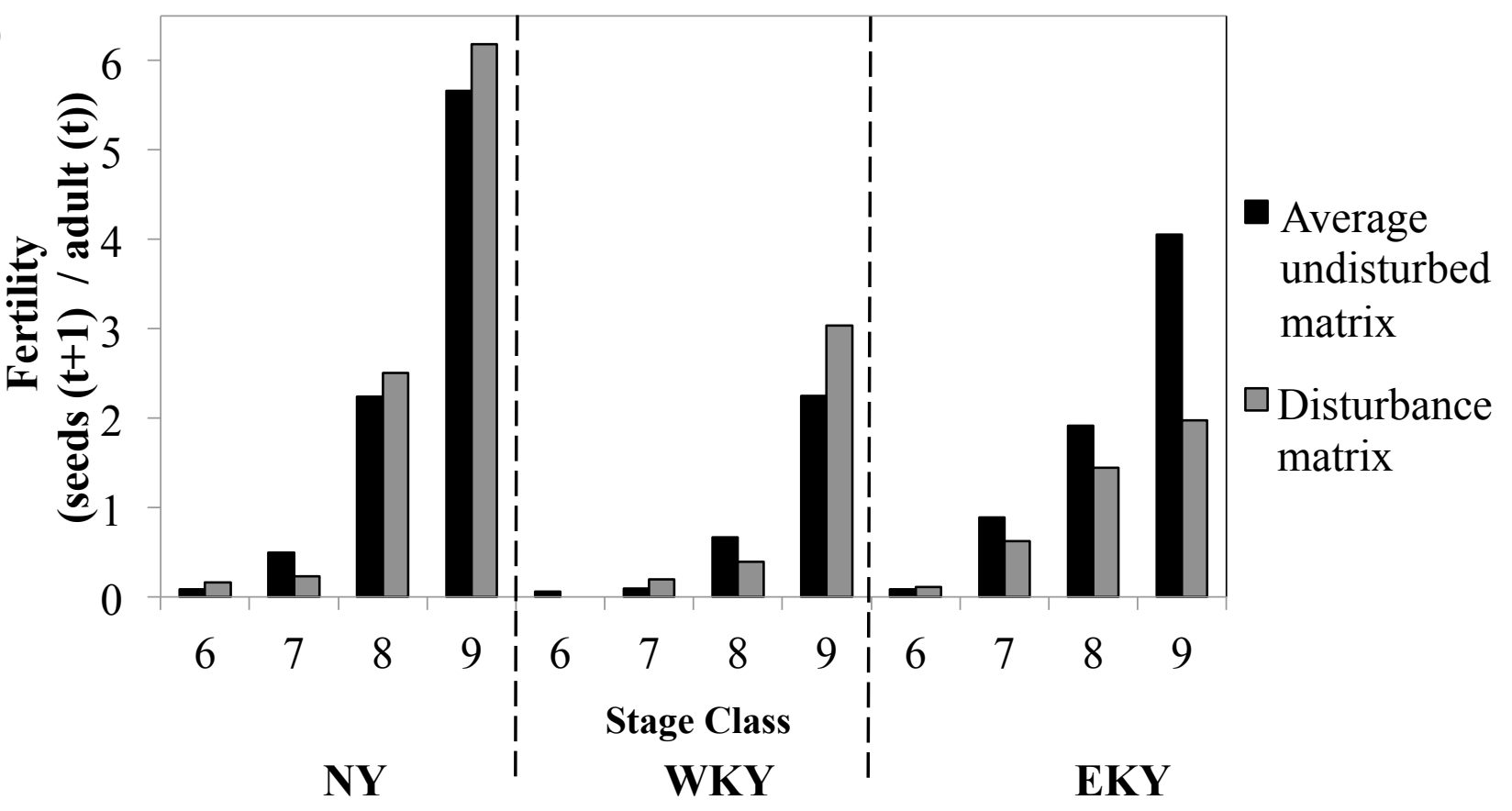

Figure 5.5. Percent mortality for the average undisturbed matrix and for the matrix representing the disturbance period (a) and fertility for the average undisturbed matrix and for the matrix representing the disturbance period (b) for each of the three populations (NY, WKY and EKY). All aboveground stage classes (5, 6, 7, 8 and 9) are depicted in the figure that quantifies mortality (a), while only reproductive aboveground stage classes $(6,7,8$ and 9$)$ are depicted in the figure that quantifies fertility (b). 


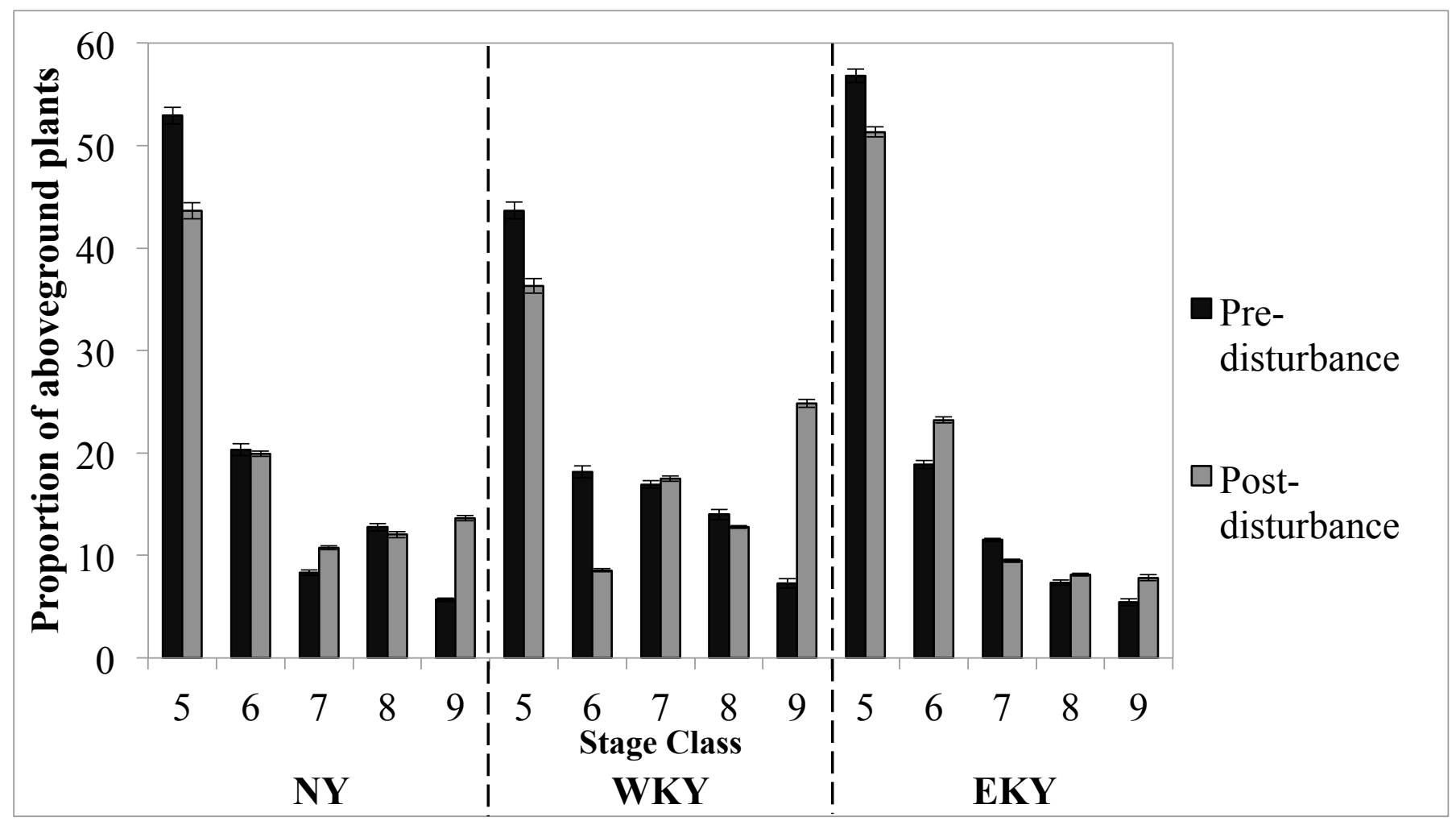

Figure 5.6. Proportion of plants in each of the five aboveground stages (5, 6, 7, 8 and 9) for the pre-disturbance period (Year 4) and the post-disturbance period (Year 5) for each of the three populations (NY, WKY and EKY). 


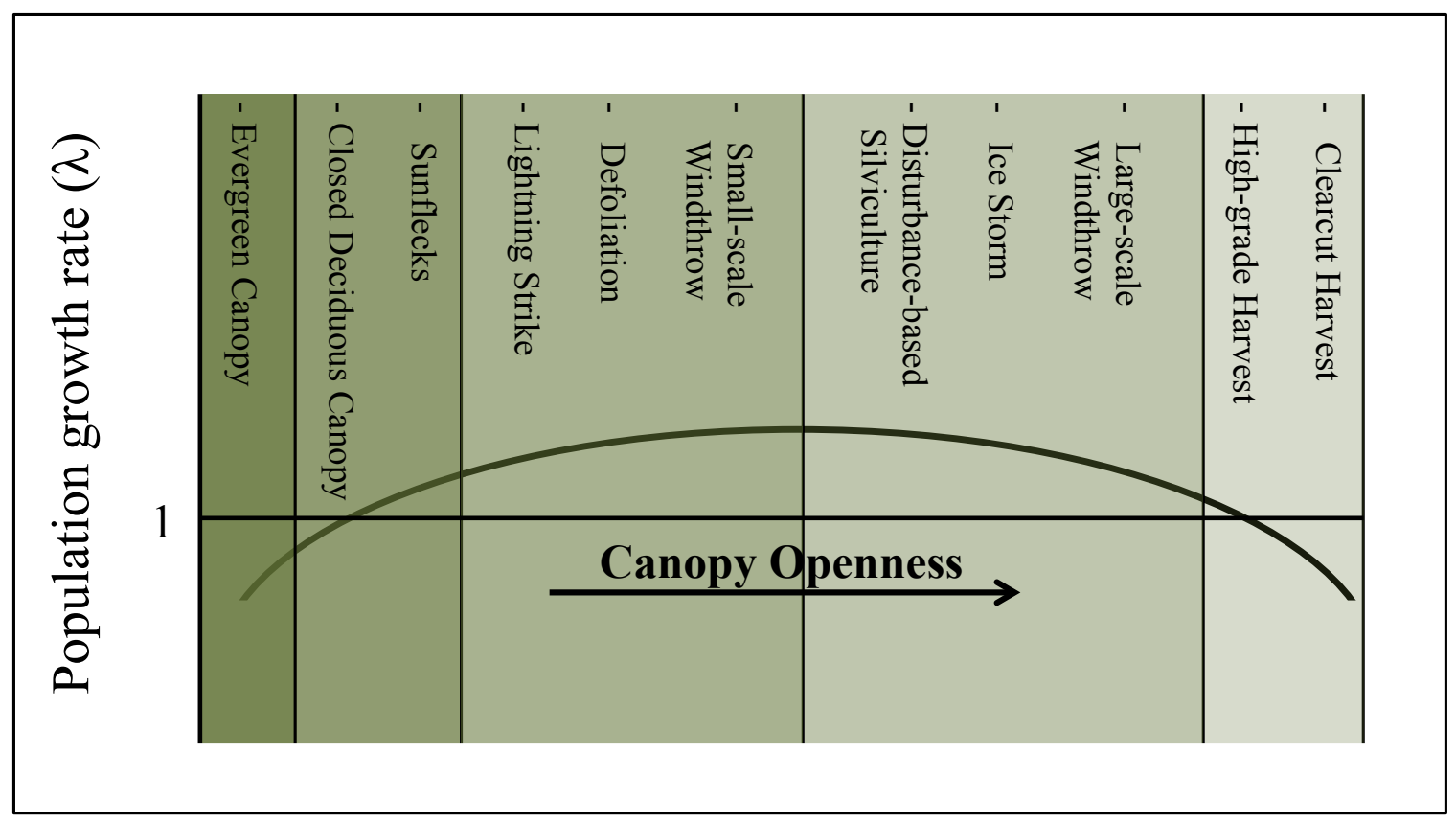

Figure 5.7. Theoretical model illustrating the population-level response of $P$. quinquefolius to varying levels of canopy openness. Specific forest types and specific types of disturbances are offered as examples of corresponding level of canopy openness. 


\subsection{Literature Cited}

Anderson, R.C., Fralish, J.S., Armstrong, J.E. \& Benjamin, P.K. (1993) The ecology and biology of Panax quinquefolium L. (Araliaceae) in Illinois. American Midland Naturalist, 129, 357-372.

Babst, F., Alexander, M.R., Szejner, P., Bouriaud, O., Klesse, S., Roden, J., Ciais, P., Poulter, B., Frank, D., Moore, D.J.P. \& Trouet, V. (2014) A tree-ring perspective on the terrestrial carbon cycle. Oecologia, 176, 307-322.

Baker, W. (1995) Long-term response of disturbance landscapes to human intervention and global change. Landscape Ecology, 10, 143-159.

Battisti, A., Stastny, M., Buffo, E. \& Larsson, S. (2006) A rapid altitudinal range expansion in the pine processionary moth produced by the 2003 climatic anomaly. Global Change Biology, 12, 662-671.

Beckage, B., Clark, J.S., Clinton, B.D. \& Haines, B.L. (2000) A long-term study of tree seedling recruitment in southern Appalachian forests: The effects of canopy gaps and shrub understories. Canadian Journal of Forest Research, 30, 1617-1631.

Bellard, C., Bertelsmeier, C., Leadley, P., Thuiller, W. \& Courchamp, F. (2012) Impacts of climate change on the future of biodiversity. Ecology Letters, 15, 365-377.

Bentz, B., Logan, J., MacMahon, J., Allen, C.D., Ayres, M., Berg, E., Carroll, A., Hansen, M., Hicke, J., Joyce, L., Macfarlane, W., Munson, S., Negron, J., Paine, T., Powell, J., Raffa, K., Regniere, J., Reid, M., Romme, B., Seybold, S.J., Six, D., Tomback, D., Vandygriff, J., Veblen, T., White, M., Witcosky, J. \& Wood, D. (2009) Bark beetle outbreaks in western North America: causes and consequences. Bark Beetle Symposium.

Bentz, B., Regniere, J., Fettig, C., Hansen, M., Hayes, J., Hicke, J., Kelsey, R., Negron, J. $\&$ Seybold, S. (2010) Climate change and bark beetles of the Western United States and Canada: Direct and indirect effects. BioScience, 60, 602-613.

Brooks, H.E. (2013) Severe thunderstorms and climate change. Atmospheric Research, 123, 129-138.

Cannell, M. \& Smith, R. (1986) Climatic warming, spring budburst and frost damage on trees. Journal of Applied Ecology, 23, 177-191.

Carpenter, S.G. \& Cottam, G. (1982) Growth and reproduction of American ginseng (Panax quinquefolius) in Wisconsin, U.S.A. Canadian Journal of Botany, 60, 26922696.

Caswell, H. (1989) Matrix Population Models. Sinauer Associates, Sunderland, Massachusetts.

Caswell, H. (2001) Matrix Population Models: Construction, Analysis, and Interpretation, 2nd ed. Sinauer Associates, Sunderland, Massachusetts.

Chandler, J.L. \& McGraw, J.B. (2015) Variable effects of timber harvest on the survival, 
growth, and reproduction of American ginseng (Panax quinquefolius L.). Forest Ecology and Management, 344, 1-9.

Chandler, J.L., McGraw, J.B., Bennington, C., Shaver, G.R., Vavrek, M.C. \& Fetcher, N. (2015) Tiller population dynamics of reciprocally transplanted Eriophorum vaginatum L. ecotypes in a changing climate. Population Ecology, 57, 117-126.

Charron, D. \& Gagnon, D. (1991) The demography of northern populations of Panax quinquefolium (American ginseng). Journal of Ecology, 79, 431-445.

Chazdon, R.L. (1988) Sunflecks and their importance to forest understory plants. Advances in Ecological Research (eds M. Begon),, A.H. Fitter),, E.D. Ford), \& A. Macfadyes), pp. 1-63. Academic Press Limited, San Diego.

Chazdon, R.L. \& Pearcy, R.W. (1991) The importance of sunflecks for forest understory plants. BioScience, 41, 760-766.

Dale, V.H., Joyce, L.A., McNulty, S., Neilson, R.P., Ayres, M.P., Flannigan, M.D., Hanson, P.J., Irland, L.C., Lugo, A.E., Peterson, C.J., Simberloff, D., Swanson, F.J., Stocks, B.J. \& Wotton, B.M. (2001) Climate change and forest disturbances. BioScience, 51, 723-734.

Darwin, A.T., Ladd, D., Galdins, R., Contreras, T.A. \& Fahrig, L. (2004) Response of forest understory vegetation to a major ice storm. Journal of the Torrey Botanical Society, 131, 45-52.

Dukes, J.S., Pontius, J., Orwig, D., Garnas, J.R., Rodgers, V.L., Brazee, N., Cooke, B., Theoharides, K.A., Stange, E.E., Harrington, R., Ehrenfeld, J., Gurevitch, J., Lerdau, M., Stinson, K., Wick, R. \& Ayres, M. (2009) Responses of insect pests, pathogens, and invasive plant species to climate change in the forests of northeastern North America: What can we predict? Canadian Journal of Forest Research, 39, 231-248.

Elza, M.C., Slover, C. \& McGraw, J.B. (2015) Analysis of wood thrush (Hylocichla mustelina) movement patterns to explain the spatial structure of American ginseng (Panax quinquefolius) populations. Ecological Research, 31, 195-201.

Ezard, T.H.G., Bullock, J.M., Dalgleish, H.J., Millon, A., Pelletier, F., Ozgul, A. \& Koons, D.N. (2010) Matrix models for a changeable world: The importance of transient dynamics in population management. Journal of Applied Ecology, 47, 515523.

Fournier, A.R., Gosselin, A., Proctor, J.T.A., Gauthier, L., Khanizadeh, S. \& Dorais, M. (2004) Relationship between understory light and growth of forest-grown American ginseng (Panax quinquefolius L.). Journal of the American Society for Horticultural Science, 129, 425-432.

Frost, C.J. \& Hunter, M.D. (2004) Insect canopy herbivory and frass deposition affect soil nutrient dynamics and export in oak mesocosms. Ecology, 85, 3335-3347.

Furedi, M.A. (2004) Effects of Herbivory by White-Tailed Deer (Odocoileus Virginianus Zimm.) on the Population Ecology and Conservation Biology of American Ginseng (Panax Quinquefolius L.). West Virginia University. 
Le Gouallec, J.L., Cornic, G. \& Blanc, P. (1990) Relations between sunfleck sequences and photoinhibition of photosynthesis in a tropical rain forest understory herb. American Journal of Botany, 77, 999-1006.

Hackney, E.E. \& McGraw, J.B. (2001) Experimental demonstration of an allee effect in American ginseng. Conservation Biology, 15, 129-136.

Harrington, R., Woiwod, I. \& Sparks, T. (1999) Climate change and trophic interactions. Trends in Ecology \& Evolution, 14, 146-150.

Hastings, A. (2001) Transient dynamics and persistence of ecological systems. Ecology Letters, 4, 215-220.

Hruska, A.M., Souther, S. \& McGraw, J.B. (2014) Songbird dispersal of American ginseng (Panax quinquefolius). Ecoscience, 21, 46-55.

Hunter, M.D. (2001) Insect population dynamics meets ecosystem ecology: Effects of herbivory on soil nutrient dynamics. Agricultural and Forest Entomology, 3, 77-84.

Hunter, C.M., Caswell, H., Runge, M.C., Regehr, E. V, Amstrup, S.C. \& Stirling, I. (2010) Climate change threatens polar bear populations: A stochastic demographic analysis. Ecology, 91, 2883-2897.

IPCC. (2007) Climate Change 2007: Impacts, Adaptation and Vulnerability. Contribution of Working Group II to the Fourth Assessment Report of the Intergovernmental Panel on Climate Change (eds M. Parry),, O. Canziani),, J. Palutikof),, P. van der Linden), \& C. Hanson), Cambridge University Press, Cambridge and New York.

Irland, L.C. (2000) Ice storms and forest impacts. Science of the Total Environment, 262, 231-242.

Jönsson, A.M., Linderson, M.-L., Stjernquist, I., Schlyter, P. \& Bärring, L. (2004) Climate change and the effect of temperature backlashes causing frost damage in Picea abies. Global and Planetary Change, 44, 195-207.

Klutsch, J.G., Negrón, J.F., Costello, S.L., Rhoades, C.C., West, D.R., Popp, J. \& Caissie, R. (2009) Stand characteristics and downed woody debris accumulations associated with a mountain pine beetle (Dendroctonus ponderosae Hopkins) outbreak in Colorado. Forest Ecology and Management, 258, 641-649.

Knohl, A., Schulze, E.-D., Kolle, O. \& Buchmann, N. (2003) Large carbon uptake by an unmanaged 250-year-old deciduous forest in Central Germany. Agricultural and Forest Meteorology, 118, 151-167.

Koons, D.N., Grand, J.B., Zinner, B. \& Rockwell, R.F. (2005) Transient population dynamics: Relations to life history and initial population state. Ecological Modelling, 185, 283-297.

Kunkel, K., Bromirski, P., Brooks, H., Cavazos, T., Douglas, A. \& Easterling, D.R. (2008) Observed changes in weather and climate extremes. Weather and climate extremes in a changing climate. Regions of focus: North America, Hawaii, Caribbean, and U.S. Pacific Islands (eds T. Karl),, G. Meehl), C. Miller),, S. Hassol),, A. Waple), \& W. Murray), pp. 35-80. Washington, D.C. 
Kursar, T.A. \& Coley, P.D. (1993) Photosynthetic induction times in shade-tolerant species with long and short-lived leaves. Oecologia, 93, 165-170.

Lewis, W.H. \& Zenger, V.E. (1982) Population dynamics of the American ginseng Panax quinquefolium (Araliaceae). American Journal of Botany, 69, 1483-1490.

Liechty, H., Holmes, M., Reed, D. \& Mroz, G. (1992) Changes in microclimate after stand conversion in two northern hardwood stands. Forest Ecology and Management, 50, 253-264.

Linkosalo, T., Carter, T.R., Häkkinen, R. \& Hari, P. (2000) Predicting spring phenology and frost damage risk of Betula spp. under climatic warming: A comparison of two models. Tree Physiology, 20, 1175-1182.

Logan, J.A., Régnière, J. \& Powell, J.A. (2003) Assessing the impacts of global warming on forest pest dynamics. Frontiers in Ecology and the Environment, 1, 130-137.

Manabe, T., Shimatani, K., Kawarasaki, S., Aikawa, S.-I. \& Yamamoto, S.-I. (2009) The patch mosaic of an old-growth warm-temperate forest: Patch-level descriptions of 40-year gap-forming processes and community structures. Ecological Research, 24, $575-586$.

MathWorks. (2015) MATLAB.

McGraw, J.B. (1989) Effects of age and size on life histories and population growth of Rhododendron maximum shoots. American Journal of Botany, 76, 113-123.

McGraw, J.B. \& Furedi, M.A. (2005) Deer browsing and population viability of a forest understory plant. Science, 307, 920-922.

McGraw, J.B., Lubbers, A.E., Van der Voort, M., Mooney, E.H., Furedi, M.A., Souther, S., Turner, J.B. \& Chandler, J. (2013) Ecology and conservation of ginseng (Panax quinquefolius) in a changing world. Annals of the New York Academy of Sciences, 62-91.

Mooney, E.H. \& McGraw, J.B. (2009) Relationship between age, size, and reproduction in populations of American ginseng, Panax quinquefolius (Araliaceae), across a range of harvest pressures. Ecoscience, 16, 84-94.

Morris, W.F. \& Doak, D.F. (2002) Quantitative Conservation Biology: Theory and Practice of Population Viability Analysis (eds WF Morris and DF Doak). Sinauer Associates, Sunderland, Massachusetts.

Muscolo, A., Bagnato, S., Sidari, M. \& Mercurio, R. (2014) A review of the roles of forest canopy gaps. Journal of Forestry Research, 25, 725-736.

Nantel, P., Gagnon, D. \& Nault, A. (1996) Population viability analysis of American ginseng and wild leek harvested in stochastic environments. Conservation Biology, 10, 608-621.

Neufeld, H. \& Young, D. (2014) Ecophysiology of the herbaceous layer in temperate deciduous forests. The Herbaceous Layer in Forests of Eastern North America, 2nd ed (ed F.S. Gilliam), pp. 35-95. Oxford University Press, New York. 
North, M.P. \& Keeton, W.S. (2008) Emulating natural disturbance regimes: An emerging approach for sustainable forest management. Patterns and Processes in Forest Landscapes pp. 341-372. Springer, Netherlands.

Oláh, R. \& Masarovičová, E. (1997) Response of CO2 uptake, chlorophyll content, and some productional features of forest herb Smyrnium perfoliatum L. (Apiaceae) to different light conditions. Acta Physiologiae Plantarum, 19, 285-293.

Parmenter, G. \& Littlejohn, R. (2000) Effect of shade on growth and photosynthesis of Panax ginseng. New Zealand Journal of Crop and Horticultural Science, 28, 255269.

Parmesan, C. (2006) Ecological and evolutionary responses to recent climate change. Annual Review of Ecology, Evolution, and Systematics, 37, 637-669.

Ramula, S., Rees, M. \& Buckley, Y.M. (2009) Integral projection models perform better for small demographic data sets than matrix population models: a case study of two perennial herbs. Journal of Applied Ecology, 46, 1048-1053.

Roberts, M.R. (2004) Response of the herbaceous layer to natural disturbance in North American forests. Canadian Journal of Botany, 82, 1273-1283.

Roberts, M.R. \& Gilliam, F.S. (2014) Response of the herbaceous layer to disturbance in eastern forests. The Herbaceous Layer in Forests of Eastern North America, 2nd ed (ed F.S. Gilliam), pp. 321-340. Oxford University Press, Oxford.

Ryan, M.G., Archer, S.R., Birdsey, R., Dahm, C., Heath, L., Hicke, J., Hollinger, D., Huxman, T., Okin, G., Oren, R., Randerson, J. \& Schlesinger, W. (2008) Land Resources: Forest and Arid Lands. Washington, D.C.

Scanga, S.E. (2014) Population dynamics in canopy gaps: Nonlinear response to variable light regimes by an understory plant. Plant Ecology, 215, 927-935.

Sletvold, N., Dahlgren, J.P., Øien, D.I., Moen, A. \& Ehrlén, J. (2013) Climate warming alters effects of management on population viability of threatened species: Results from a 30-year experimental study on a rare orchid. Global Change Biology, 19, 2729-2738.

Souther, S., Lechowicz, M.J. \& McGraw, J.B. (2012) Experimental test for adaptive differentiation of ginseng populations reveals complex response to temperature. Annals of Botany, 110, 829-837.

Souther, S. \& McGraw, J.B. (2011a) Vulnerability of wild American ginseng to an extreme early spring temperature fluctuation. Population Ecology, 53, 119-129.

Souther, S. \& McGraw, J.B. (2011b) Evidence of local adaptation in the demographic response of American ginseng to interannual temperature variation. Conservation Biology, 25, 922-31.

Souther, S. \& McGraw, J.B. (2014) Synergistic effects of climate change and harvest on extinction risk of American ginseng. Ecological Applications, 24, 1463-1477.

Spies, T.A., Hemstrom, M.A., Youngblood, A. \& Hummel, S. (2006) Conserving old- 
growth forest diversity in disturbance-prone landscapes. Conservation Biology, 20, 351-362.

Taylor, A.R. (1971) Lightning - Agents of change in the forest ecosystems. Journal of Forestry, 69, 476-480.

Thomas, C.D., Cameron, A., Green, R.E., Bakkenes, M., Beaumont, L.J., Collingham, Y.C., Erasmus, B.F.N., de Siqueira, M.F., Grainger, A., Hannah, L., Hughes, L., Huntley, B., van Jaarsveld, A.S., Midgeley, H.F., Miles, L., Ortega-Huerta, M.A., Peterson, A.T., Philips, O.L. \& Williams, S.E. (2004) Extinction risk from climate change. Nature, 427, 145-148.

Trapp, R.J., Diffenbaugh, N.S., Brooks, H.E., Baldwin, M.E., Robinson, E.D. \& Pal, J.S. (2007) Changes in severe thunderstorm environment frequency during the 21st century caused by anthropogenically enhanced global radiative forcing. Proceedings of the National Academy of Sciences of the United States of America, 104, 1971919723.

Tremblay, R.L., Raventos, J. \& Ackerman, J.D. (2015) When stable-stage equilibrium is unlikely: Integrating transient population dynamics improves asymptotic methods. Annals of Botany, 116, 381-390.

Turner, M.G., Baker, W.L., Peterson, C.J. \& Peet, R.K. (1998) Factors influencing succession: Lessons from large, infrequent natural disturbances. Ecosystems, 1, 511523.

Vavrek, M.C., McGraw, J.B. \& Yang, H.S. (1996) Within-population variation in demography of Taraxacum officinale: Maintenance of genetic diversity. Ecology, 77, 2098-2107.

Van der Voort, M.E. \& McGraw, J.B. (2006) Effects of harvester behavior on population growth rate affects sustainability of ginseng trade. Biological Conservation, 130, 505-516.

Vowels, K.M. (2012) Ice storm damage to upland oak-hickory forest at Bernheim Forest, Kentucky. The Journal of the Torrey Botanical Society, 139, 406-415.

Wagner, A. \& McGraw, J.B. (2013) Sunfleck effects on physiology, growth, and local demography of American ginseng (Panax quinquefolius L.). Forest Ecology and Management, 291, 220-227.

Whigham, D. (2004) Ecology of woodland herbs in temperate deciduous forests. Annual Review of Ecology, Evolution, and Systematics, 35, 583-621.

White, P.S. (1979) Pattern, process, and natural disturbance in vegetation. Botanical Review, 45, 229-299.

White, P.. \& Pickett, S.T.. (1985) Natural disturbance and patch dynamics: an introduction. The Ecology of Natural Disturbance and Patch Dynamics (eds S.T.A. Pickett), \& P.S. White), pp. 3-13. Academic Press, Orlando.

Williams, D. \& Liebhold, A. (1995) Forest defoliators and climatic change: Potential changes in spatial distribution of outbreaks of western spruce budworm 
(Lepidoptera: Tortricidae) and gypsy moth (Lepidoptera: Lymantriidae).

Environmental Entomology, 24, 1-9. 


\section{Chapter 6. General Conclusion}


The effects that humans have on natural landscapes are often profound. Current anthropogenic activities are altering natural disturbance regimes that maintained resource heterogeneity and biodiversity in the past, and are shaping disturbance regimes that are often greater in frequency, spatial extent, and severity (Sousa 1984b, Dale et al. 2000). Two common forms of anthropogenic influences affecting forests worldwide are direct disturbance caused by timber harvest, and changes in natural disturbance regimes caused indirectly by climate shifts. Forest disturbances affect a multitude of processes, including canopy dynamics, mid-story and understory growth, forest floor and soil properties, and competition within and among forest strata (Roberts 2004). Changes in the distribution, extent, frequency, and severity of disturbance events are already affecting forest species and communities (Dale et al. 2001). However, ambiguity remains concerning the general response of the herbaceous layer to disturbances across a wide range of environmental conditions, especially in regard to timber harvest (Gilliam 2007). This research quantified the multidimensional response of a model understory herb, American ginseng, to varying intensities of discrete canopy disturbances.

To determine if patterns in canopy openness and relative closure above the herbaceous layer differed based on the intensity of timber harvests implemented, I analyzed openness from the perspective of ginseng immediately before and after three common partial harvest strategies. As expected, absolute canopy openness varied the growing season directly after timber harvest, with openness being greatest after the patch cut harvest (Chapter 2). Relative canopy closure two growing seasons after timber harvest was rapid on all sites, but contrary to my original hypothesis, was not greatest following the patch cut harvest. Instead, relative closure was most pronounced on the site 
where timber was removed using a $30.5 \mathrm{~cm}$ diameter limit harvest (site 41). Canopy closure was particularly high on this site due to rapid, dense growth of weedy and invasive species (Chapter 2).

Canopy openness in the herbaceous layer two growing seasons after timber harvest was lower than reported in a study that measured the same variable from $5 \mathrm{~m}$ above the forest floor (Beaudet and Messier 2002). The understory strongly alters light penetration in canopy gaps, and the patterns of gap closure in the understory differed from higher strata because herbaceous plants experienced more dense overtopping from multiple strata, including plants that co-exist within the understory (Canham et al. 1990, Beaudet et al. 2004). Canopy dynamics surrounding disturbance events strongly affect the growth, reproduction, and general demography of understory species (as reviewd by Valverde and Silvertown 1997). Moderately severe canopy disturbances, such as the ones examined in Chapter 2, produce an intermediate pulse of light in the understory that may be longer lasting than those produced by high-severity disturbances, particularly when competition from shade-intolerant species is relaxed. As a result, frequent moderate disturbances could lead to increases in the duration and degree of stimulation in understory herbs.

Species stress responses may not manifest in the same ways at different levels of organization, and because of this, it is important to quantify species response to canopy disturbance on physiological, individual, and demographic levels. Chapters 3, 4, and 5 accomplished this goal by analyzing multiple levels of response to canopy disturbances that vary both in their severity and in their source; direct anthropogenic canopy 
disturbance via timber harvest, and natural canopy disturbances whose frequency, severity, and spatial extent are being indirectly affected by anthropogenic climate shifts.

Previous research suggests that American ginseng is adapted to the heterogeneous light regimes of old growth forests, which include spatially and temporally varying sunflecks and dynamic canopy gap formations and closures (Knohl et al. 2003, Spies et al. 2006, Manabe et al. 2009, Wagner and McGraw 2013). Unknown, however, was whether sudden and more intense increases in light availability caused by timber harvest would be a physiological stressor to ginseng or whether this addition of light would produce physiological benefits in terms of carbon accumulation and growth. To resolve this uncertainty, I quantified the effects of a patch cut timber harvest on ginseng physiology and growth (Chapter 3). Individuals displayed signs of leaf-level stress the first growing season following harvest, including reddened, desiccated leaves, higher respiration, and early senescence. Further, ginseng survival was lower following the patch-cut harvest than was observed at other, undisturbed populations. However, leaf respiration was not elevated two growing seasons after timber harvest, and maximum rate of photosynthesis was higher than both the year before and the year after harvest, with photosynthesis being $67 \%$ higher two years after harvest relative to the year before harvest, indicating that individuals had acclimated to the higher light environment (Chapter 3). Additionally, initial decreases in survival were mediated by significant increases in growth rate above-and-beyond those of undisturbed populations. In fact, the relative growth rate of individuals after the patch cut was ca. twice that of relative growth at nearby uncut control populations during the same time period. Despite initial stress caused by timber harvest, transient, intense increases in light availability following 
harvest could provide relief from the slow growth and prolonged suppression experienced by herbaceous species in undisturbed environments. Results suggested that ginseng is a 'slow opportunist;' ginseng photosynthesis and growth increases after sudden light increases caused by canopy gap formation, but because ginseng growth is determinate, stimulation lags behind changes in canopy structure. A similar lag in response to gap formation is seen in many shade-adapted species that experience prolonged suppression and slow growth (Canham 1989). Periodic physiological stimulations caused by both timber harvest and by the natural death of trees could promote growth of populations whose canopies are disturbed.

Timber harvest strategies common throughout the United States exist along a scale of severity with the least severe being single tree selection and the most severe being clearcuts (Roberts and Gilliam 2014). Prior to this study, it was unknown whether timber harvests of varying intensities had net negative, neutral, or positive effects on the survival, growth, and reproduction of American ginseng. I found that ginseng survival was variable, but generally decreased following timber harvest, and was lowest at the most intensely harvested site (Chapter 4). Though not directly measured, I attributed the significantly lower survival at this site largely to substantial soil compaction and disturbance caused by numerous skid roads. Nevertheless, the growth rate and seed production of those individuals that survived increased following harvest, suggesting that although the plants showed visible signs of stress to higher light, net carbon assimilation across a growing season increased (Chapter 4). The elevated growth rates and seed production observed at the populations following timber harvest suggest that forest management techniques that mimic natural disturbance regimes, such as single-tree 
selection and group selection, could benefit ginseng populations (Chapter 4), and could further restore and maintain native biodiversity (Franklin et al. 1997, Seymour and Hunter 1999, Seymour et al. 2002). However, timber extraction should occur on frozen or snow-covered ground using a minimal number of skid roads to avoid excessive mortality caused by soil profile disturbances. Stimulation of growth and seed production will benefit population performance post-harvest especially in populations where seed death due to desiccation is low, allowing individuals to be added to the seed bank. However, larger plants and plants with bigger, more visible fruit sets could also attract ginseng harvesters. Anecdotal evidence suggests that some harvesters seek out large ginseng plants in open areas following timber harvest, and increases in ginseng harvest activity could mitigate stimulation following timber harvest.

Survival and reproduction rates differ among ginseng sizes and stage classes, and the stage structure of a population can largely determine future population success (Silvertown and Charlesworth 2001, McGraw et al. 2013). To better understand how timber harvest affects population structure, it was crucial that I determine if the leaf number of an individual affected the probability of survival after timber harvest. I found that an individual's size does affect the probability of surviving, with survival being less likely in one and two leaved plants in comparison to the larger three and four leaved plants. The persistence of larger, more reproductive individuals after timber harvest, rather than younger plants that have long pre-reproductive periods, will promote population recovery after the initial loss of individuals. The addition of seeds into the seed bank soon after timber harvest will protect against population declines caused by 
ginseng harvest and possible increases in deer browse, something that would be improbable in a population composed primarily of seedlings and juveniles.

Chapters 3 and 4 suggested that timber harvest could increase ginseng population growth if land managers take precautions to reduce initial mortality. However, neither of these chapters fully integrated measures of survival, growth, and fertility over the dynamic period surrounding a disturbance event to measure overall population response. The purpose of Chapter 5 was to determine 1) if a species found primarily in low light understory environments benefits demographically from additional inputs of light from natural canopy disturbances, or alternatively, due to long-term selection under low light conditions, such disturbances bring about a net population decline; and 2) if the demographic response was consistent across different canopy disturbance types, regardless of severity, duration, and effects beyond light enhancement. Chapter 5 suggested that the growth rate of American ginseng populations increased in response to all three types of discrete, natural canopy disturbance events. Further, populations benefited from canopy disturbance even at the current rates of occurrence in ginseng populations. Additionally, in each model, short-term stimulations increased population size due to an influx of seeds to the seed bank, and these increases in population size were sustained following disturbance.

The frequency of other anomalous disturbances such as late spring frosts are predicted to increase as climates warm (IPCC 2007c, Souther and McGraw 2011a). While ginseng populations benefit from some disturbances whose regimes are changing as climates change, the response is not ubiquitous among all disturbance events whose regimes are being altered. In contrast to the findings of Chapter 5, one study determined 
that ginseng populations responded negatively to frost events that occurred after spring emergence (Souther and McGraw 2011a). The discrepancy between these studies was likely due to the contrasting methods in which populations were affected. The disturbances in Chapter 5 reduced canopy cover and increased understory light availability, which stimulated ginseng population growth. Conversely, frost events directly affect ginseng plants and can cause ice crystal formation in aboveground tissue, cellular dehydration, and leaf abrasion (Pearce 2001, Inouye 2008), and the net effect of frost on ginseng was partial or total loss of leaves, buds, and shoots (Souther and McGraw 2011a). Thus, while ginseng populations benefit from some disturbances whose regimes are changing as climates shift (Chapter 5), the response is not ubiquitous among all climate-induced disturbances.

Stress was evident in individual ginseng plants exposed to high light environments, and was most obvious after timber harvests (Chapters 3 and 4) and after the ice storm event (Chapter 5). Individuals commonly exhibited thickened, chlorotic leaves, desiccated inflorescences, and early senescence in the growing seasons after canopy disturbance. Based solely on qualitative observations, one may be tempted to conclude that canopy disturbance is damaging to ginseng. However, these studies indicate that the visual signs of stress at the individual level did not translate into lower photosynthetic rates, growth rates, or population performance. In fact, I observed the opposite; American ginseng utilized and benefited from canopy disturbances and understory light increases at each organizational level.

The temporary stimulation in physiology, growth, and demography of ginseng following canopy disturbance can have sizeable effects on populations after canopies 
close and other pressures continue to act on populations. Across its range, ginseng populations are decreasing in size and abundance due to the overharvesting of its root for international trade, extensive browse by white-tailed deer, and the effects of climate change (McGraw and Furedi 2005, Van der Voort and McGraw 2006, McGraw et al. 2010, 2013, Souther and McGraw 2011b). Although the growth and increased fertility of plants following canopy disturbance may promote ginseng harvest, harvesting can be done sustainably through stewardship (McGraw et al. 2013). Demographic stimulation caused by canopy disturbance combined with ginseng stewardship harvest practices could maintain, or even increase, population growth rates. Additionally, disturbances that create small gaps in the forest canopy can provide favorable habitat for wood thrush, a known disperser of ginseng seeds (Crawford et al. 1981, Hruska et al. 2014). Increases in seed production coupled with wood thrush presence could facilitate intermediate and long distance dispersal of ginseng seeds to other locations where threats to ginseng population performance are not as pronounced. The demographic upsurge induced by canopy gap formation, along with other positive forces that act on ginseng populations, could contribute to the "rescue" of populations from decline, and could be one component preventing populations from falling too far into an extinction vortex (McGraw et al. 2013).

American ginseng is a long-lived obligate understory herb with growth patterns and habitat requirements similar to many other ecologically, economically, and culturally valuable herbs in North American forests (McGraw et al. 2013, Chamberlain et al. 2013). These studies suggest that ginseng and perhaps other species in this guild utilize and benefit from light increases caused by dynamic canopy disturbances (Chapters 3 and 4). 
Individual growth and demographic success of American ginseng can be viewed as a parabolic function of canopy disturbance, with maximum performance occurring after moderate disturbances (Chapter 5; Fig. 5.7). Population performance at the low end of the disturbance spectrum, an example of which is densely shaded evergreen canopies, is likely lower than populations under deciduous canopies that are rich in sunfleck activity. However, performance in both of the prior scenarios is likely suboptimal due to light limitation. Photosynthesis, individual growth, and population growth are optimized when canopies are moderately disturbed, as is the case with the natural disturbances and timber harvests outlined in these studies. The optimal performance of ginseng at this point along the disturbance spectrum may be attributed the adaptation of ginseng to the dynamic environments of old growth forests, which consist of spatially and temporally varying gap formations and closures. Although not directly quantified in this research, canopy disturbances at the highest end of the spectrum, an example of which is large-scale clearcut timber harvest, will likely elicit decreases in performance. This conceptual, parabolic model suggests that American ginseng and perhaps other plants in this guild can exploit and benefit from moderate increases in light availability caused by canopy disturbance. Further, these findings suggest that American ginseng is surprisingly resilient in the face of rapid environmental shifts.

American ginseng abundance was far greater historically than it is today as is evidenced by the precipitous decline in exports from the mid-1800's to the late 1900's, and overharvesting of ginseng for its root is most often described as the primary cause for the precipitous decline (Carlson 1986, Nantel et al. 1996, Robbins 1998, 2000, McGraw et al. 2010). However, forest landscapes were being altered by extensive clearcut timber 
harvests concurrent to the declines in ginseng abundance during the late 1800's and early 1900's (Carlson 1986, Robbins 1998, Wyatt and Silman 2014). Historic clearcutting resulted in the removal of over $99 \%$ of the old growth eastern deciduous forest (Wyatt and Silman 2014). The large slash piles left behind after clearcutting provided the fuel needed to sustain the heavy forest fires that were ignited by sparks from railcar engines used to export timber, resulting in large areas of scorched surface soil (Clarkson 1964, Wyatt and Silman 2014). This suite of studies did not examine the response of ginseng to the types of clearcuts that occurred historically. However, based on the findings of this research, the parabolic model set forth in Chapter 5, and the known extent of canopy and soil disturbance caused by early clearcut harvests, I postulate that the clearcuts of the 1800 's and early 1900's contributed considerably to ginseng population declines.

These studies provide evidence that a model understory herb, American ginseng, benefits from moderate canopy disturbance, which is a response that may be shared among similar herbaceous species. This research should help shape management strategies that have multifaceted goals that include the continued production of valuable timber, the maintenance of forest biodiversity, and the conservation of ecologically, economically, and culturally valuable understory herbs like American ginseng.

\section{Critical Future Questions}

Prior to this suite of studies, little was known about the response of American ginseng to the types of canopy disturbances that are common throughout the eastern deciduous forest. While these studies provide evidence that the physiological, individual, and demographic responses of American ginseng respond positively to moderateintensity canopy disturbance, additional questions remain. Future research that quantifies 
the multi-level response of ginseng to the lowest level of canopy openness, represented by evergreen forests, and to the highest level of canopy openness, represented by clearcut harvest, will be important in confirming the theoretical parabolic model set forth throughout these studies. American ginseng populations have been found under dense evergreen canopies, but the small population sizes in these locations precluded demographic analyses in the current set of studies. Additionally, the opportunity to study the response of ginseng to a large, clearcut timber harvest was not presented in the course of this research. Climate shifts are predicted to continue long into the future. Studies that quantify the response of American ginseng to the interaction of discrete canopy disturbance events and both direct and indirect effects of climate shift are necessary to better understand the future trajectory of ginseng populations in a changing world. 


\subsection{Literature Cited}

Beaudet, M., and Messier, C. 2002. Variation in canopy openness and light transmission following selection cutting in northern hardwood stands: An assessment based on hemispherical photographs. Agric. For. Meteorol. 110(3): 217-228.

Beaudet, M., Messier, C., and Leduc, A. 2004. Understorey light profiles in temperate deciduous forests: Recovery process following selection cutting. J. Ecol. 92(2): 328338.

Canham, C.D. 1989. Different responses to gaps among shade-tolerant tree species. Ecology 70(3): 548-550. doi:10.2307/1940200.

Canham, C.D., Denslow, J.S., Platt, W.J., Runkle, J.R., Spies, T.A., and White, P.S. 1990. Light regimes beneath closed canopies and tree-fall gaps in temperate and tropical forests. Can. J. For. Res. 20: 620-631. doi:10.2307/1940194.

Carlson, A. 1986. Ginseng-America's botanical drug connection to the Orient. Econ. Bot. 40: $233-249$.

Chamberlain, J.L., Prisley, S., and McGuffin, M. 2013. Understanding the relationships between American ginseng harvest and hardwood forests inventory and timber harvest to improve co-management of the forests of eastern United States. J. Sustain. For. 32(6): 605-624. doi:10.1080/10549811.2013.798828.

Clarkson, R.B. 1964. The destruction of the forest by fire. In Tumult on the Mountains, 1st edition. McClain Printing Company, Parsons. pp. 42-44.

Crawford, H.S., Hooper, R.G., and Titterington, R.W. 1981. Songbird population response to silvicultural practices in central Appalachian hardwoods. J. Wildl. Manage. 45(3): 680-692.

Dale, V.H., Joyce, L. a., McNulty, S., and Neilson, R.P. 2000. The interplay between climate change, forests, and disturbances. Sci. Total Environ. 262(3): 201-204. doi:10.1016/S0048-9697(00)00522-2.

Dale, V.H., Joyce, L.A., McNulty, S., Neilson, R.P., Ayres, M.P., Flannigan, M.D., Hanson, P.J., Irland, L.C., Lugo, A.E., Peterson, C.J., Simberloff, D., Swanson, F.J., Stocks, B.J., and Wotton, B.M. 2001. Climate change and forest disturbances. Bioscience 51(9): 723-734.

Franklin, J.F., Berg, D.R., Thornburgh, D.A., and Tappeiner, J.C. 1997. Alternative silvicultural approaches to timber harvest: Variable retention harvest systems. In Creating a Forestry for the 21st Century: The Science of Ecosystem Management. Edited by K.A. Kohm and J.F. Franklin. Island Press, Seattle. pp. 111-140. 
Gilliam, F.S. 2007. The ecological significance of the herbaceous layer in temperate forest ecosystems. Bioscience 57(10): 845-858.

Hruska, A.M., Souther, S., and McGraw, J.B. 2014. Songbird dispersal of American ginseng (Panax quinquefolius). Ecoscience 21(1): 46-55.

Inouye, D.W. 2008. Effects of climate change on phenology, frost damage, and floral abundance of montane wildflowers. Ecology 89(2): 353-362.

IPCC. 2007. Fourth Assessment Report of the Intergovernmental Panel on Climate Change. Cambridge University Press, Cambridge.

Knohl, A., Schulze, E.-D., Kolle, O., and Buchmann, N. 2003. Large carbon uptake by an unmanaged 250-year-old deciduous forest in Central Germany. Agric. For. Meteorol. 118(3-4): 151-167. doi:10.1016/S0168-1923(03)00115-1.

Manabe, T., Shimatani, K., Kawarasaki, S., Aikawa, S.-I., and Yamamoto, S.-I. 2009. The patch mosaic of an old-growth warm-temperate forest: Patch-level descriptions of 40-year gap-forming processes and community structures. Ecol. Res. 24: 575586. doi:10.1007/s11284-008-0528-7.

McGraw, J.B., and Furedi, M.A. 2005. Deer browsing and population viability of a forest understory plant. Science (80-. ). 307: 920-922.

McGraw, J.B., Lubbers, A.E., Van der Voort, M., Mooney, E.H., Furedi, M.A., Souther, S., Turner, J.B., and Chandler, J. 2013. Ecology and conservation of ginseng (Panax quinquefolius) in a changing world. Ann. N. Y. Acad. Sci. (The Year in Ecology and Conservation): 62-91. doi:10.1111/nyas.12032.

McGraw, J.B., Souther, S., and Lubbers, A.E. 2010. Rates of harvest and compliance with regulations in natural populations of American ginseng (Panax quinquefolius L.). Nat. Areas J. 30(2): 202-210. doi:10.3375/043.030.0207.

Nantel, P., Gagnon, D., and Nault, A. 1996. Population viability analysis of American ginseng and wild leek harvested in stochastic environments. Conserv. Biol. 10(2): 608-621. doi:10.1046/j.1523-1739.1996.10020608.x.

Pearce, R.S. 2001. Plant freezing and damage. Ann. Bot. 87: 417-424. doi:10.1006/anbo.2000.1352.

Robbins, C.S. 1998. American ginseng: The root of North America's medicinal herb trade. TRAFFIC, Washington, D.C.

Robbins, C.S. 2000. Comparative analysis of management regimes and medicinal plant trade monitoring mechanisms for American ginseng and goldenseal. Conserv. Biol. 14(5): 1422-1434. 
Roberts, M.R. 2004. Response of the herbaceous layer to natural disturbance in North American forests. Can. J. Bot. 82(9): 1273-1283. doi:10.1139/b04-091.

Roberts, M.R., and Gilliam, F.S. 2014. Response of the Herbaceous Layer to Disturbance in Eastern Forests. In The Herbaceous Layer in Forests of Eastern North America, 2nd edition. Edited by F.S. Gilliam. Oxford University Press, Oxford. pp. 321-339.

Seymour, R.S., and Hunter, M.L. 1999. Principles of ecological forestry. In Maintaining Biodiversity in Forest Ecosystems. Cambridge University Press, Cambridge. pp. 2261.

Seymour, R.S., White, A.S., and deMaynadier, P.G. 2002. Natural disturbance regimes in northeastern North America-Evaluating silvicultural systems using natural scales and frequencies. For. Ecol. Manage. 155: 357-367. doi:10.1016/S03781127(01)00572-2.

Silvertown, J., and Charlesworth, D. 2001. Dynamics of age-structured and stagestructured populations. In Introduction to Plant Population Biology, 4th edition. Edited by J. Silvertown and D. Charlesworth. Blackwell Publishing, Oxford. pp. 153-176.

Sousa, W.P. 1984. The role of disturbance in natural communities. Annu. Rev. Ecol. Syst. 15: 353-391. doi:10.1146/annurev.es.15.110184.002033.

Souther, S., and McGraw, J.B. 2011a. Vulnerability of wild American ginseng to an extreme early spring temperature fluctuation. Popul. Ecol. 53(1): 119-129. doi:10.1007/s10144-010-0218-5.

Souther, S., and McGraw, J.B. 2011b. Evidence of local adaptation in the demographic response of American ginseng to interannual temperature variation. Conserv. Biol. 25(5): 922-31. doi:10.1111/j.1523-1739.2011.01695.x.

Spies, T.A., Hemstrom, M.A., Youngblood, A., and Hummel, S. 2006. Conserving oldgrowth forest diversity in disturbance-prone landscapes. Conserv. Biol. 20(2): 351362. doi:10.1111/j.1523-1739.2006.00389.x.

Valverde, T., and Silvertown, J. 1997. Canopy closure rate and forest structure. Ecology 78(5): 1555-1562.

Van der Voort, M.E., and McGraw, J.B. 2006. Effects of harvester behavior on population growth rate affects sustainability of ginseng trade. Biol. Conserv. 130(4): 505-516. doi:10.1016/j.biocon.2006.01.010.

Wagner, A., and McGraw, J.B. 2013. Sunfleck effects on physiology, growth, and local demography of American ginseng (Panax quinquefolius L.). For. Ecol. Manage. 
291: 220-227. Elsevier B.V. doi:10.1016/j.foreco.2012.11.038.

Wyatt, J.L., and Silman, M.. 2014. Long-term effects of clearcutting in the southern Appalachians. In The Herbaceous Layer in Forests of Eastern North America, 2nd edition. Edited by F.S. Gilliam. Oxford University Press, New York. pp. 412-437. 